Florida International University FIU Digital Commons

FIU Electronic Theses and Dissertations

University Graduate School

6-24-2010

\title{
Structure of International Cooperation in Trade, Investment and Environment
}

Harun Onder

Florida International University, honde001@fiu.edu

DOI: $10.25148 /$ etd.FI10080405

Follow this and additional works at: https://digitalcommons.fiu.edu/etd

\section{Recommended Citation}

Onder, Harun, "Structure of International Cooperation in Trade, Investment and Environment" (2010). FIU Electronic Theses and Dissertations. 240.

https://digitalcommons.fiu.edu/etd/240

This work is brought to you for free and open access by the University Graduate School at FIU Digital Commons. It has been accepted for inclusion in FIU Electronic Theses and Dissertations by an authorized administrator of FIU Digital Commons. For more information, please contact dcc@fiu.edu. 
FLORIDA INTERNATIONAL UNIVERSITY

Miami, Florida

\section{STRUCTURE OF INTERNATIONAL COOPERATION IN TRADE, INVESTMENT AND ENVIRONMENT}

A dissertation submitted in partial fulfillment of the

requirements for the degree of

DOCTOR OF PHILOSOPHY

in

ECONOMICS

by

Harun Onder

2010 


\section{To: Dean Kenneth Furton}

College of Arts and Sciences

This dissertation, written by Harun Onder, and entitled Structure of International Cooperation in Trade, Investment and Environment, having been approved in respect to style and intellectual content, is referred to you for judgment.

We have read this dissertation and recommend that it be approved.

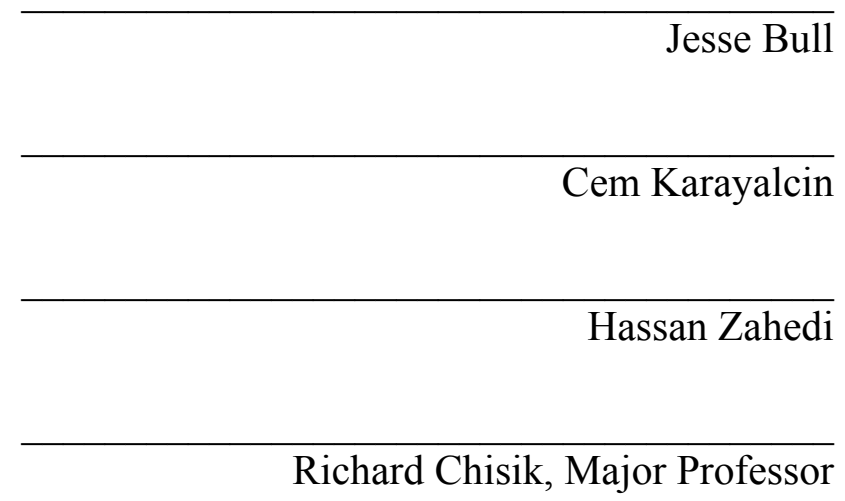

Date of Defense: June 24, 2010

The dissertation of Harun Onder is approved.

Dean Kenneth Furton College of Arts and Sciences

Interim Dean Kevin O'Shea University Graduate School

Florida International University, 2010 


\section{DEDICATION}

\section{I dedicate this dissertation to my parents, siblings and M.}

This work is a modest attempt to thank them for their invaluable love and support. 


\section{ACKNOWLEDGMENTS}

I would like to take this opportunity to thank my committee members for their support and patience. Dr. Hassan Zahedi was always patient and understanding, I have benefited from his comments. Dr. Jesse Bull has always supported and encouraged me about my research; I've had several beneficial conversations with him. Dr. Cem Karayalcin was always supportive and friendly. I have always admired his intellectual skills and depth of knowledge. Finally, I would like to thank my major professor, Dr. Richard Chisik. I've had a wonderful experience with him, which provided me with the chance to observe and benefit from his excellent analytical and intellectual skills. His challenging and demanding guidance has the most influence on my intellectual development. I would also like to acknowledge the Dissertation Year Fellowship (DYF) that provided me with the financial support during my last year in the program. 


\title{
ABSTRACT OF THE DISSERTATION \\ STRUCTURE OF INTERNATIONAL COOPERATION IN \\ TRADE, INVESTMENT AND ENVIRONMENT
}

\author{
by
}

Harun Onder

Florida International University, 2010

Miami, Florida

Professor Richard Chisik, Major Professor

This dissertation analyzes the obstacles against further cooperation in international economic relations. The first essay explains the gradual nature of trade liberalization. I show that existence of asymmetric information between governments provides a sufficient reason for gradualism to exist. Governments prefer starting small to reduce the cost of partner's betrayal when there is sufficient degree of information asymmetry regarding the partner's type. Learning about partner's incentive structure enhances expectations, encouraging governments to increase their current level of cooperation. Specifically, the uninformed government's subjective belief for the trading partner being good is improved as the partner acts cooperatively. This updated belief, in turn, lowers the subjective probability of future betrayal, enabling further progress in cooperation.

The second essay analyzes the relationship between two countries facing two policy dilemmas in an environment with two way goods and capital flows. When issues are independent and countries are symmetric, signing separate agreements for tariffs 
(Free Trade Agreements-FTA) and for taxes (Tax Treaties-TT) provides the identical level of enforcement as signing a linked agreement. However, linkage can still improve the joint welfare by transferring the slack enforcement power in a case of asymmetric issues or countries. I report non-results in two cases where the policy issues are interconnected due to technological spillover effect of FDI. Moreover, I show that linking the agreements actually reduces enforcement when agreements are linked under a limited punishment rule and policy variables are strategic substitutes.

The third essay investigates the welfare/enforcement consequences of linking trade and environmental agreements. In the standard literature, linking the agreements generate non-trivial results only when there is structural relation between the issues. I focus on institutional design of the linkage and show that even if environmental aspects of international trade are negligible linking the agreements might still have some interesting welfare implications under current GATT Rules. Specifically, when traded goods are substitutes in consumption, linking the environmental agreement with trade agreement under the Withdrawal of Equivalent Concession Rule (Article XXVIII) will reduce the enforcement. However, enforcement in environmental issue increases when the same rule is implemented in the absence of linkage. 


\section{TABLE OF CONTENTS}

CHAPTER

PAGE

I. STARTING SMALL IN FREE TRADE AGREEMENTS 1

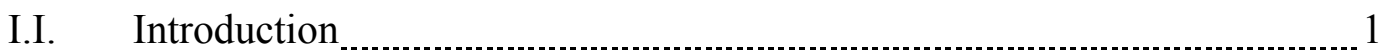

I.II. The Model _............................................................................. 8

I.III Non-Stationary Cooperation under Incomplete Information _................... 21

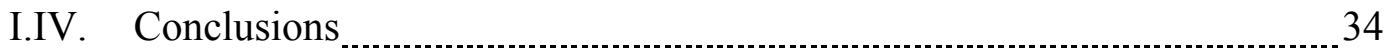

II. INTERNATIONAL COOPERATION IN TRADE AND INVESTMENT: (WHEN) DOES LINKING THE AGREEMENTS HELP?

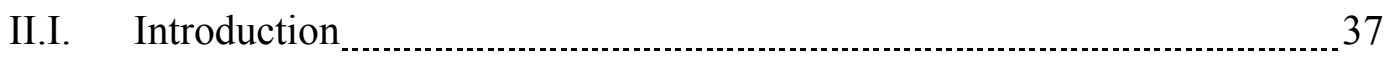

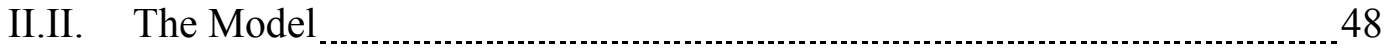

II.III. Interconnected Trade and Investment _............................................. 58

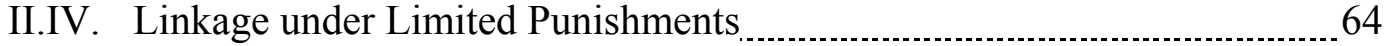

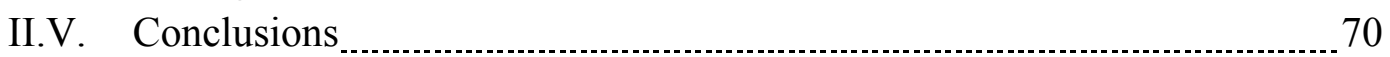

III. RECONCILIATION OF INTERNATIONAL TRADE AND

ENVIRONMENT REGIMES AND GATT ARTICLE XXVIII _..................... 74

III.I. Introduction _............................................................................ 74

III.II. A Trade and Environment Model _.............................................. 79

III.III. Reconciling Trade and Investment Regimes under

GATT Article XXVIII _................................................................ 87

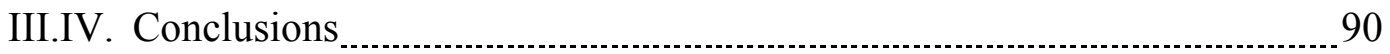

LIST OF REFERENCES

APPENDICES

VITA 


\section{LIST OF FIGURES}

FIGURE

PAGE

1. Payoffs from a Bundle of Goods in Different States of Nature Under an Agreement 13

2. Incentive Structure and Testing in Separating Equilibrium 32

3. Incentive Compatibility in Free Trade Agreement 54

4. Optimal Deviation Tariff: Nash Reversion and Limited Punishment 67

5. Optimal Deviation Under Linkage and Limited Punishment Rule 69 


\section{STARTING SMALL IN FREE TRADE AGREEMENTS}

\section{I.I. INTRODUCTION}

Trade liberalization does not occur overnight. A series of bilateral and multilateral agreements have gradually reduced the average tariff rate from $18 \%$ in Europe and $15 \%$ in North America in the late 1950 s to $4 \%$ in the North Atlantic nations by the end of $20^{\text {th }}$ century (Baldwin, 2006). Gradualism in free trade agreements, however, is not limited to tariff reductions. A noteworthy aspect of the transition from protectionist trade policies to freer trade is the gradually increasing scope of liberalization. Trading partners might prefer starting with a few-goods-agreement, and gradually transform it to a more comprehensive one under favorable circumstances.

Historically, one can observe that sector-based gradualism has been manifested in multilateral, bilateral, and regional forms. New tariff concessions under the General Agreement on Tariffs and Trade (GATT) terms were negotiated on a product-by-product basis in Geneva (1947), Annecy (1949), Torquay (1951), Geneva (1956) and Dillon (1960-61) rounds. Almost two decades after the initial negotiations for the GATT negotiators expanded the method to an industry/sector-wide schedule for the first time in the Kennedy Round of 1962-67. The European Coal and Steel Community (1951) and the US-Canada Auto Pact (1965) are other well known cases which prepared the ground for further cooperation between signatory governments. Yet, not all sector-specific agreements are designed to evolve into broad cooperation schemes. More recently, the US government negotiated sector-specific agreements on "zero-for-zero" basis. Information Technology Agreement (ITA) was developed in 1996 and followed by 
Financial Services Agreement (FSA) in 1997. Following the success of the former agreement, APEC ministers negotiated nine additional sectors in Vancouver in 1997, which failed because of the objections of Japan and other Asian countries. The most important difference between the agreements with a gradually increasing scope and the recent zero-for-zero sector-based agreements arises in dispute settlement procedure. The former type of agreement denotes a body of linked issues with relatively flexible crossretaliation prospects; whereas the latter one defines a series of unlinked issues with very limited cross-retaliation possibilities. This paper examines gradualism in free trade agreements in the framework of linked agreements. More specifically, I investigate the mechanism behind the gradual increments in the number of issues linked to the original body. Why do countries prefer starting an agreement with a few sectors rather than settling with the optimal scope at the outset of an agreement? Under which conditions does the initial agreement with limited scope provide further cooperation later on?

This paper proposes an answer for these questions within a stylized perspective. Unilaterally optimal trade policies harm trading partners through terms-of-trade externalities. Reciprocal concessions in otherwise selfishly commanded trade, therefore, provide gains for both countries in a long term relationship. I show, however, that the presence of asymmetric information regarding the partner's incentive to betray in the future impedes full cooperation in early stages of the relationship. Governments prefer "starting small" in an uncertain environment in order to reduce the cost of partner's betrayal. Learning about trading partner's incentive structure enhances expectations and encourages governments to increase their current level of cooperation. More specifically, the uninformed government's subjective belief for the trading partner being "good" is 
improved as the partner cooperates under a self-enforcing agreement. This updated belief, in turn, lowers the subjective probability of future betrayal, enabling further progress in cooperation. Learning, therefore, is the mechanism that provides gradualism in my model.

To assess the evolution of cooperation I develop a simple model in which two large countries produce and trade a continuum of goods. Although I assume that countries are symmetric in both demand and supply conditions, there are two important asymmetries: the presence of one-sided incomplete information and the privilege of uninformed government to propose a contract. Foreign government privately observes its dynamically stochastic political economy concerns. It may experience political economy shocks in the form of protectionist bias for its import competing sectors. Home government proposes a contract using its subjective belief, in response, since it cannot observe the actual probability of a shock. Therefore, the model suggests a case where a "weak" (foreign) country requests access to a free trade agreement and the "strong" country (home or a customs union) proposes the terms of the agreement, specifically the scope of the agreement. Some typical examples for these "new regionalist" agreements (Ethier, 1998) are Mexico's accession to North American Free Trade Agreement (NAFTA), European Union's enlargement in Eastern Europe, and free trade agreements between US and others ${ }^{1}$ which prevail or are proposed.

My analysis builds on a recursive structure that emerges from an infinitely repeated interaction. I define the type of the foreign government on the basis of its likelihood of experiencing a political economy shock. By choice of parameters, if the

\footnotetext{
${ }^{1}$ These countries include Australia, Bahrain, Chile, Colombia, Israel, Jordan, Korea, Morocco, Singapore, Panama, Peru and Oman.
} 
probability of that shock is high enough (type-2), then the foreign government betrays by choosing unilaterally optimal tariffs whenever that shock is realized. On the other hand, it cooperates even when the shock occurs if the probability is low enough (type-1). In the absence of informational asymmetry, where the type of foreign government is common knowledge, governments cooperate at a maximum level starting with the first period if they are patient enough given the probability of a shock. Cooperation when the type of foreign government is not observed by the home government is, however, more cumbersome. Home government's prior belief about the foreign government's type is updated in a Bayesian fashion upon observing foreign government's action in each period. Therefore, an agreement should take any additional information revealed in the course of a relationship into consideration. One way to do this is to assume that the longterm relationship is run by a sequence of short-term contracts. Alternatively, the initial agreement can be designed so as to avoid reneging without loss of generality (see Laffont and Tirole, 1990). I follow the second option.

I specify two classes of equilibrium in asymmetric information environment. In a pooling equilibrium, both types of foreign government cooperate perpetually as long as no shock is observed. Only a type- 2 foreign government betrays whenever a shock is realized. I show that the home government proposes increasing the cooperation gradually, conditional on the cooperative action of foreign government in equilibrium. Eventually the cooperation level reaches the maximum and stays stationary afterwards unless betrayal is observed. In a separating equilibrium, on the other hand, probability of political economy shock for a type-2 foreign government is high enough that it betrays, even before a shock is realized, when the cooperation is stationary. Home government 
needs to provide sufficient intertemporal incentives to keep type-2 foreign government in a cooperative relationship. This comprises my version of the well known "Bicycle Theory," which was discussed by Bhagwati (1988). A failure to provide further liberalization ends up bringing cooperation to an end. However, "pedaling" cannot be sustained forever in my model since the level of cooperation is bounded above by the number of goods. Therefore, cooperation with a "bad" partner is dissolved eventually once the countries deplete their liberalization prospects, if not before. Yet the dissolution of partnership through the separation of types is also non-trivial as a result of the "ratchet effect." After the foreign government is revealed to be type-1, the home government optimally proposes maximum cooperation for the rest of the relationship. However, foreseeing this jump in cooperation level, type- 2 foreign government postpones the betrayal one period to get a higher deviation payoff in maximum cooperation stage. I show that when the home government is optimistic enough about the foreign government's type, it prefers "testing" the foreign government in the beginning of their relationship by proposing a high cooperation level. An interesting implication is that the more patient that an uninformed government is, the more likely it resolves the uncertainty in the beginning of relationship by "testing" its partner.

The literature on gradualism in trade agreements extensively utilizes a nonstationary economic environment as the source of dynamic adjustment in tariffs. Staiger (1995) formalizes gradual tariff reduction in a self-enforcing trade agreement framework. Existence of import competing sector workers with sector-specific skills provides rentgenerating potential of tariff hikes. Liberalization relocates a portion of these workers. Once a worker is relocated from the import competing sector, she loses her sector- 
specific skill with a given probability, which yields a non-stationary environment. As the supply of workers with sector specific skills shrinks, high tariffs become less desirable and the sustainable cooperative tariff drops. Therefore, initial progress in trade liberalization enables further liberalization in the future. Similarly, Furusawa and Lai (1999) show that gradualism emerges when adjustment costs arise because of labor mobility among the sectors. Chisik (2003) explicitly recognizes the non-stationary aspect of trading environment. In his paper, specialization and development of partner specific capital decreases the most cooperative tariff within time. A small tariff reduction provides further accumulation of capital in the export sector with a certain degree of irreversibility, which in turn increases both the benefit of continuing the liberalization and cost of a tariff war. Chisik (2009) analyzes multi-sector free trade agreements with an emphasis on dynamic changes in the scope of linked agreements and the emergence of zero-for-zero agreements. Linking agreements provide further liberalization in the presence of irreversible partner specific costs and perfectly correlated noise across sectors. As the correlation decreases, however, liberalization becomes more enforceable in some sectors in an unlinked agreement. The paper also shows that unlinked agreements will eventually be pursued as the body of linked agreements matures. In Maggi and Rodriguez-Clare (2005), frictions in capital mobility and lobbying lead to gradualism in trade liberalization.

As opposed to previous literature, Bond and Park (2002) formalize a case where the gradualism result does not depend on evolution of a state variable. Given asymmetric country sizes, liberalization exhibits a non-stationary pattern when the small country smoothes consumption over time. As the non-stationary and efficient trade agreement 
promises rising payoffs to the small country, most cooperative tariffs are reduced over time through relaxation in its incentive constraint, which is the binding one. Conconi and Perroni (2004) also focus on asymmetric country size as a source of dynamic change in degree of liberalization, however with an emphasis on commitment issues in small countries. Finally, Zissimos (2007) investigates the impact of GATT dispute settlement procedure (specifically Article XXIII) on gradual liberalization.

My work differs from the first group of literature in the sense that I show gradualism can emerge without adjustment costs. Similar to Bond and Park (2002), economic environment is stationary in my model. However, unlike the second group of literature, I do not use asymmetries between economies. Hence, my result of gradualism is robust with changes in the economic environment. The game theoretic technique employed in the present paper is similar to a long term partnership model with two-sided incomplete information developed in Watson (1999) and Watson (2002). Formalizing dynamic games with variable stakes and two types of players, the latter work describes the equilibrium regimes where different types of players separate in the beginning since a certain type of player 1 deviates, and level of cooperation rises gradually then after, under commitment. The former paper models cooperation under renegotiation condition and shows a quick separation phase followed by a gradual cooperation one. Furusawa and Kawakami (2006) shows that gradualism arises in a two sided incomplete information game with variable stakes and outside options. In this paper I characterize a long term relationship with one-sided incomplete information and Prisoner's Dilemma type payoff structure. A major difference that brings my problem close to a screening framework is 
hierarchical relationship between players, i.e. home government has privilege to design the contract.

The paper proceeds as follows. The next section describes the basic economic environment and trade relationship between countries. I solve for a complete information optimal cooperation model as a benchmark case. Section 3 introduces asymmetric information into the model. I derive incentive constraints in a self-enforcing trade agreement and define incentive feasible cooperation with respect to different types of the foreign government and the optimal cooperation with respect to the home government. The last section concludes the paper. Proofs are contained in the appendix.

\section{I.II. THE MODEL}

In this section, I present the characteristics of my basic model of trade between two large countries. I start by defining the structure of trade within a simple framework; I introduce an optimal agreement model with complete information where the home government, observing conditions in the foreign country, proposes an incentive compatible contract that maximizes its expected welfare.

\section{Basic Set Up}

I consider a two country partial equilibrium model, where both countries produce goods in a continuous interval $[0, n]$. I assume that demand functions are identical across goods and countries: $\mathcal{D}_{i}\left(\boldsymbol{F}_{i}\right)=A-\boldsymbol{E}_{i}$, and $\boldsymbol{D}_{i}^{*}\left(\boldsymbol{F}_{i}^{*}\right)=A-\boldsymbol{F}_{i}^{*}, \boldsymbol{t} \in[0, n]$, where $P_{i}$ and $\boldsymbol{P}_{i}^{*}$ denote the local prices of good $i$ in the home and foreign countries. All goods in the 
model are produced in both countries, however have different supplies: $\boldsymbol{Q}_{i}\left(\boldsymbol{E}_{i}\right)=\mathscr{G}_{i} \boldsymbol{F}_{t}$ and $Q_{i}=a_{i} E_{i}$. The corresponding home and foreign country export supply and import demand functions are then: $E_{i}\left(\boldsymbol{P}_{i}\right)=Q_{i}\left(\boldsymbol{P}_{i}\right)-\boldsymbol{D}_{i}\left(\boldsymbol{P}_{i}\right), \quad M_{i}\left(\boldsymbol{P}_{i}\right)-D_{f}\left(P_{f}\right)-Q_{i}\left(P_{f}\right)$,

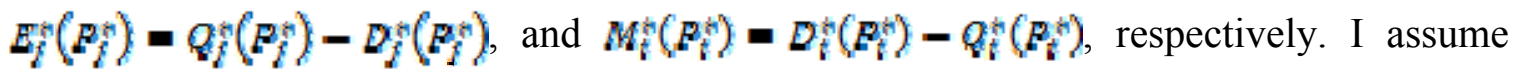
$a_{i}=a_{j}=\bar{\alpha}$, and $x_{f}=a_{i}=\underline{a} \forall t \in[0, n / z), t \in(x / 2, n]$, where $\bar{a}>\underline{a}$. It is immediate that the home country exports in the region $[0, n / 2)$, and imports in the region $(n / 2, n]$. I will denote the former interval as export sector, and the latter one as import sector for the home country. Countries, therefore, have identical supplies of goods within a specific sector, and they are symmetric; i.e., the supplies of home export goods and foreign exports goods are identical.

Each government imposes a specific import tariff, $\tau_{j}$ and $\tau_{i}^{*}$ on their importable goods. Importers pay the world price of an imported good and the specific import tariff, whereas exporters of that good get only the world price $P_{f}\left(\tau_{f}\right) \equiv P_{f}^{w_{f}}\left(\tau_{f}\right)+\tau_{f}$ and $P_{z}^{W}\left(\tau_{2}\right)-P_{F}^{\prime}\left(\tau_{j}\right)$, where the asterisk denotes foreign value. In the presence of nonprohibitive tariffs market clearing conditions provide the equilibrium world and local prices. Solving $M_{f}\left(E_{f}^{W}+\tau_{l}\right)=E_{f}\left(P_{l}^{W^{-}}\right)$I obtain the equilibrium prices $\boldsymbol{F}_{f}\left(\mathrm{r}_{f}\right)$

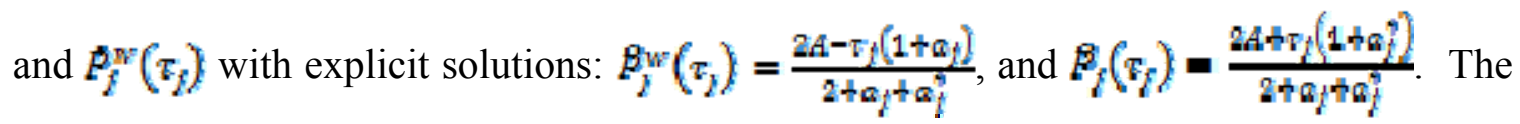
prices of import goods in the foreign country are found similarly.

Following the convention in the corresponding literature, I assume that each government maximizes a social welfare function composed of consumer surplus, 
producer surplus and tariff revenues from import goods. Formally, social welfare on a single exportable good in the home country is given by:

$$
W_{i}\left(R_{i}\right)=x_{i}=\int_{B W_{i}^{W}}^{A} D_{i}\left(R_{i}\right) d P_{i}+w_{i}\left(E_{i}^{W}\right)
$$

Welfare generated by a single importable good in the home country is:

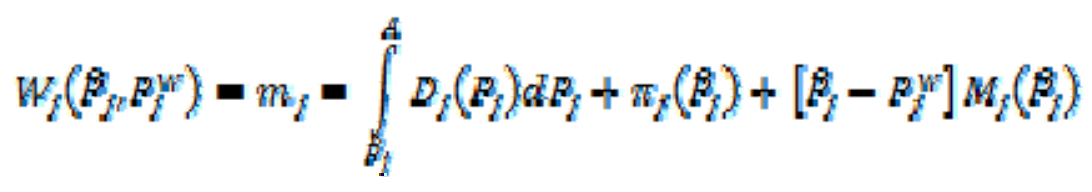

I define the aggregate welfare in home country as the sum of welfares generated by individual export and import goods: $w(n)=\int_{t=0}^{t} x_{t} d t+\int_{j=\underline{k}}^{m} m_{i} d l$. As opposed to the home government, I assume that foreign government faces political economy considerations in import competing goods. These considerations are represented by identical weight parameters, $\gamma$, assigned to producer surpluses of respective goods imported by the foreign country. Formally, the foreign country welfare on an importable good is, then:

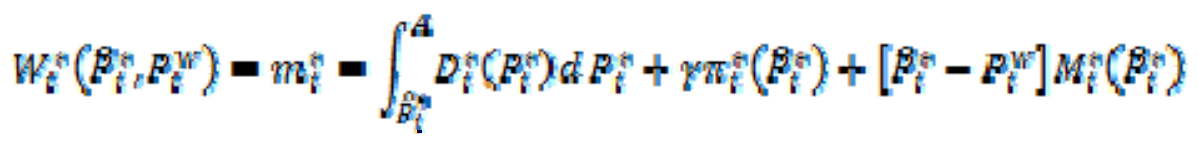

Foreign country political-economy parameter $\gamma$ is drawn from a discrete set of possible values $\Gamma \equiv\left\{\gamma^{L}, \gamma^{E E}\right\}$ in each period, where $\gamma^{L}$ and $\gamma^{H}$ denote the low and high values of $\gamma$ respectively. Therefore, we associate a "state of nature" with the realized political-economy parameter: A high (low) state denotes the realization of a high (low) political economy parameter in an arbitrary period. On the other hand, the "type" of foreign government is defined with respect to the probability of getting low state of 
nature in each period. A type-1 (good type) foreign government has probability $p_{1}$ of getting a low state of nature (good state) in a given period, whereas the likelihood of a type-2 (bad type) draw for foreign government is defined with $p_{g}$, where $0<k_{2}<p_{1}<1$. The type of foreign government is determined by nature beforehand and is fixed throughout the game as opposed to state of nature.

In the absence of a trade agreement, governments apply Nash tariffs in importable goods, which unilaterally maximize their own welfares, $\tau_{f}^{f} \mathbf{a r g m a x} m_{f}\left(\tau_{f}\right)$ and $\tau_{i}^{N}(Y)=\arg \operatorname{maxm}\left(\boldsymbol{F}_{i}^{*}(Y)_{Y} Y\right)$. Using the first order conditions one can show that the foreign country Nash tariff is increasing in its political economy parameter. Because of the identical demand and supply structures, unilaterally optimal tariffs, and therefore welfares on goods in the same sector, are equal. This equality enable me remove subscripts that denote different goods in the same sector. With no cooperative agreement the relationship between the trade partners exhibits characteristics of a repeated prisoner's dilemma game. Each country's welfare is increasing in its own tariff but is decreasing in partner's tariff because of terms-of-trade deterioration. Jointly efficient tariffs maximize the world welfare, but are undermined by unilateral incentives to deviate.

A trade agreement specifies a sequence of cooperative tariffs $\left(\tau_{t}, \tau_{t}^{*}\right)$ and a sequence of cooperation level $\alpha_{t}$ for $\alpha \in\left[0, \frac{r}{2}\right)$ and $t \in\left\{1, z_{p \ldots}\right\}$, which denotes the number of goods included in the agreement. I restrict attention to a symmetric and stationary tariff case, where both countries apply the identical cooperative tariff throughout the cooperative relationship, in order to focus on effects of cooperation level. 
This cooperative tariff is lower than the unilaterally optimal one, and can be equal to zero as well. Any particular value, however, does not have a critical implication for my purposes in this paper; therefore I do not specify it explicitly to avoid an unnecessary restriction. Stage game payoffs are defined as the sum of cooperative welfares on agreement goods and non-cooperative welfares on non-agreement goods. The cooperative payoff of the home country in period $t$ is:

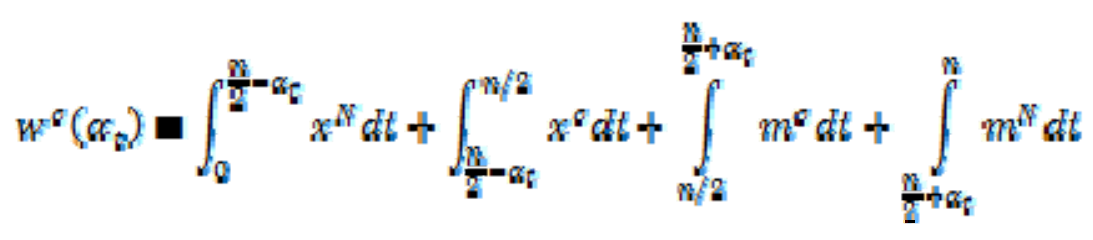

Given the level of cooperation in an arbitrary period, $\alpha_{t}$, the first term on the right hand side in equation (1.4) denotes the sum of the welfares from export goods that are not included in the agreement, the second term is the welfare from export goods that are in the agreement, the third term is the welfare from import goods in the agreement, and the final term is the welfare from import goods that are not included in the agreement. The identical structure of demand and production across the goods in each sector enables us write this equation as $w^{\sigma}\left(\alpha_{2}\right)=\left(\frac{n}{2}-\alpha_{2}\right) \cdot\left(m^{S}+x^{N}\right)+\alpha_{2}\left(m^{\sigma}+x^{\sigma}\right)$. I will write the welfare of foreign government in a high (low) state of nature with an over-bar (underbar). Figure 1 displays the payoff matrices for a bundle of goods in different states of nature under the agreement. 


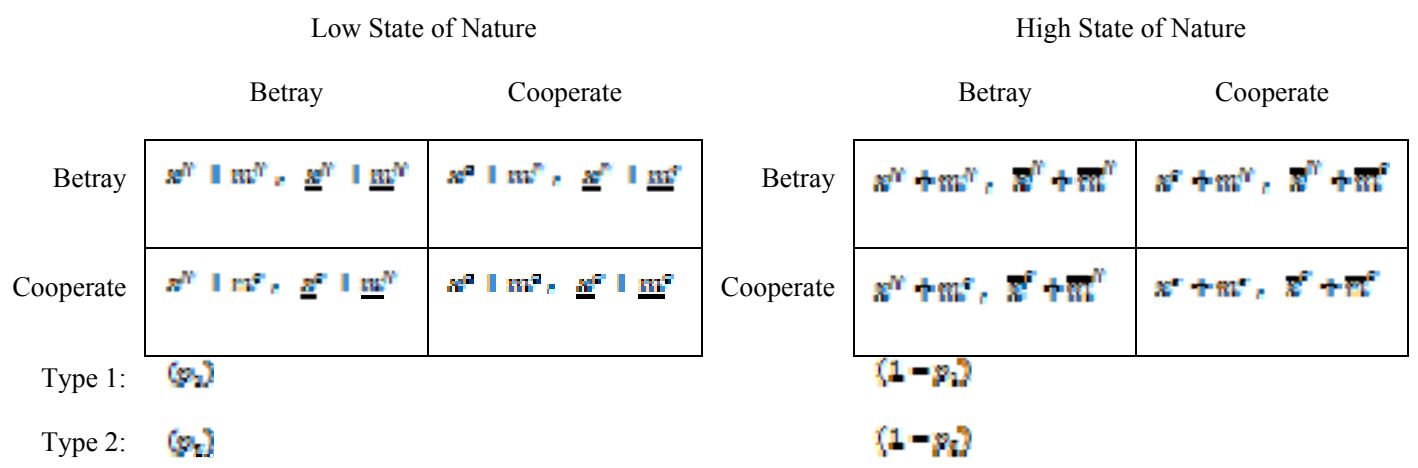

Figure 1. Payoffs from a bundle of goods in different states of nature under an agreement

In the absence of an external enforcement mechanism, I characterize a selfenforcing agreement that depends on credible threats of future punishments to enable cooperation in a non-cooperative environment. I assume that governments abrogate the agreement and permanently reverse to unilaterally optimal tariffs following a deviation by either country. Nash reversion strategies imply that when a government betrays by applying Nash tariffs, it prefers to do so in all import goods since the partner applies Nash tariffs in all goods in the punishment stage. Stage game payoff of the betraying foreign government in a low state of nature

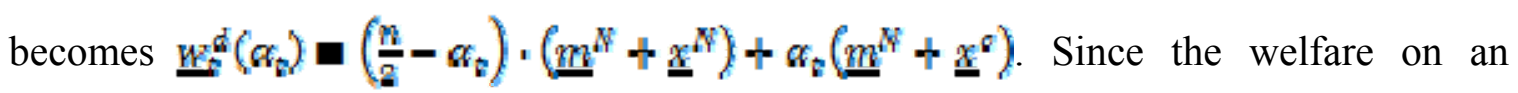
import good is always greater with unilaterally optimal tariffs by definition, the stage game payoff in a deviation period is greater than the one in a cooperative period. The payoff in the Nash reversion period has the lowest value among others $w_{m}^{\text {nV }}=\frac{m}{2}\left(m^{N}+x^{N}\right)$. Payoffs of the home country are defined analogously. However, I introduce an assumption about unilaterally optimal tariffs. 


\section{Assumption 1. Foreign Nash tariffs are prohibitive.}

The reasoning behind this assumption is as follows. Foreign government's Nash tariff changes with different political economy parameter values, which is bounced in variations in home government welfares on export goods. However, I want to restrict the mechanism through which the home government can extract signals about the type of foreign government in my model with one-sided incomplete information. Therefore, the practice of foreign government in non-agreement goods is assumed to provide no further information about its type and state of nature. Nevertheless, this assumption provides great simplification without changing qualitative results of my model. This condition is represented by identical home government Nash payoffs in export goods in Figure 1. The interaction between trading partners is then an infinitely repeated prisoner's dilemma in $\alpha$ non-stationary identical issues with stochastic payoffs in each period. The next section characterizes the equilibrium of this relationship in the absence of informational asymmetries.

\section{Stationary Cooperation in a Complete Information Environment}

This section introduces a benchmark case with a long-term relationship in the absence of informational asymmetry. I provide a non-result for the emergence of gradualism in a complete information environment. The idea here is that when the home government observes the probability of a shock in the foreign country, then whatever policy is incentive compatible for a single good is also incentive compatible for the entire import sector. The number of goods included in an agreement does not induce the foreign government with more or less incentives to cooperate. The future costs of betrayal and 
the current benefits from it change proportionally with scope of an agreement. Similarly, costs for the home government borne by the risk of foreign government betrayal rises in proportion to the rise in benefits from cooperation. Hence, both governments prefer cooperating at a maximum rate given that it is incentive compatible.

The game starts after the realization of foreign government's type by nature in period 0 , and the home government proposes a contract upon observing this type. Equilibrium is characterized by an incentive compatible path of cooperation level and tariffs. I consider a stationary cooperation level, i.e. $\alpha_{\mathfrak{v}}-\boldsymbol{\alpha}_{\ell} \forall \mathbf{z}[1, \infty)$, to show this ex-post. A cooperative action profile is sustainable if payoff structure does not induce the governments with a profitable one-shot deviation. I analyze the incentive structure of foreign government in the presence of an agreement, and then go back to period 0 to investigate the home government's optimal contracting problem. I start with a type-1 foreign government. Incentive compatibility requires that:

$$
\begin{aligned}
& (1-8) \cdot \underline{\Omega}^{d} \leq \delta \cdot E\left(\Omega^{\sigma} \mid p_{1}\right) \\
& (1-8) \cdot \bar{\Omega}^{d} \varepsilon^{8} \cdot E\left(\Omega^{\sigma} \mid p_{1}\right)
\end{aligned}
$$

Where $\underline{\Omega}^{\alpha}-\underline{m}^{N /}-\underline{m}^{\sigma}$ denotes a onetime gain from deviation on a single good in a low state of nature. Foreign government uses expected gain from an agreement, $E\left(\Omega^{*} \mid p_{1}\right) \equiv\left(1-p_{1}\right) \cdot \bar{\Omega}^{\odot}+p_{1} \cdot \underline{\Omega}^{\sigma}$, in order to calculate the future payoff stream. The expected gain is a weighted sum of gains in a high state of nature $\bar{\Omega}^{\ell}=\bar{m}^{e}+\bar{x}^{e}-\bar{m}^{N}-\bar{x}^{N}$ and in a low state $\underline{\Omega}^{e} \equiv \underline{m}^{e}+\underline{x}^{e}-\underline{m}^{N E}-\underline{x}^{N}$, since the states are not correlated through consecutive periods. A notable aspect of these incentive constraints is the non-existence of cooperation level in the explicit formulation 
even though they denote overall payoffs. This non-existence arises because the cooperation level appears linearly on both sides of the inequalities ${ }^{2}$, hence are cancelled. This shows that if a type-1 foreign government betrays (cooperates) in a complete information environment with a stationary cooperation level, it does so regardless of the time and cooperation level.

I now compare the two incentive constraints in terms of strictness to show that the one in a high state of nature binds first. The following Lemma specifies some characteristics of complete information game regarding the payoffs of foreign government, which will be useful to determine the binding constraint.

Lemma 1. For small enough cooperative tariffs in foreign country,

(a) Gains from cooperative agreement decreases in political economy parameter,

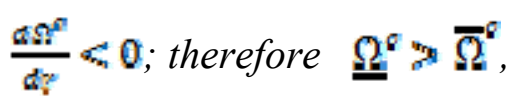

(b) Gains from deviation increases in political economy parameter

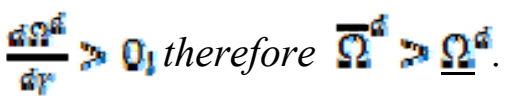

Using the results from Lemma 1, I see that the constraint in high state of nature binds first. Intuitively, if a type-1 foreign government does not betray at a time when domestic political pressures are at a peak, then it does not do so when the pressure is lower. Solving $(I C-1 E)$ for the critical level of probability, I get a necessary condition

\footnotetext{
${ }^{2}$ To see how the cooperation level is eliminated from these constraints we write them in the following way. For a type-

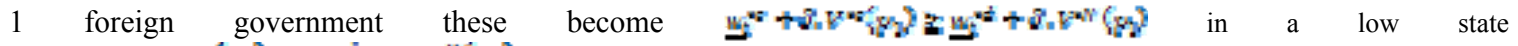

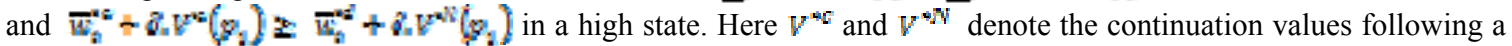
cooperative and non-cooperative action profile in the current period. Formally, $v^{*}\left(q_{2}\right)=\frac{1}{b-v_{2}}\left[\left(1-q_{1}\right) w^{*}+q_{3} \underline{w}^{*}\right]$,

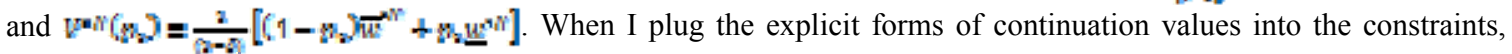
cooperation levels are cancelled out since both sides contain it in multiplicative form.
} 
for cooperation $p_{1} p_{1}$, where $p_{1}=\frac{b_{1}-a^{d}-a^{2}}{d\left[\Omega^{6}-n^{2}\right]}$. By Lemma 1 , again, it is straightforward to show that this critical level of probability decreases in discount factor for high enough values. Therefore, the requirement regarding the frequency of a shock is stricter for relatively impatient foreign governments.

I now describe the incentive compatibility issues for a type-2 foreign government. A type-2 foreign government characterizes a "risky" partner for the home government as opposed to the "safe" type-1 foreign government in my model. To introduce this characteristic, I start with a key assumption that will hold throughout this paper.

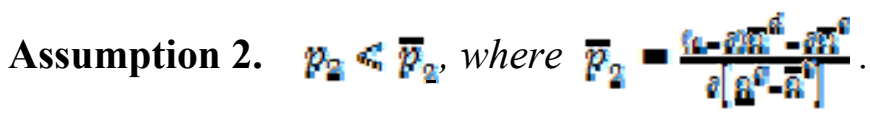

Remember that the foreign government betrays regardless of time in a complete information environment with stationary cooperation levels. Assumption 2 formally specifies that a type-2 foreign government always betrays in a high state of nature. Hence, the realization of a political economy shock is a sufficient but not necessary condition for a type-2 foreign government to deviate from cooperative path. The incentive constraint of a type- 2 foreign government in a low state of nature is different than the one for type- 1 in the sense that the former constraint incorporates possible future betrayal payoffs. Formally,

$$
\left(1-\delta p_{2}\right) \Omega^{d} \Omega^{2} \cdot\left[E\left(\Omega^{\sigma} \mid p_{2}\right)+\left(1-p_{2}\right) \cdot \bar{\Omega}^{d}\right]
$$

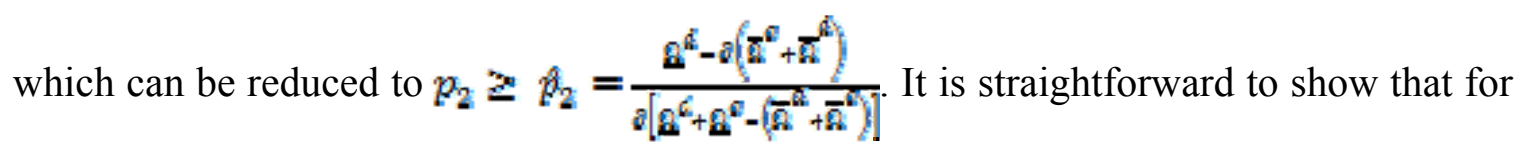
$\delta \geq \frac{p^{d i}}{\left(\bar{R}^{2}+\bar{s}^{2}\right)}$, this inequality is satisfied trivially, and for discount rate values lower than 
this critical level there is no solution. These characteristics illustrate that for a sufficiently patient type-2 foreign government, a relationship with stationary cooperative level is sustainable as long as a shock does not occur.

In a complete information environment, the type of foreign government, the associated minimum probability that provides cooperation, and the actual probabilities are all common knowledge. Therefore, the home government is provided with the ability to tailor the agreement to maximize its expected payoffs. It is obvious that I have equilibria in which the foreign government betrays in the first period, and the home government does not propose any cooperation. These cases arise when sufficiently small probabilities violate the incentive constraints of foreign government, i.e., $p_{1} f_{1} p_{1}$ and $P_{2} p_{1} P_{2}$. However, I shall focus on more interesting cooperative equilibria in which the foreign government cooperates perpetually and the home government proposes positive cooperation level. Incentive compatibility condition for the home government interacting with a type-1 foreign government is:

$$
w^{\alpha}(\alpha)+\delta V^{\alpha} w^{*}(\alpha)+\delta V^{\sigma}
$$

Similar to foreign government incentive constraints, this condition rules out a profitable one-shot deviation for the home government. In the absence of an external enforcing mechanism, the agreement proposed by the home government needs to be credible, i.e., the home government should have no incentive to betray. The following proposition provides an important result regarding the complete information case.

Proposition 1. If incentive compatibility constraints are satisfied for both governments, then a trade agreement with maximum cooperation in all periods Pareto dominates others in a complete information environment. 
Proposition 1 shows that the home government proposes a maximum cooperation in the beginning of a relationship, when incentive constraints are satisfied. Using this result to define the cooperative continuation value on the right hand side, I get $v^{0}-\sum{ }_{i=0} s^{t} w^{0}(\bar{\alpha})$, where $\bar{\alpha}$ denotes the maximum cooperation level. Therefore,

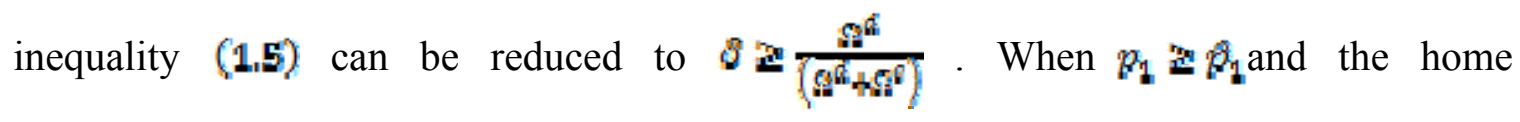
government is patient enough, cooperation starts at maximum level and is sustained afterwards. If foreign government is known to be type-2, then home government needs to incorporate the probability of high state of nature into account, since the foreign government betrays in that case. Incentive constraint for the home government becomes:

$$
p_{2} w^{d}(\bar{\alpha})+\left(1-w_{2}\right) w^{N}(\bar{\alpha})+\delta V^{N} \leq p_{2}\left[w^{\sigma}(\bar{\alpha})+\delta V^{\sigma}\right]+\left(1-p_{2}\right)\left[w^{-d}(\bar{\alpha})+\delta V^{N}\right]
$$

$$
\text { I obtain } V^{s}=\frac{1}{1-\delta p_{2}}\left[p_{2} w^{s}(\bar{\alpha})+\left(1-p_{2}\right) w^{-d}(\bar{\alpha})+\frac{\delta\left(1-p_{q}\right)}{1-\delta} w^{v *}\right] \text { using the results }
$$

from Proposition 1, which involves the risk of being betrayed in each period. Plugging this in (1.6) and solving for the minimum discount factor that satisfies the incentive

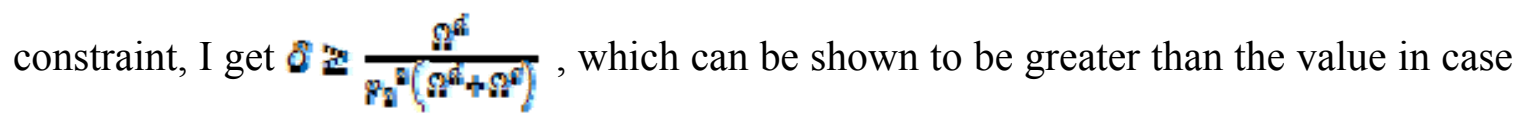
of a type-1 foreign government. Therefore, there exists an interval of discount factor values where home government cooperates only with a type-1 foreign government. A greater probability of low state of nature for a type-2 government implies that the home government needs to be more patient to propose full cooperation.

This result shows that cooperation level proposed in a complete information trade agreement is given by the following conditions: 


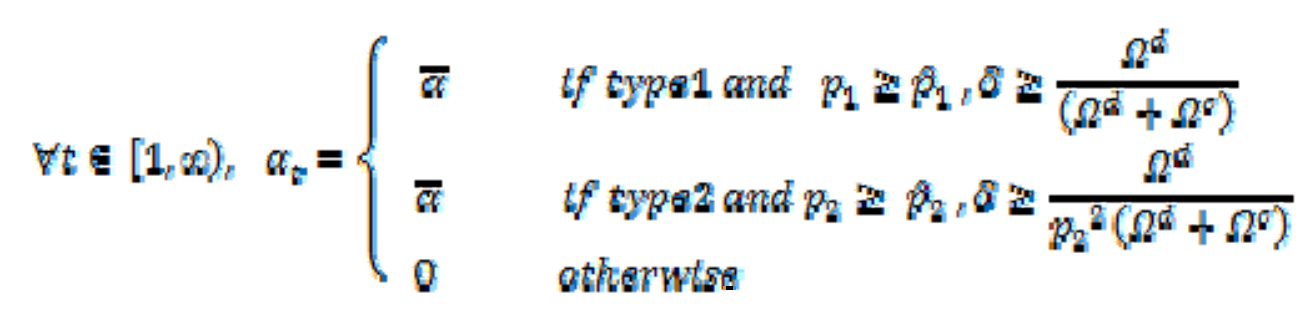

As a result, given that the probabilities of a shock are low enough to provide cooperation for both types of the foreign government, home government employs its privilege to design a contract in order to implement the optimal level of cooperation immediately in the absence of informational asymmetry in my model. The home government's incentive constraints do not face dynamic changes since there is no update in the state variables of maximization problem. Therefore, the optimal cooperation does not exhibit a gradual path. Stochastic states of nature do not contribute much to the analysis besides changing it from an interim maximization to an ex-ante maximization problem for the home government.

My result for the complete information case is analogous to the findings reported in the linkage literature (such as Chisik, 2009). I model identical structure in demand and supply conditions. Combined with the assumption of identical tariffs across the goods within an import sector, the degree of enforcement is also identical across the bundle of goods in an agreement. This identity shows that there is no slack enforcement power that could be transferred to other goods through linking separate agreements. Therefore, whatever is enforceable for a single bundle is also enforceable for the entire sector. This result holds both for the static and incremental linkage story. I now focus on my gradualism results and condition that give rise to them. 


\section{III. NON-STATIONARY COOPERATION UNDER INCOMPLETE INFORMATION}

I solve an infinitely repeated game with stochastic states of nature and one-sided incomplete information in this section. I assume that state of nature in each period and type of foreign government are privately observed by the foreign government. However, the prior probability of foreign government being type-1 $\left(\mu_{0}\right)$ and type-2 $\left(1-\mu_{q}\right)$ are common knowledge, where $\mu_{0} \in(0,1)$. Probabilities of low and high states of nature conditional on foreign government's type are identical with complete information scenario. Game follows the identical path described in previous section ${ }^{3}$.

Given incomplete information structure, home government faces the problem of choosing an optimal cooperation path $\left\{\alpha_{t}\right\}_{t=1}^{\infty}$ that maximizes welfare. Remember that the home government observes only actions of the foreign government in each period.

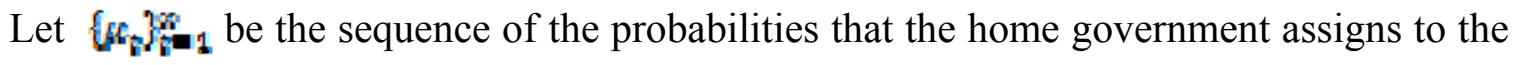
event of foreign government being type-1 in respective periods. Each $\mu_{\tau}$ denotes the posterior belief upon observing the foreign government's action in period $(t-1)$, and is used to construct expectations for period $t$ and afterwards. This belief evolves in a Bayesian fashion, formally:

\footnotetext{
${ }^{3}$ To put this environment in perspective, note that it is similar to a two-type screening model and repeated prisoner's dilemma game. However, there are both static and dynamic differences. In a standard principal-agent framework, the "good" type agent (efficient or low cost) has an incentive to imitate the "bad" type (inefficient or high cost), which instigates the principal to decrease transaction with the latter one to reduce the information rent extracted by the former type. The ability of principal to propose a menu of contracts with respective transfers assures this result. On the other hand, the agency problem therefore optimal contracting issue is ignored in a standard repeated prisoner's dilemma game. My model unifies these two environments in the sense that we have payoff structure of a repeated prisoner's dilemma game with agency problem. The good type agent (type-1 foreign government) is the one who pays for its inability to reveal its type, whereas the bad type agent (type-2 foreign government) extracts information rent. The principal (home government) is constraint to propose a single contract that specifies a unique cooperation level.
} 


$$
\mu_{b+1}=\mu_{2} /\left[\mu_{2}+\left(1-\mu_{2}\right) p_{2}\right]
$$

In order to define this posterior probability in terms of the prior belief, $\mu_{\vartheta}$, I iterate it:

$$
\mu_{2}=\mu_{0} /\left[\mu_{0}+\left(1-\mu_{Q}\right)\left(p_{2}\right)^{t-1}\right]
$$

The only exception is the first period, where there is no new information available before players move, hence home government uses the prior belief $\mu_{1}=\mu_{0}$. It is obvious that after enough periods of successful cooperation this belief will converge to one, $\lim _{t \rightarrow+} f_{t}=1$. I define the home government's belief of foreign government acting cooperatively in current period by $q_{t}$. This probability is composed of probability of the foreign government to be a type-1, and probability of nature choosing a low state if it is type-2. This corresponds to home government's subjective belief of not getting a type-2 foreign government with a high-state of nature. Formally, $q_{\varepsilon}=\mu_{\varepsilon}+\left(1-\mu_{2}\right) p_{2}$. Iterating this, I get the subjective probability of foreign government cooperating in $k$ 'th period after period $t$, given that it cooperates in period $t-1$ :

$$
\prod_{i=0}^{k} q_{t+t}-\mu_{i}+\left(1-\mu_{t}\right)\left(p_{2}\right)^{k+1}
$$

Cooperation levels specified in the contract for each period and belief sequence, together with governments' strategies form a Perfect Bayesian Equilibrium if: Foreign government's actions are optimal given the cooperation level in each period; home government's actions are optimal given its posterior beliefs and subsequent strategies in each period; and the posterior belief is derived from the prior, foreign government's strategy and observed action profile. These conditions require that governments act optimally at any point in history of the game. Self-enforcing character of the agreement 
eliminates commitment concerns, yet following Laffont and Tirole (1990) I assume that the initial contract is designed to incorporate additional information. Intuitively, Bayesian updating mechanism alters home government's incentive scheme after each period, relaxing the incentive constraint and providing further cooperation. Both types of foreign government receive higher payoffs with higher cooperation, therefore renegotiation is allowed. However, without loss of generality, the original contract is designed to avoid future renegotiation.

I can now characterize the incentive structure of the foreign government. Incentive constraints for different types of foreign government differ from complete information case due to non-stationary character of cooperation level through consecutive periods. Remember that in a complete information case, where cooperation is stationary, net balance of discounted gains and punishments is the single factor that provides the foreign government with the incentive to act cooperatively or not. Therefore this incentive form is also stationary during the entire game. On the contrary, in an incomplete information game I have inter-temporal incentives in addition to static balance of one period gains and punishments. An expected augmentation in stage game cooperative payoff in the future because of the rising level of cooperation provides an additional incentive for the foreign government to cooperate in the current period. Therefore, postponing betrayal becomes profitable if cooperation level increases fast enough to more than compensate for the time discounting.

I start with a type-1 foreign government. As mentioned in the previous section, I assume that this type of foreign government cooperates perpetually throughout the game. 
And as in the previous section, the incentive constraint for this type binds in a high state of nature. Formally:

$$
\alpha_{t} \cdot \bar{\Omega}^{d} \leq E\left(\Omega^{\circ} \mid p_{1}\right) \cdot \sum_{t=t+1}^{\infty} s^{t-t_{i}}
$$

Intuitively, this condition states that discounted sum of expected future gains from an agreement, which is contingent on probabilities of different state of natures and the increasing level of cooperation, should be at least as large as benefit from betraying in current period, which is a function of current cooperation level. This condition would be null had the cooperation level could grow infinitely in the future. But existence of an upper bound implies a structural change in above mentioned condition once the maximum level of cooperation is reached. Solving this incentive constraint, I get the condition for perpetual cooperation once the maximum cooperation level is attained, $p_{1} p_{1}$, which is identical with complete information case.

Solution for a type- 2 foreign government incorporates the fact that it always betrays in a high state of nature. The incentive constraint for this type in a low state of nature reflects this effect through the alteration in cooperative continuation values. Formally:

$$
\left.\sum_{t=t+1}^{\infty}\left(p_{2} \delta\right)^{t-(t+1)} a_{t} \cdot\left[E\left(\Omega^{\alpha} \mid p_{2}\right)+\left(1-p_{2}\right) \cdot \bar{\Omega}^{d}\right] \geq \frac{1}{\delta} \alpha_{t} \Omega^{d} \quad(I C-2 L)\right)^{\prime}
$$

Intuitively, current cooperative behavior is conditioned on the comparison between discounted future gains from agreement with a possible gain from betrayal, and the current net benefit of betraying. The left hand-side of the inequality incorporates the intertemporal gains due to non-stationary level of cooperation. The condition under 
which type-2 foreign government cooperates perpetually once the maximum level of cooperation is reached is found analogously, and identical to the one in complete

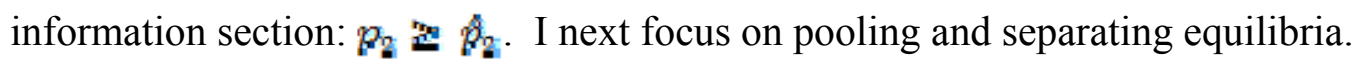

\section{Gradualism in Cooperation}

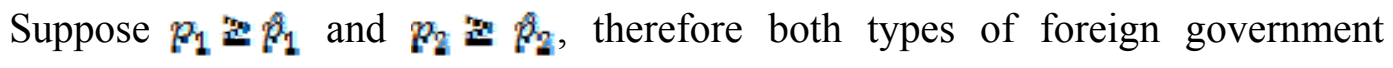
cooperates perpetually once maximum level of cooperation is attained. Then I get the following result.

Lemma 2. If $P_{1}$ is $P_{1}$ and $P_{2}$ is $P_{2}$, then both $($ IC $-1 H)$ and $(I C-2 L)^{4}$ do not bind unless the cooperation level decreases sufficiently within time.

Intuitively, Lemma 2 implies that the home government can only extract "weak" signals from foreign government's cooperative actions. Then, revelation of the type of foreign government in pooling equilibrium occurs only when betrayal is observed, which is reserved for type-2 foreign government in a high state of nature. Nevertheless, the home government's subjective belief about the foreign government being type-1 increases gradually as cooperative action profile is observed through periods. A selfenforcing agreement requires incentive compatibility for the home government as well. Formally in period $t$ :

$$
\begin{aligned}
& q_{t} \cdot\left[w^{\sigma}\left(\sigma_{2}\right)+\delta V^{\sigma}\left(q_{t+1}\right)\right]+\left(1-q_{2}\right) \cdot\left[w^{-\alpha}\left(\sigma_{2}\right)+\delta V^{F}\right] \\
& 2 q_{\tau} w^{d}\left(\alpha_{\tau}\right)+\left(1-q_{\tau}\right) \cdot w^{H}\left(\alpha_{\tau}\right)+\delta v^{x},
\end{aligned}
$$

Plugging the explicit payoffs in, I get:

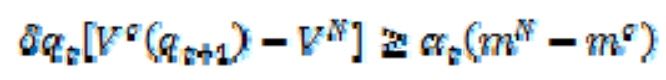


Nash cooperation value is deterministic and defined as discounted sum of payoffs when unilaterally optimal tariffs are applied. The cooperative continuation value for the decision maker in period $t$ is formally defined as:

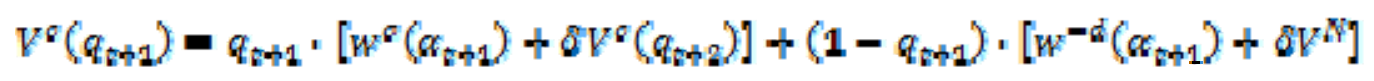

Therefore, there a recursive structure in cooperation values. There are two features that worth pointing out here: First, there is more than one (two, specifically) nonstationary variables, the belief $q$ and cooperation level $\alpha$. Second, both of these nonstationary variables are bounded above: i.e., the belief has an upper limit of one, and the level of cooperation is limited by amount of goods traded between countries. However, although the upper limit is reached for latter one in the course of game, as I will show, the upper limit for the belief is never attained in a pooling equilibrium. I take advantage of this structural change in the game by defining the critical period in which the cooperation level reaches to its maximal level, and analyze the rest of the game with reference to that period in the proof of Lemma 3. I call the subsection of the long-term relationship where the level of cooperation is stationary at the maximum level the "maximum cooperation phase", and the subsection where cooperation level rises gradually the "gradual cooperation phase." First, I define a general form for continuation value at an arbitrary point in time, without signifying the structural break point. Solving (3.4) iteratively, I get this general form:

$$
V^{\sigma}\left(\alpha_{t}\right)-\sum_{i=t}^{\infty} g^{i-t}\left[w^{\sigma}\left(\alpha_{i}\right)+\left(1-\alpha_{i}\right) \cdot\left[w^{-d}\left(\alpha_{i}\right)+g v^{N}\right]\right] \prod_{i=t}^{t} \alpha_{i}
$$


Intuitively, let $\bar{t}$ be the first period with maximum level of cooperation, then continuation value in period $\bar{t}-k$ is the discounted sum of expected payoffs from cooperation in both phases. Expected stage game payoffs increase in gradual cooperation phase as long as governments act cooperatively. This characteristic is determined by two non-stationary variables I mentioned. Holding the level of cooperation constant, expectation of future payoffs increase solely because the home government assigns a higher probability to the foreign government acting favorably in the future. This increase in belief, in turn, manipulates the continuation values in both phases of the relationship. Given a higher probability of favorable play in the future, the home governments' incentive constraint is relaxed after a cooperative period. This slackness in the constraint provides some room for further cooperation that makes the incentive constraint bind again. Therefore the continuation value increases because of these two effects after each successfully cooperative action profile in gradual cooperation phase. The following lemma summarizes these findings.

Lemma 3. $V^{\sigma}\left(q_{t+1}\right) V^{*}\left(q_{2}\right)$ for the home government as a result of:

\section{i. $q_{t+1} \rightarrow q_{0}$ in maximum cooperation phase (pure belief effect), and \\ ii. $q_{t+1} \geqslant q_{\varepsilon}$ and $\alpha_{t+1} \geq \alpha_{z}$ in gradual cooperation phase.}

I now show technically that cooperation level increases in gradual cooperation phase. The home government can increase its expected payoff by increasing the level of cooperation when there is slackness in its incentive constraint. Therefore, optimality requires the incentive constraint to bind in every period in gradual cooperation phase. 
Using $(I C-H)$, the level of cooperation that satisfies the incentive constraint with equality can be written as:

$$
\alpha_{t}=\frac{\delta q_{t}}{m^{N}-m^{e}}\left[V^{e}\left(q_{t+1}\right)-V^{N E}\right]
$$

Since $V^{q}\left(q_{t+2}\right)>V^{q}\left(q_{\tau+1}\right)$ by Lemma 3 and $q_{t+1}>q_{q}$ by definition of $q$ and $(1, q)$, I show that $\alpha_{t+1} \alpha_{n}$. The following proposition specifies gradualism in my model.

Proposition 2. By Lemmas 2 and 3, and using (1.13) the optimal contract proposes a gradual transition to maximum cooperation phase in a pooling equilibrium where $p_{1}$ ins $p_{1}$ and $p_{2} p_{2}$.

In order to derive the optimal cooperation explicitly, I employ two characteristics of the game: The home government selects the highest possible cooperation level that exante satisfies its incentive constraint based on the subjective belief in each period ${ }^{4}$. This selection implies that home government is indifferent between betraying and cooperating in each period. More interestingly, being indifferent between cooperation and betrayal in two consecutive periods implies being indifferent between betraying in the first period and cooperating in the first but betraying in the second period ${ }^{5}$. I take advantage of this property to characterize the optimal increments in level of cooperation. In an arbitrary period $\mathrm{t}$ I formally show this as:

$$
q_{t} w^{d}\left(\alpha_{t}\right)+\left(1-q_{t}\right) w^{N /}\left(\alpha_{t}\right)+\delta V^{H}=\left(1-q_{t}\right) \cdot\left[w^{-\alpha}\left(\alpha_{t}\right)+\delta V^{W H}\right]
$$

\footnotetext{
${ }^{4}$ Otherwise, it could increase the cooperation level and get a higher payoff without violating incentive constraints of foreign government, which contradicts with optimality condition.

${ }^{5}$ A simple example helps elaborate this. Assume there is a two period game with discounting (discount factor $\delta$ ) where a player faces the problem of choosing between left $(\mathrm{L})$ and right $(\mathrm{R})$ in both periods. In the first period, L ends the game, whereas $\mathrm{R}$ starts the second period. Choosing $\mathrm{L}$ and $\mathrm{R}$ gives the same payoff in the second period, call this $\pi$. In order for the player to be indifferent between $\mathrm{L}$ and $\mathrm{R}$ in the first period, $\mathrm{L}$ needs to earn him $\bar{\xi} \boldsymbol{\phi} \boldsymbol{\pi}$ whereas $\mathrm{R}$ gives $\xi$ plus the discounted payoff from second period. In this case the strategies of playing $\mathrm{L}$ in the first period, and $\mathrm{R}$ in the first period and L in the second period both earns him $\xi^{\prime \prime}+h$.
} 


$$
+q_{t}\left[w^{\sigma}\left(\alpha_{t}\right)+8\left[q_{t+1} w^{d}\left(\alpha_{t+1}\right)+\left(1-q_{t+1}\right) w^{N E}\left(\alpha_{t+1}\right)+\delta V^{N}\right]\right]
$$

Where the left hand side of the equation shows the home government's payoff on deviation in including possibility of foreign government betraying simultaneously. The right hand side of the equation, on the other hand, describes the payoff generated by cooperating in the current period and betraying in the next one, with the payoffs associated with possible betrayal by the foreign country in the current period or the next one. Plugging definitions of welfares in, and employing gains from actions notation, I get the explicit correlation between two consecutive cooperation levels:

$$
\alpha_{t}=a_{t+1} \cdot q_{t} \cdot q_{t+1} \frac{\delta\left[\Omega^{d}+\Omega^{g}\right]}{\Omega^{d}}
$$

Note that this relationship is relevant only in gradual cooperation phase. Once the maximum level of cooperation is attained, additional beliefs favoring the cooperation only increases expected future payoffs slightly. However, this correlation gives us a welldefined path of optimal cooperation until it reaches a maximum. Setting $\alpha_{\varepsilon}=\alpha_{\mathrm{p}+1}=\bar{\alpha}$, (3.9) gives us the level of belief sufficient to reach maximum cooperation:

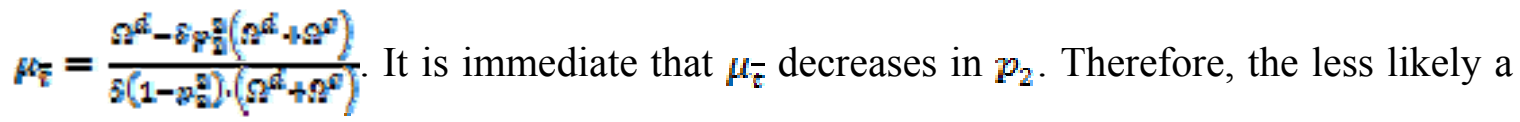
type-2 foreign government will experience a political economy shock, the faster maximum cooperation is reached in a pooling equilibrium. Next section displays the case where different types of foreign government are separated relatively quickly in the course of the game. 


\section{Bicycle Theory and Testing the Partner}

I now focus on a case where type-2 foreign government reveals its type even before a high state of nature is realized. Suppose $p_{2} \alpha_{2} k_{2}$, so that type-2 foreign government betrays in case of maximum cooperation. This condition implies that the type-2 foreign government betrays whenever the cooperation level remains stationary for the rest of the game. This characteristic changes the structure of cooperation dramatically. If the home government wants to keep a type- 2 foreign government in cooperative relationship, it needs to provide sufficient inter-temporal incentives. Enhancing the cooperation level through consecutive periods postpones foreign government's betrayal, but never eliminates it since the level function is bounded above. Terminating a relationship with a type-2 foreign government is not trivial. Renegotiation-proofness of the agreement implies that the home government takes advantage of additional information revealed in each period to redesign the contract optimally ${ }^{6}$. Therefore after a critical period where types are separated with type-2 betraying, home government proposes maximum cooperation if trading partner has not betrayed. However, home government should also be concerned about the "ratchet effect." Observing the proposed cooperation path, the type-2 foreign government can gain substantially by pooling with a type-1 foreign government. Postponing betrayal one more period provides it with betrayal payoff in the maximum cooperation stage. This effect makes separation of types more

\footnotetext{
${ }^{6}$ Assuming contract being designed at the outset of the game does not change this property. The initial contract conditions the path of cooperation on observed action profile in each period.
} 
costly for home government, since it needs to provide more incentives for the trading partner to reveal its type ${ }^{7}$.

I start with deriving the cooperative path that provides intertemporal incentives and make the type- 2 foreign government delay betrayal. The condition $p_{2} \leftarrow p_{2}$ implies that there is no cooperative continuation value in period $\bar{t}$, where the level of cooperation is supposed to reach a maximum level. I can define the incentive constraint of a type- 2 foreign government in period $\bar{t}-1$ as:

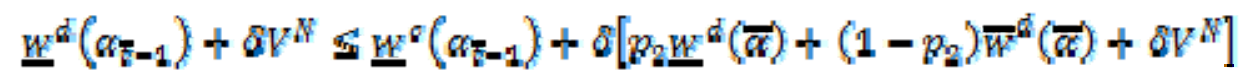

I get the maximum value of cooperation level that makes the type-2 foreign government indifferent between betraying in consequtive periods as the following: $\alpha_{\bar{F}-1}=\frac{\bar{\alpha}}{\Omega^{d}} \delta\left[p_{2}\left(\Omega^{d}+\Omega^{\sigma}\right)+\left(1-p_{2}\right) \cdot\left(\bar{\Omega}^{d}+\bar{\Omega}^{\sigma}\right)\right]$. It is straightforward to show

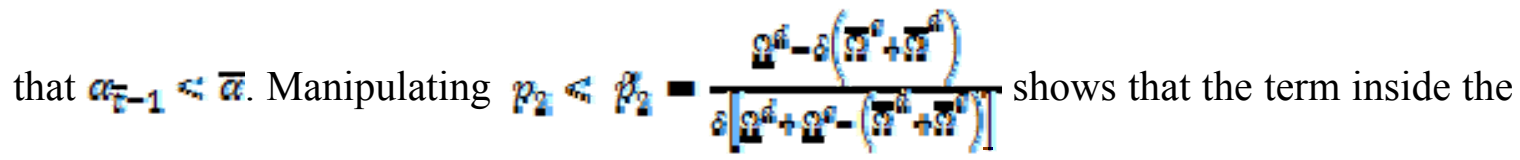
brackets is smaller than one. Solving for the maximum incentive compatible levels of cooperation backwards, I obtain a general rule for an arbitrary period:

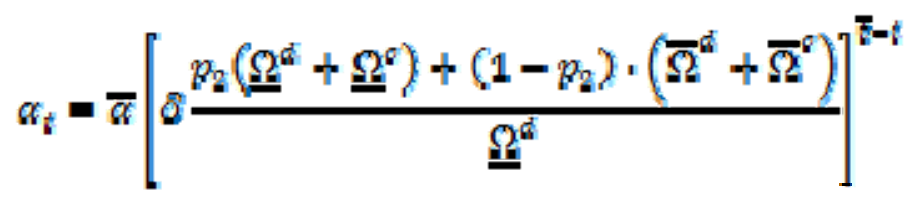

\footnotetext{
${ }^{7}$ We do not have further complications related with the good type partner in our model. A good type agent might "takethe-money-and-run" when principal raises incentives to separate types in a standard dynamic principal agent framework. This might make the incentive constraints bind both "upward" and "downward". Since a type-1 foreign government prefers perpetual cooperation we do not need to worry about this.
} 
This rule defines a convex path increasing in time. Intuitively, it represents the minimum increment in cooperation level that makes foreign government indifferent between betraying in an arbitrary period and postponing it for the next one.

Ratcheting is manifested in the following way: A one shot-deviation from equation (1.15) in early stages does not induce type-2 foreign government reveal its type. Since revelation of type is followed by maximum cooperation or no cooperation at all, home government needs to propose at least $\alpha_{\bar{\gamma}-1}$ in an arbitrary period to "test" its trading partner credibly. Figure 2 displays two cases. The left panel shows the ratchet effect baffling a non-credible test; whereas the right panel shows a successful separation in the first period of relationship. Note that if home government could fully commit to the gradual path (bold concave curve in panel a), then a small deviation from incentive compatible path for the type- 2 foreign government would successfully separate the types. However, in the absence of full commitment, ex-post efficiency through renegotiation upon complete revelation of types requires a higher initial incentive to implement separation.

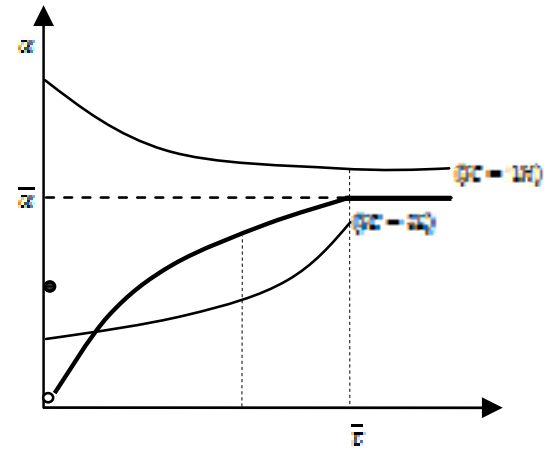

(a) A Non-credible "Test"

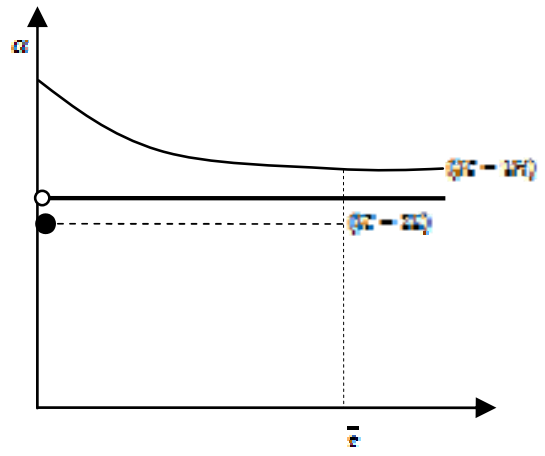

(b) A Credible "Test"

Figure 2: Incentive Structure and Testing in Separating Equilibrium 
I now characterize the conditions under which testing is an equilibrium strategy for home government. Expected payoff from a credible-test strategy for the home government in the first period is given by:

$$
\mu_{\sigma}\left[w^{\sigma}\left(\alpha_{\bar{Q}-1}\right)+\delta V^{\sigma}(\bar{\alpha})\right]+\left(1-\mu_{\sigma}\right) \cdot\left[w^{-\alpha}\left(\alpha_{\bar{V}-1}\right)+\delta V^{N}\right]
$$

This is basically a weighted sum of expected payoffs when the foreign country is type-1 (cooperates) and type-2 (betrays) using the prior belief. Note that cooperative continuation value in a separating equilibrium is $V^{\sigma}(\bar{\alpha})=\sum_{i=\rho}^{\infty} \bar{\delta}^{t} w^{\sigma}(\bar{\alpha})$ since the home government's posterior belief is equal to one after the first period. It is obvious that the equation (1.16) is increasing in prior belief $\mu_{\odot}$. The more likely a foreign government is a good partner, the higher is expected payoff from a testing strategy. Following incentive constraint gives us the condition under which testing in the first period is an equilibrium strategy for home government:

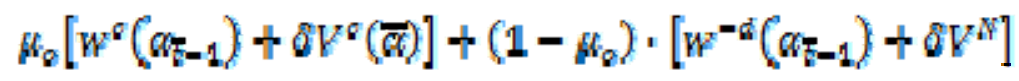

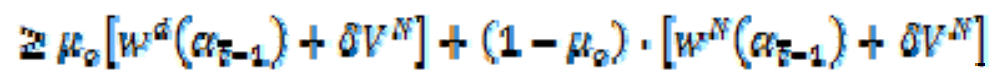

Intuitively, the expected payoff from the testing strategy needs to be greater than or equal to the payoff from betraying in the first period after proposing a testing strategy in the contract for the home government. I can define this as $\mu_{\circ} \frac{\delta}{1-\delta} \bar{\alpha} \Omega^{\circ}-\alpha_{\mathbb{E}-1} \Omega^{d} \geq 0$. Plugging the value of $\alpha_{\mathbb{7}-1}$ I displayed before in the above inequality and solving for $\mu_{Q} \mathrm{I}$ get:

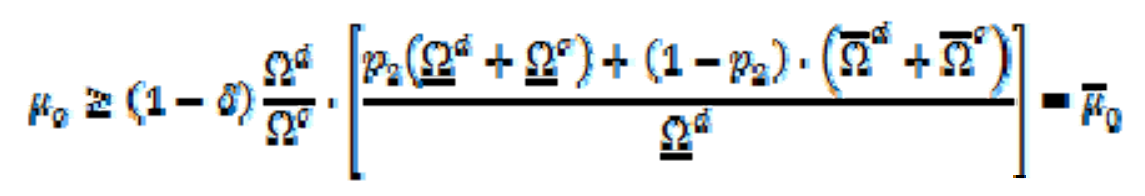


The following proposition summarizes conditions for the existence of this separating equilibrium.

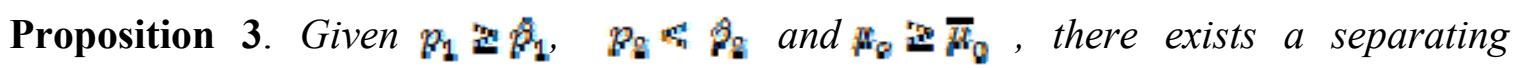
equilibrium in which home government proposes $\alpha_{1}=\alpha_{\bar{\gamma}-1}$ and $\alpha_{t}=\bar{\alpha} \forall t \geq 2$ conditional on cooperative action in the first period. Therefore the type of the foreign government is revealed in the first period, and cooperation continues with maximum level from the second period onward if the foreign government does not betray in the first period.

Corollary 1. $\bar{H}_{0}$ is decreasing in $\delta$.

The result by Corollary 1 is interesting in the sense that it shows that more patient governments are more likely to resolve uncertainties as a result of informational asymmetry in the beginning of a relationship by eliminating the "bad type" partners. Intuitively, gradual adjustment enables cooperation but at the same time some payoff is lost because maximum cooperation is postponed. Therefore, the higher discount factor increases the discounted value of this additional payoff that can be earned by maximizing cooperation quickly.

\section{I.IV. CONCLUSIONS}

This paper helps understand the structure of cooperation between countries in the presence of informational asymmetry. In the absence of incomplete information, the home government observes the probability of a foreign government to experience political economy shocks in the form of protectionism in each period. Given that this 
probability is low enough to satisfy the foreign government's incentive constraint, and that the home government is patient enough, partners start the relationship with maximum cooperation. I show that home government needs to be patient enough for the partnership to be sustainable, when this probability is relatively high. Nevertheless, cooperation does not exhibit dynamic variation in a complete information environment.

Non-stationary cooperation emerges when the foreign government's probability of experiencing political economy shock is privately observed. I consider a case where a foreign government betrays perpetually with or without political economy shock realization if probability of the shock is relatively small. However, the foreign government prefers betraying when the political economy shock is realized if this probability is relatively high. The home government hesitates to start cooperation at a maximum level in this case. Using the privilege to design the contract, it proposes gradually increasing cooperation level conditional on cooperative action profiles. The home government becomes more optimistic about its partner as it cooperates through successive periods. I show that the threshold level of belief sufficient for the home government to propose maximum cooperation is increasing in the probability of shock. Hence, maximum cooperation is attained faster with low probability of shock.

I next consider a case where the foreign government prefers betraying even before a shock is realized when probability of political economy shock is high enough. In this case, the home government needs to provide this type of foreign government with sufficient intertemporal incentives to keep it in partnership. These incentives are in the form of increasing level of cooperation. I show that this necessary increment is decreasing in discount factor: Patient governments can sustain a longer cooperative 
relationship as long as a shock is not realized. The home government might prefer "testing" the trading-partner in the beginning of relationship by proposing a high enough cooperation level that violates foreign government's incentive constraint if it has a high probability of shock. Interestingly, I see that the minimum prior belief that makes this testing attainable is the decrease in discount factor. The more patient is home government, the more likely it prefers resolving uncertainty in the beginning of relationship by rectifying the "bad" type partner.

A potential limitation of my analysis is its inability to refer sector-based composition of agreement under different supply schemes. I believe that non-uniform and non-asymmetric conditions in different sectors may provide significant enrichment for analysis of trade agreements. I also believe that further work is needed to understand optimal dynamic behavior of governments under asymmetric information. 


\section{INTERNATIONAL COOPERATION IN TRADE AND INVESTMENT: (WHEN) DOES LINKING THE AGREEMENTS HELP?}

\section{II.I. INTRODUCTION}

Distinctions between international trade and tax policies become blurred as further international investment deepens globalization. On the one hand, de facto tariff policies reflect the effect of international investment patterns, on the other hand, governments increasingly explore the prospects of their income tax system for protectionism (see Brauner, 2005). However, the institutional framework regulating international cooperation in these issues does not reflect this connectivity. International trade and tax regimes consist of fragmented legal constructs which deal with proliferating trade and investment independently. Trade liberalization has been successfully promoted and coordinated by a series of multilateral agreements, whereas the cooperation in international investment is predominantly served by bilateral tax treaties. Two regimes have recently faced escalated tension because of this mismatch between fragmented legal framework and interconnected economic structure ${ }^{8}$. This tension has raised considerable efforts in various disciplines to advance a method for reconciling the two regimes. Among the proposals are a multilateral agreement for tax issues in services and

\footnotetext{
${ }^{8}$ Foreign Sales Corporations (FSC) dispute between European Communities (EC) and United States (US) in 1998 is an interesting example in this regard. US Congress enacted FSC regime as a mechanism to encourage exports. Income from export related activities through FSC's, which were required to carry out substantial economic activities outside the US, were partially exempted from income taxes as opposed to the application of foreign tax credits for other international commerce. EC claimed that this partial tax exemption meets the definition of a subsidy since it does not apply to all income earned abroad but covers only export related earnings, violating the Agreement on Subsidies and Countervailing Measures (SCM) of World Trade Organization (WTO). US argued that WTO should not be involved in the dispute for a number of jurisdictional reasons, and claimed that the matter should be resolved under the framework of current bilateral tax treaties. This request was rejected. EC was permitted by arbitrator to impose $\$ 4$ billion sanctions in tariffs on selected imports from the US (McDaniel, 2004).
} 
investment (Avi-Yonah and Slemrod, 2002), establishment of an International Tax Organization (Brauner, 2005), and maintaining the current system, as a normative tax structure and free trade principles are not in conflict (McDaniel, 2004). This paper investigates the option of linking Free Trade Agreements and Tax Treaties in terms of its implications for welfare and enforcement of cooperation. I conclude that linking the two agreements provide further cooperation between governments when there is significant asymmetry between the countries. Without asymmetry linkage does not generate any further enforcement power even when the issues are inherently linked because of spillovers; but it does not reduce the cooperation either. However, this last result changes when the linkage is established under limited punishments. I show that linking the agreements may actually reduce the cooperation when Withdrawal of Equal Concessions (WEC) rule of WTO is applied.

There are three principal ways in which a country might employ its trade and tax policy variables for protectionist purposes. First, it could favor domestic products over foreign products by imposing import tariffs. Second, it could favor domestic products over foreign products by providing income tax exemptions on export related activities. Finally, it could favor domestic producers over foreign producers by discriminating in income tax on a residency basis. Cooperation among governments to prevent discrimination against foreign products through import tariffs and related non-tariff barriers is coordinated by multilateral agreements such as General Agreements on Tariffs and Trade (GATT), and is relatively well understood in the literature. The second type of protectionism favors domestic products in foreign markets. Among the common practices 
are providing deductions in income taxes for domestically produced inputs ${ }^{9}$, and deferring the income tax only in export related earnings until an actual distribution is made $^{10}$. The activities in this department are prohibited and regulated under 1979 GATT Subsidies and Countervailing Measures Agreement (SCM). The third type of protectionism, where a government taxes foreign enterprises operating in its territory more heavily than the domestic producers in similar conditions, is the domain of bilateral tax treaties.

Bilateral tax treaties basically disentangle transnational tax base, which otherwise contain a disagreement between residence (enterprise's home country) and source-based (the country where income is generated) taxation principles. Revenues are shifted from source to residence jurisdictions under tax treaties. The revenue transfer might occur in two channels: A lower source tax limits the tax burden of enterprises investing abroad, or the countries applying the credit method for double-taxation-relief can collect the residual tax on income earned abroad when the source tax is lowered. Tax treaties usually designate a reduction in statutory rates of withholding tax implemented on foreign

\footnotetext{
${ }^{9}$ There are several examples for this type of act. Foreign Sales Corporation legislation provided a tax exemption for FSC's conditional on a rule of origin: "no more than $50 \%$ of the fair market value of the exported property could be attributable to articles imported into the US" (McDaniel, 2004). Similarly, Sweden imposed a fifteen percent tax on premiums paid by Swedish residents to foreign life insurance companies, as opposed to no taxes on premiums paid to Swedish companies; and Denmark provided more business deductions for meetings at Danish tourist sites than the ones at foreign sites (Graetz\&Warren, 2006).

${ }^{10}$ The US Domestic International Sales Corporation (DISC) enactment of 1971 provides a good example in this case. A DISC was defined as a corporation with at least $95 \%$ of its assets devoted to export related activities and at least $95 \%$ of its income must be generated by export related activities. Income tax for DISC's were deferred, with no interest charges, until an actual distribution is made to its parent corporation. This was considered to be an interest-free loan from the government, and was constituted an export subsidy in the GATT panel (McDaniel, 2004).
} 
enterprises on a reciprocal basis ${ }^{11}$. Therefore, governments prefer different taxation principles depending on their net investment flow in relation to the partner. Developed countries prefer residence based taxation, whereas developing countries favor source based taxation in a tax treaty. This asymmetry in tax preferences rebounds in the composition of bilateral tax treaties all over the world. A significant majority of more than 2500 tax treaties are between developed nations ${ }^{12}$. The affirmative result in this paper indicates that limitations against cooperation between developed and developing nations, which arise from the mismatch between asymmetric investment flows and reciprocity requirement in tax treaties, could be overcome by linking the tax treaty with free trade agreements. The idea here is that the developing country is the "short-side" in a tax treaty since an equal tax reduction in both countries reduces its net revenues. On the contrary, the developed country is the "short-side" of a free trade agreement because of export-dependence of the developing country. Linking in this case serves as a transfer payment to the "short-side" in a specific agreement for undertaking further concessions it would not do otherwise. Therefore, linking helps countries aggregate dispersed enforcement power and reallocate it efficiently, which increase the cooperation both in trade and tax policies. This aspect of linkage has been analyzed in different contexts with similar results in the literature (for environmental agreements see Cesar \& de Zewe,

\footnotetext{
${ }^{11}$ OECD Model Convention limits source country tax on dividends to $5 \%$ for owners of $25 \%$ or more shares of the enterprise and 15\% for others (Avi-Yonah\&Slemrod, 2002).

${ }^{12}$ The OECD Model Convention, which is adopted in all of these treaties, puts more weight on residence based taxation. Article 5 of OECD-MC states that "Profits can only be taxed in the source state, if they are attributed to a permanent establishment. Similarly, Articles 10-12 limit the degree of taxation for dividends, interests and loyalty payments at source. However, there are limitations on residence country as well. Article 23 states that residence government is obliged to provide relief from double taxation in cases of full or limited source taxation, which can be in the form of tax credits or exemptions (Rixen, 2008). An earlier version of United Nations Model Convention emphasized source based taxation, but was modified in later versions.
} 
1996; for regional trade agreements between large and small countries see Abrego et al., 2001 and Limão 2002). I report non-results for linkage with symmetric countries.

To elaborate these results, I use a two country-two goods model with goods and capital flowing in both directions. In the absence of an agreement, governments apply unilaterally optimal import tariffs and FDI taxes, which are jointly inefficient. Therefore, the non-cooperative equilibrium is characterized by tariffs and taxes that are too high, and little international trade and investment. Governments overcome this inefficiency by maintaining cooperation in each policy with a separate agreement in the benchmark case. The cooperative relationship in each agreement is constructed as an infinitely repeated Prisoner's Dilemma game, where the Nash reversion threat provides incentive compatibility for sufficiently patient governments. A no-linkage regime is identified with confinement of punishment in the policy where deviation is observed. Following the common application in literature, I first define the linkage regime under Nash reversion strategies when betrayal is observed in either or both agreements, to change this assumption later. I show that the structure of enforcement does not change much under linkage when countries are symmetric and trade and investment issues are independent, i.e., there is no interaction between Foreign Direct Investment (FDI) and production of goods, besides reallocating enforcement capacity from one agreement to the other if necessary. I specify two cases with interdependent trade and FDI: First, foreign investment generates technological spillovers in the export sector of the host country, i.e., the cost of producing the export good is a decreasing function of FDI inflow. Second, FDI has technological spillovers in the import competing sector of host country. The former type of spillover does not change cooperation structure in this case since tariffs 
and taxes are strategically independent in host country welfare function. On the contrary, policy arguments are strategic complements when there is import-biased type of spillovers. Intuitively, the strategic complementarity between FDI taxes and import tariffs reflects the fact that protectionism in tariff policy has greater welfare gains when domestic producers are less efficient in import competing industries. In other words, a tax hike increases marginal returns on tariff by increasing the cost of production for the import competing industry. Costs rise since foreign investment decreases in tax rate, which leads to lower technological spillovers. Therefore, a simultaneous deviation in both policies brings a greater gain than sum of the gains from deviation in each policy. I show that, linkage under these conditions cannot provide further cooperation in both policies at the same time. However, it cannot reduce enforcement either, since a simultaneous deviation is always an option even under a no-linkage regime.

I next analyze linking the free trade agreements with tax treaties under the conditions defined by GATT rules. Specifically, I am interested in showing the effects of limited punishments on enforcement when cross-retaliation is allowed. As for the magnitude of punishments, Understanding on Rules and Procedures Governing the Settlement of Disputes (DSU) implements an equivalence standard (Withdrawal of Equivalent Concessions-WEC), where retaliation should be equal to or below the nullification or impairment ${ }^{13}$. Type of the retaliation is set by Article 22.3 of DSU under three-stage retaliation: A parallel retaliation is defined as a punishment by requesting

\footnotetext{
${ }^{13}$ Bown and Ruta (2008) provide an economic interpretation for "equivalence" of retaliation with original nullification or impairment.
} 
party in the same sector(s) as that in which nullification or impairment has been found ${ }^{14}$.

A cross-sector retaliation is applicable only in services trade and intellectual property rights issues, since retaliation across goods is already classified as within sector punishment. Finally, a cross-agreement retaliation is suspending concessions or other obligations under another covered agreement ${ }^{15}$. The three stage retaliation process restricts the use of cross-sector and cross-agreement retaliations significantly. The requesting party must first elaborate why parallel retaliation is not practicable or effective in case of cross-sector retaliation request. Similarly, it needs to demonstrate why parallel and cross-sector retaliations are not practicable or effective in case of cross-agreement retaliation request ${ }^{16}$. The term "not effective" implies inability to induce compliance and existence of substantial harm for the complaining party in this case. My main result in this paper confirms the intuition behind the restriction of cross-retaliation across tax and trade agreements.

In order to elaborate my main result, I drop the Nash reversion assumption. I formalize the dispute settlement process under different regimes as follows: 1 . Under a no-linkage regime, a deviation from the cooperative path is punished by withdrawal of

\footnotetext{
${ }^{14}$ Sector means all goods if the dispute has aroused in goods trade, i.e. punishment in any traded good as a response to betrayal in another one is considered to be parallel retaliation. In case of services, sector is identified as in the current "Services Sectoral Classification List", i.e. educational services, communication services etc. In case of Trade Related Aspects of Intellectual Property Rights (TRIPS), each category of property rights such as trademarks, copyrights and patents of TRIPS Agreement is considered a sector (Shadikhodjaev, 2009).

${ }^{15}$ For goods, an agreement denotes whole multilateral and plurilateral agreements on trade in goods, of course if both parties to the dispute are parties thereto. Whereas for services and intellectual property rights it points GATS and TRIPS, respectively (Shadikhodjaev, 2009).

${ }^{16}$ In US-Antigua and Barbuda dispute, the Appellate Body found US restrictions on gambling and betting services violating US market access commitments under the GATS. Antigua and Barbuda requested authorization to suspend its concessions and obligations under TRIPS Agreement, since a retaliation under GATS was not practicable or effective due to significant asymmetry between the parties.
} 
equivalent concessions within the same agreement, i.e., both governments deviate from the cooperative equilibrium by the initial amount of deviation forever. A failure to comply with this limited punishment path invokes standard grim-trigger punishments ${ }^{17}$, 2. Under a linkage regime the requesting party is allowed to withdraw equivalent concessions in the other agreement upon observing betrayal in a specific issue, i.e., each party deviates from the cooperative equilibrium path by an amount equivalent to the initial deviation in different agreements forever, but complies in the other agreement. A failure to implement this punishment path invokes standard grim-trigger play. I first show that limited punishment under no-linkage regime induces a deviating government to apply a limited deviation, i.e., the deviation tariff under limited punishment is smaller than the one under maximum punishment. Intuitively, a deviating government imposes the highest beneficial tariff and/or tax in a deviation period when the maximum punishment will be applied regardless the level of deviation. On the other hand, when punishment is tailored to the deviation, possible reductions in future punishments restrict the optimal tax/tariff level in a deviation period. I then show that allowing cross retaliation increases the deviation tax/tariff when the home and foreign tariffs (taxes) are strategic substitutes in each country's welfare function. Finally, I show that more trade disputes arise under the linkage regime. The idea here is that, when cross-retaliation is allowed, the punisher prefers it over parallel retaliation since it generates a relatively higher average payoff during the punishment phase. However, the motive to reduce the

\footnotetext{
${ }^{17}$ Our motivation here is as follows: when a deviator fails to comply in its punishment, or when a punisher applies more aggressive retaliation than the initial deviation, this is considered to be an "abusive" deviation and punished at a maximum level. Under general international law, a state violating a rule must "cease that act, if it's continuing" in conformity with cessation and non-repetition principles. These principles are meant to reinforce a "continuing legal relationship" between the states concerned (Shadikhodjaev, 2009). See Zissimos (2007) for a similar interpretation.
} 
cost of retaliation for punisher also reduces the magnitude of punishment for initial deviator. Therefore, betrayal at a limited scale becomes beneficial for relatively impatient governments.

My results correlate to different classes of work in the literature. Bernheim and Whinston (1990) analyze firm collusion under multimarket interaction. They recognize the enforcement reallocation aspect of linkage when applied by asymmetric firms. However, linkage does not facilitate further cooperation on aggregate level when firms are symmetric. Besides, linkage never reduces the aggregate enforceability. Spagnolo (1999a) extends the Bernheim and Whinston (1990) by showing that an increase in the cooperation in both markets through linkage is possible if firms have concave objective functions. Strategic interactions become interdependent in this case since the concavity generates "scale economies" in how firms evaluate the profits. Therefore, more collusion in both policies become feasible when profits are submodular in objective functions. Spagnolo (1999b) applies this framework to international agreements. In this case, governments value the payoffs on de facto independent issues nonlinearly. Limão (2005) relaxes this condition and allows structural interdependence between the issues. In his story, traded goods have a negative production externality which might have a crossborder effect. Governments use import tariffs and externality taxes as policy variables, however since the Terms of Trade and production externalities in the absence of agreements, a non-cooperative equilibrium is identified with high tariffs and low externality taxes. When tariffs and externality taxes are strategic complements, deviation in both policies simultaneously grants the deviator less benefit than the sum of the gains in each policy independently. Similarly, gains from cooperation in both policies are 
greater than the sum of the gain from cooperation in each policy. Therefore, linkage incentive constraint holds with a slack when evaluated in a no-linkage solution. These conditions are satisfied when the externality has cross-border effect and is sufficiently weighted in contrast to import competing lobbies. I extend this literature by providing an analysis of linkage under limited punishments, where conditions imposed by the WTO are adopted. The credible conditioning of punishments on the magnitude of deviation from a cooperation path allows us to characterize the equilibria with partial cooperation as a punishment. Therefore, I have more than one incentive constraint under the linkage regime as opposed to the previous works in the literature, which enables me to show that linkage might actually reduce the cooperation when punishments are limited and home and foreign country policy variables are strategic substitutes, which is not possible under the framework of previous papers.

Chisik (2009) investigated linking symmetric issues when parties observe partner's trade policy with a noise, which can generate trade disputes. The paper shows that when the noise is perfectly correlated across independent issues, there is no reason not to link the agreements. However, linkage provides less cooperation as the degree of correlation decreases. Similarly, Ederington (2002) also uses information asymmetry to question the benefits of linking trade and environmental agreements. With no crossborder effects, he finds that linking might be detrimental when countries incorrectly observe cheating, and might be beneficial when they fail to detect cheating. Matsushima (2001) provides the efficiency conditions under multimarket contact when firms cannot perfectly observe their competitor's choice. My results do not depend on asymmetric information. Characterization of the agreements in this paper is derived from previous 
works by Bagwell and Staiger (1999), Chisik and Davies (2004), and Zissimos (2007). Bagwell and Staiger develop the intuition for trade agreements as mechanisms that induce the countries to internalize the Terms of Trade effect of import tariffs. I use the self-enforceability assumption throughout the present paper. Chisik and Davies provide the framework of tax treaties as the cooperative solution for inefficiently high unilateral taxation. However, I do not employ the structure of irreversibility in capacity installations, which Chisik and Davies use to explain gradualism in tax treaties. Hence, my model does not incorporate dynamic adjustments in trade agreements. Finally, Zissimos elaborates how limited punishment affects cooperative behavior under strategic substitutability between policy variables. He does not consider multimarket interaction between the countries. I extend his work by introducing the cross-retaliation option. Blanchard (2007) explicitly recognizes the effect of export platform FDI on unilateral tariff liberalization. However, she does not consider tax on FDI a policy variable, hence there is only a single cooperation problem.

The next section of this paper elaborates the economic environment by defining the production and consumption structure of goods, determinants of capital flows, and behavior of governments under a no cooperation scenario. I then introduce establishment of free trade agreement and tax treaty under the assumption of independent issues, and investigate the effects of linkage under symmetric and asymmetric cases. The third section focuses on linkage when trade and tax issues are correlated. I provide two cases in subsections, export-biased and import-biased technological spillovers. The fourth section studies linkage under limited punishments. Last section discusses policy implications of my results. 


\section{II.II. THE MODEL}

\section{Economic Environment}

There are three countries in the model: Home, Foreign and Rest of the World (ROW). The home (foreign) country is populated with $l\left(l^{2}\right)$ identical agents. Each agent is endowed with one unit of labor and $k\left(k^{m}\right)$ units of capital. Labor is assumed to be immobile, whereas capital is mobile between Home and Foreign countries.

\section{Demand Side:}

There are two independent goods, $x$ and $y$, and a numeraire good, $z$, consumed by Home and Foreign consumers. There are also two goods consumed by only ROW consumers besides the numeraire, which do not require separate notations in this paper because they do not affect my results. Preferences of agents in Home and Foreign are

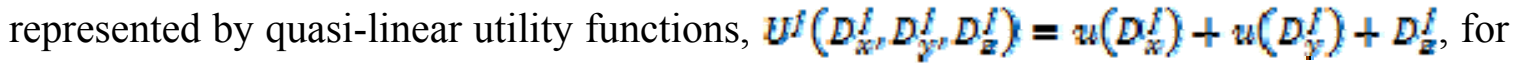
$f=\mathbb{1}_{l=w_{\ell}} l$. Sub-utility functions are assumed to be quadratic so that demand for a nonnumeraire good is only a decreasing function of its own price, $D_{t}-D_{t}\left(p_{t}\right)$ and $\frac{A_{D_{t}}}{\partial \nabla_{t}} \alpha_{t} 0$ for $t \in\{x, y\}$.

\section{Supply Side:}

The numeraire good is produced under constant returns to scale (CRS) technology, using one unit of labor per unit of output. I assume that the supply of labor is high enough to guarantee the production of the numeraire. Therefore, both the numeraire good and labor have price of unity in equilibrium. Good $x$ and $\operatorname{good} y$, on the other hand, are produced in both countries subject to different quadratic cost functions, $\Phi_{\infty}\left(q_{W}\right)$ and 


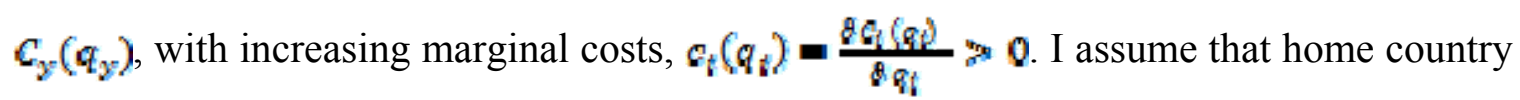
producers have lower marginal costs in good $x$ at each level of production, $c_{y}\left(q_{x}\right)<c_{y}\left(q_{y}\right)$, and foreign producers have lower marginal costs in good $y$, $c_{y}^{8}\left(q_{y}^{*}\right)<c_{x}^{*}\left(q_{x}^{*}\right)$, so that home country exports good $x$ and imports good $y$.

Capital is invested either in the home country or in the foreign country to produce independent goods, which are traded freely with ROW at prices of unity. Denoting the amount of home capital invested in the foreign country by $Z$, gross return for the home investors becomes $h(\mathbb{K}-Z)+f(Z)$. Home and foreign production functions are increasing and concave in capital, $h^{\prime}\left(C_{2}\right), f^{\prime}\left(C_{0}\right)=0$ and $h^{\prime \prime}\left(C_{2}\right), f^{\prime \prime}\left(C_{0}\right) \times 0$, and they also

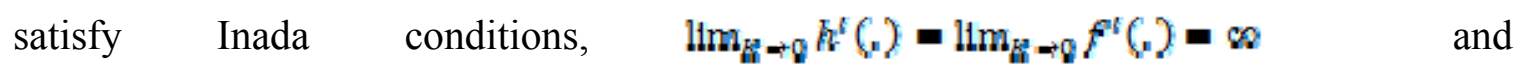
$\operatorname{llm}_{E \rightarrow \infty} h(n)=\ln _{E \rightarrow \infty} f^{t}(n)=0$.

\section{Governments:}

Governments maximize indirect utilities of corresponding representative agents using specific import tariffs, $\tau(\tau)$, and corporate income taxes on repatriated profits of incoming Foreign Direct Investment (FDI), $t\left(t^{*}\right)$. This maximization problem can be written in two stages when trade and FDI issues are not correlated: $\max _{T, t} W\left(\tau, \tau^{*}, t, t^{*}\right)=\max _{T} V\left(\tau, \tau^{*}\right)+\max _{\tau} Y\left(t, t^{*}\right)$. Tax and tariff revenues are redistributed to consumers in lump sum.

\section{Market Equilibrium:}

Home and foreign market prices are given by $p_{y}=p_{y}^{*}+\tau$ and $p_{x}^{*}=p_{x}+\tau^{n}$ in the absence of segmentation between the markets. Producers maximize their profits given 
market prices: $\max _{q_{t}} x_{t}-p_{t} \cdot q_{t}-\varsigma_{t}\left(q_{t}\right)$ for $t \in\left\{x_{i} y\right\}$. The first order conditions for these maximization problems are shown as:

$$
q_{t}=\left(q_{t}^{k}\right)^{-1}\left(p_{t}\right)
$$

Consumers maximize their utility subject to budget constraints given market prices: $\max _{D_{x} D_{y}} U\left(D_{x} D_{y} D_{z}\right) s_{n} t_{n} \cdot p_{x} \cdot D_{x}+p_{y} \cdot D_{y}+D_{z} \leq L$, where income is given by $I=w^{*} \cdot l+\pi_{x}+\pi_{y}+h(K-Z)+\left(1-t^{\prime \prime}\right) \cdot f(z)+t \cdot h^{*}\left(Z^{*}\right)+\tau \cdot\left[D_{y}-q_{y}\right]$. The first order condition for the consumer maximization problem is, then:

$$
\mathbb{D}_{t}=\left(u^{i}\right)^{-1}\left(p_{t}\right)
$$

for non-numeraire goods. Demand for the numeraire good, on the other hand, is equal to the portion of income not spent on goods $x$ or $y$. Equilibrium prices of non-numeraire goods are given by market clearing conditions, $q_{t}\left(p_{i}\right)-D_{t}\left(p_{i}\right)-D_{i}^{8}\left(p_{i}^{*}\right)-q_{i}^{*}\left(p_{i}^{*}\right)$. Therefore, I can write the social welfare generated by the trade component of indirect utility as follows:

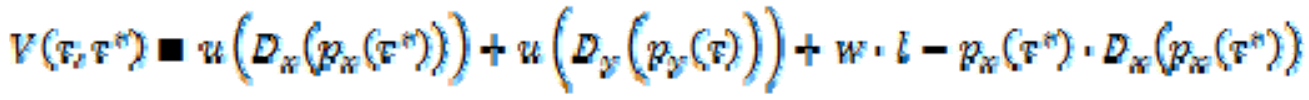

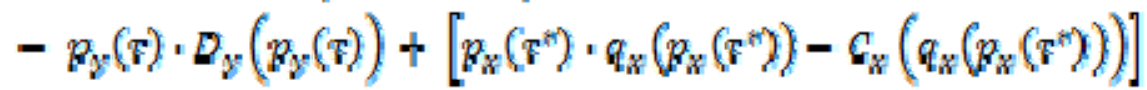

$$
\begin{aligned}
& +\left[p_{y}(\tau) \cdot q_{y}\left(p_{y}(\tau)\right)-\tilde{q}_{y} q_{y}\left(p_{y}(\tau)\right)\right]+\tau \cdot\left[D_{y}\left(p_{y}(\tau)\right)-q_{y}\left(p_{y}(\tau)\right)\right]
\end{aligned}
$$

Unilaterally optimal tariffs maximize this component of social welfare:

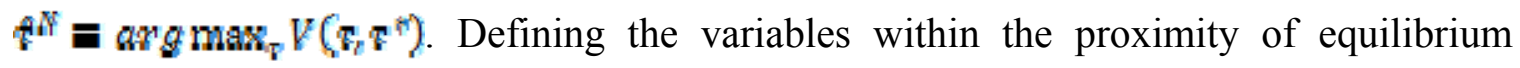
values, I can use the Envelope Theorem to characterize the first order condition for this maximization problem. Employing the first order conditions for producers $(2-\mathbf{1})$ and for consumers $(2-\mathbf{2})$, this becomes: 


$$
\frac{\partial V(S)}{\partial \tau}=\left(D_{y}-q_{y}\right) \cdot\left(1-\frac{\partial p_{y}}{\partial \tau}\right)+\tau \cdot \frac{\partial p_{y}}{\partial \tau} \cdot\left(\frac{\partial D_{y}}{\partial p_{y}}-\frac{\partial q_{y}}{\partial p_{y}}\right)=0
$$

with the solution $\tau=\tau^{N F} 0$. It is straightforward to show that home welfare decreases with foreign tariff, and increases with own tariff for values lower than the Nash level,

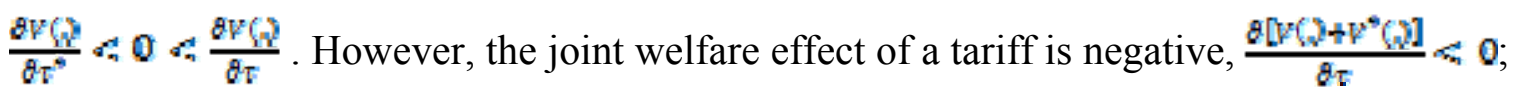
hence, joint efficiency is achieved in free trade, i.e. when governments apply zero tariffs. Therefore, there is scope for a free trade agreement.

Now I will analyze the equilibrium behavior in the investment market. Given the tax rates, investors maximize their return by optimally allocating the capital between countries, $\max _{z} h(X-Z)+\left(1-t^{*}\right) \cdot f(Z)$, with the following first order condition:

$$
\left(1-t^{n}\right) \cdot f^{\prime}(z)-h^{6}(R-Z)=0
$$

The equilibrium Foreign Direct Investment, $\hat{Z}$, decreases in the host country tax rate, $t^{*}$. To show this, I differentiate the first order condition (2-4) with respect to tax rate,

$$
\frac{\partial Z}{\partial t^{*}}=\frac{f^{t}(Z)}{h^{t}(R-Z)+\left(1-t^{*}\right) \cdot f^{n}(Z)}<0
$$

since $h^{n}(K-z)<0, f^{n}(z)<0$ and $f^{\prime}(z)=0$. Governments maximize the investment related component of social welfare by choosing optimal taxes, $\max _{\varepsilon} Y\left(t_{m} t^{*}\right)$, where $Y\left(t, t^{t}\right)=h(K-Z)+\left(1-t^{\prime \prime}\right) \cdot f(z)+t \cdot h^{n}\left(z^{\prime}\right)$. The first order condition for this maximization problem becomes:

$$
\frac{\partial Y}{\partial t}=h^{*}\left(Z^{*}\right)+t \cdot h^{*}\left(Z^{*}\right) \cdot \frac{\partial Z^{*}}{\partial t}=0
$$


Solving for $t$ and remembering that investment decreases in tax rate, I can see that the unilaterally optimal tax rate is positive, $1=0$. However, unilaterally optimal taxes are not jointly efficient. I differentiate the sum of welfares on investment with respect to tax rate to show this:

$$
\frac{\partial\left(Y+Y^{*}\right)}{\partial t}=\frac{\partial Z^{*}}{\partial t} \cdot\left[h^{*}\left(Z^{*}\right)-f^{t}\left(K^{*}-Z^{*}\right)\right]<0
$$

since $E^{*}\left(Z^{4}\right) \geqslant f^{4}\left(K^{*}-Z^{*}\right)$ within proximity of the equilibrium by the first order condition (2-4). It is straightforward to show that the jointly efficient tax rate is zero in a symmetric case. Therefore, unilaterally optimal taxes are inefficiently high and there is scope for a tax treaty. I will characterize the agreements in trade and investment in next section.

\section{Cooperation under Independent Trade and Investment}

Governments face two distinct cooperation problems when the policy variables in trade and in investment are not structurally correlated. I will keep this assumption for now to characterize the agreements separately, analyze the effects of linking under that framework and will remove it in the next section to analyze cooperative behavior under correlated policy issues. I assume commitment in both policy arguments, where governments simultaneously announce value of the policy variables first, then producers and investors undertake production and investment actions, then governments apply the announced tariffs and markets clear, and finally investors in partner countries repatriate the profits less the announced taxes ${ }^{18}$.

\footnotetext{
${ }^{18}$ This assumption enables us abstract from unnecessary complexities that would arise had the governments have the option of informing domestic agents about a planned betrayal. Our results do not depend on this assumption qualitatively.
} 


\section{Free Trade Agreement}

I characterized unilaterally optimal import policies in the previous section. Now, I elaborate the structure of cooperation under a free trade agreement. An agreement, in this case, specifies a cooperative tariff rate to be applied by both governments unless one of the parties deviate. Governments apply Nash tariffs forever following any deviation. The payoff structure constitutes a Prisoner's Dilemma type interaction; cooperation is jointly beneficial, however each government has an incentive to betray the agreement, which establishes the non-cooperative actions as the only Nash Equilibrium outcome in a oneshot game. In a dynamic framework, where the same stage game is played infinitely, governments need to compare their one-shot gains from deviation with the discounted sum of welfare gains they give up in the continuation game by betraying. In the absence of an external enforcing mechanism, the cooperative tariff rate needs to be incentive compatible, i.e., one-shot gains from betrayal need to be lower than the discounted sum of welfare gains from cooperation. I can write the incentive constraint for the home government as follows:

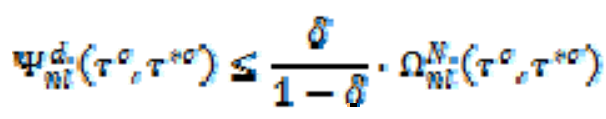

where the left hand side denotes the welfare gain from deviation in tariff policy, $\Psi_{n i}^{d}\left(\tau^{\sigma}{ }_{e} \tau^{* \sigma}\right)=V^{d}\left(\tau^{N}{ }_{e} \tau^{* \sigma}\right)-V^{\sigma}\left(\tau^{\sigma}{ }_{e} \tau^{* 0}\right)$; and the right hand side is the discounted sum

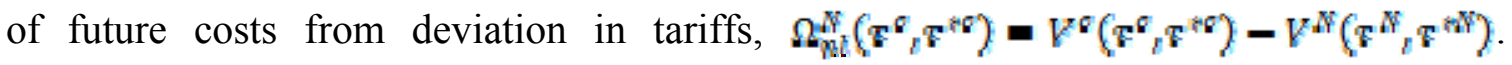
Superscripts $d$ denote the deviation values, $c$ and $N$ denote cooperation and Nash values respectively. For a given discount rate, $\delta$, I will call the minimum tariff rate that satisfies this incentive constraint with equality the most cooperative tariff, and will denote it with 
$\tau^{m e}$. Home and foreign values of corresponding tariff rates and payoffs are identical in a symmetric case.

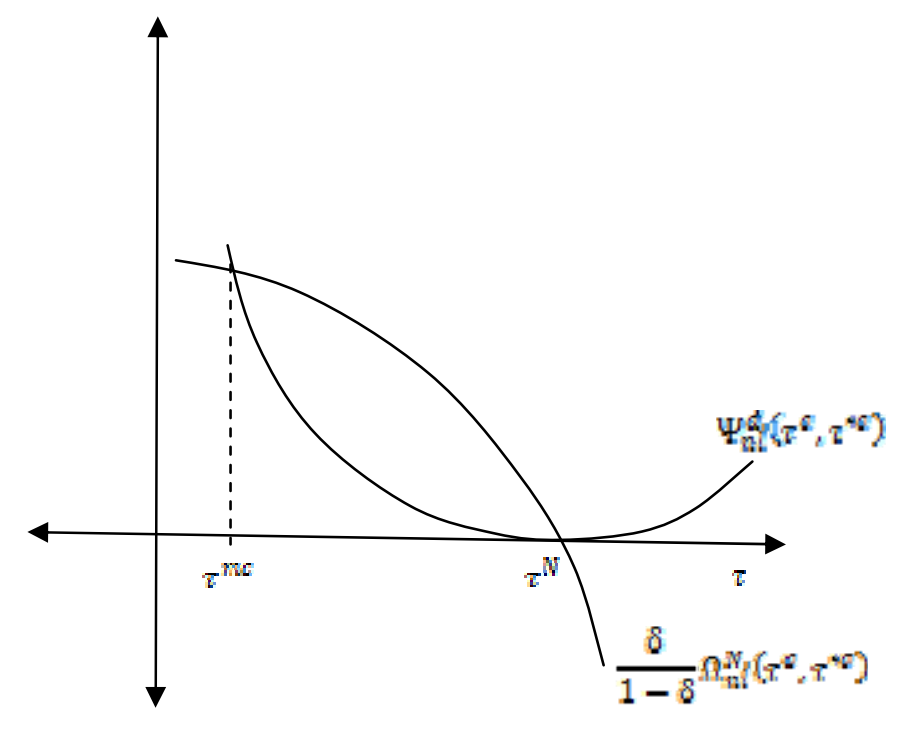

Figure 3. Incentive Compatibility in Free Trade Agreement

\section{Tax Treaty}

A tax treaty specifies a cooperative tax rate to be applied by both governments as long as no deviation is observed. Governments apply unilaterally optimal tax rates forever following a betrayal. The payoff structure constitutes a Prisoner's Dilemma game, and governments cooperate in the absence of an external enforcement mechanism as in free trade agreement. The incentive constraint of the home government is defined as:

$$
\Psi_{m l}^{+d}\left(t^{\circ}, t^{n \sigma}\right) \leq \frac{\delta}{1-\delta} \cdot \Omega_{m l}^{N E}\left(t^{\sigma}, t^{n \sigma}\right)
$$

where the notation is defined such that it is analogous to free trade agreement case,

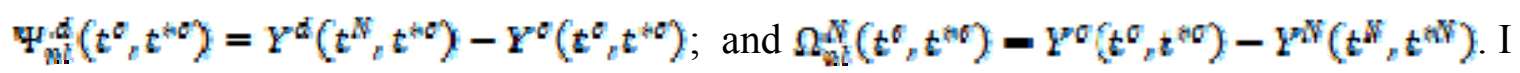
will call the minimum tax rate that satisfies this incentive constraint with equality, for a given discount rate $\delta$, the most cooperative tax rate and denote it with $t^{m e}$. 
A no-linkage regime is characterized by these two separate agreements, where governments cooperate policy-by-policy and cross-retaliation is not allowed. Therefore, punishment is constrained within the policy issue where betrayal is observed. This provides the governments with the ability to cooperate partially. I will analyze the welfare effects of linking the two agreements in a symmetric case in the next section.

\section{Linkage in a Symmetric Case}

I consider a symmetric case, where populations and capital endowments are identical, preferences and cost functions are mirror images between home and foreign

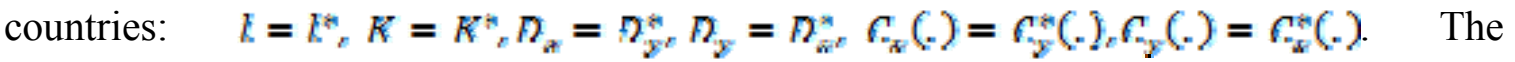
home's export (import) sector is analogous to the foreign country's export (import) sector; therefore, optimal taxes and tariffs are identical between governments under cooperation, betrayal and Nash reversion. A linkage regime is defined with the ability of governments to punish the deviating party by playing Nash reversion in both policy arguments. Hence, when a government betrays an agreement it prefers doing so both in taxes and in tariffs simultaneously. Therefore, there is only one incentive constraint for each government in this case:

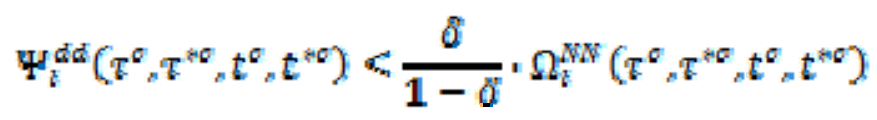

The left hand side of the inequality denotes the gain from deviation in both

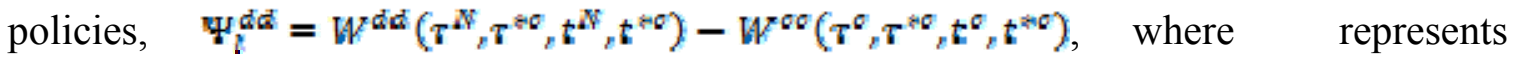
aggregate welfare which can be written in two stages when the trade and investment

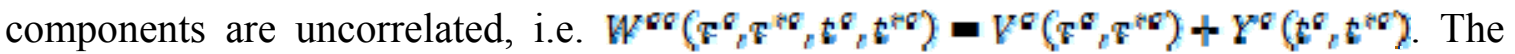
right hand side the inequality is the discounted sum of future gains from cooperation in 


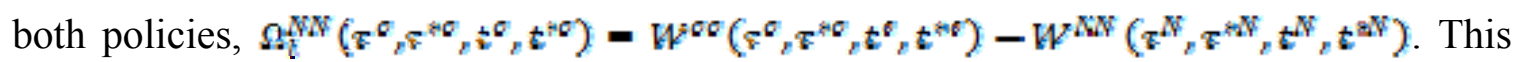
notation allows us to see the changes in incentive compatibility easily.

The effect of linking the agreements can be studied in several cases depending on how the unlinked incentive constraints given in equations (2-6) and (2-7) are structured compared to global optimum. Obviously, when both constraints are slack at global optimum, i.e., incentive constraints do not bind when $\tau^{m e}=\emptyset$ and $t^{m} \boldsymbol{v} \boldsymbol{Q}$, then linkage does not alter incentive compatibility or welfares. However, when one constraint is slack and the other one is binding at corresponding global optimum values, then linkage transfers some enforcement power from the slack one to the binding one. To see this, assume that $\tau^{m e}=0$ and there is slackness in (2-6) at this global optimum, whereas $t^{\text {me }} 0$ and $(2-7)$ binds at this value:

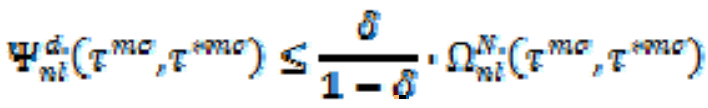

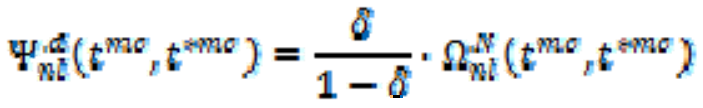

Now, subtract $V^{d}\left(T^{N}{ }_{e} T^{m \varepsilon}\right)-V^{Q}\left(T^{m \varepsilon}{ }_{e} T^{m \varepsilon}\right)$ from both sides in linkage incentive constraint to get:

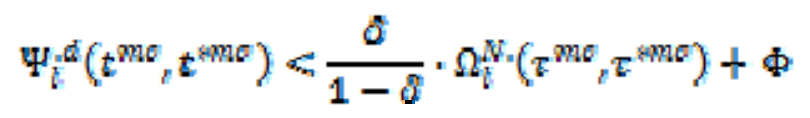

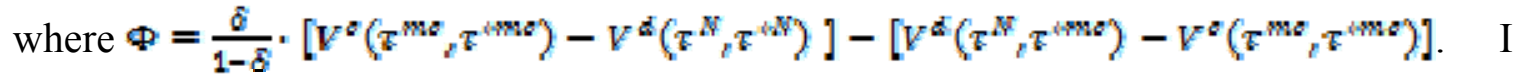
observe slackness in tax treaty for a given most cooperative tax now because the right hand side is greater in linkage regime since $\Phi$ by (2-9). Therefore, governments can enhance the cooperation by further reducing the cooperative tax rate under linkage. 
Intuitively, linking the free trade agreement with the tax treaty improves cooperation in the latter one since the former agreement brings less benefit from deviation than cost of it.

\section{Linkage in an Asymmetric Case:}

I relax my symmetry assumption in this section. I characterize effects of size differences on incentive compatibility of separate agreements, and elaborate how linkage help governments overcome the obstacles for further cooperation. The idea is that when a small country interacts with a large country, the large country has less incentive to reduce its tariffs compared to the small one, because the small country has a greater degree of export dependency. On the other hand, if the size of market in the large country is also associated with the amount of capital stock, then the large country becomes more investment dependent than the small one. The small country has less incentive to reduce the taxes in this case. Therefore, linking the agreements generate further cooperation in both issues, when the "short" sides switch between the issues.

Assume that the agents are still identical in tastes and endowments of capital, however the home country has a greater population, $l>l^{n}$. Therefore, demands for both goods are higher in the home country for a given per-capita income, and home country has a greater capital stock, $K K^{\text {th }}$. The following proposition provides the results regarding the changes in incentive compatibility for trade agreement and tax treaty stemming from this asymmetry in size and capital stock.

Proposition 1. Given identical preferences of agents, endowments of capital per-person, discount rates and mirror image costs of production; if $l b b^{n}$, then the following are observed in a no-linkage regime: 
(a) Home country has a higher most cooperative tariff, $\boldsymbol{\tau}^{\text {me }} \boldsymbol{\tau}^{\mathrm{m}}$

(b) Foreign country has a higher most cooperative tax, $b^{\text {me }}>4^{\text {tme }}$

(c) Linkage improves cooperation both in trade policy and in investment policy.

When governments apply identical tariffs and taxes in cooperation, the most cooperative tariff will be determined by home country's incentive constraint, and the most cooperative tax rate will be determined by the foreign country's incentive constraint. Therefore, each country's incentive constraint binds in one agreement and slacks in the other. Since the enforcement is transferred in opposite directions, linkage improves cooperation in both agreements by my argument in the previous section.

\section{II.III. INTERCONNECTED TRADE AND INVESTMENT}

I relax the assumption of independence between trade and FDI in this section. However, the assumption of symmetry between countries holds in order to isolate the effect of correlation between investment and trade. I analyze two different cases on the basis of the structure of interdependence to elaborate two non-results, where linkage does not provide any further enforcement power. The first case is characterized by a technological spillover effect of inbound FDI in host country's export sector. The idea here is that when FDI reduces the cost of production in the export sector of the host country, then lowering the taxes on FDI creates further trade besides increasing the investment. The second case is characterized by a FDI technological spillover effect in host country's import competing sector. Lowering the taxes, in this case, inhibits trade since the cost-gap between domestic and foreign producers are narrowed down by further investment, leading to a partial shift from imports to domestic production. 
To illustrate my results I first need to introduce the necessary analytical tools. I start with submodularity condition. Since the welfares are assumed to be continuously differentiable, I can define this as follows:

Definition. (Topkis, 1998) A real valued function $f(x) \backsim \mathbb{K}^{m} \rightarrow \mathbb{R}$ is supermodular in $x \in X$, if the following holds

$$
\left.f\left(x^{b}\right)+f\left(x^{b}\right)\right) f\left(\min \left(x^{t}, x^{t}\right)\right)+f\left(\max \left(x^{t}, x^{t}\right)\right)
$$

for all $x^{s}{ }_{2} x^{s} \in X$. It is strictly supermodular if the inequality is strict. It is (strictly) submodular if $-f(x)$ is (strictly) supermodular.

For continuously differentiable functions, supermodularity condition reduces to a

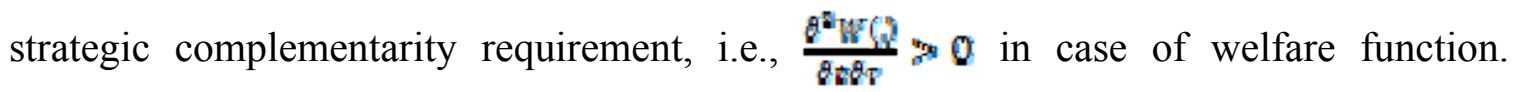
Similarly, the submodularity condition is equivalent to the strategic substitutability

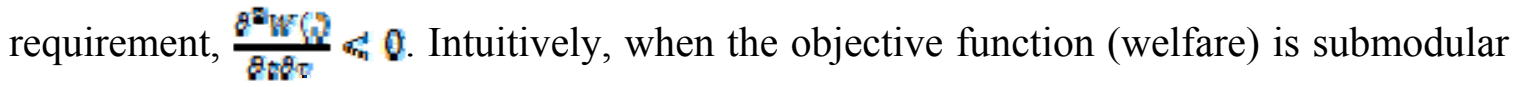
in two arguments (when taxes and tariffs are strategic substitutes), then the marginal effect of an argument (tax) decreases in the other argument (tariff). On the other hand, when the objective function is supermodular in two arguments (strategic complements), then the marginal effect of one argument increases in the other one.

Lemma 1. If the welfare function is submodular in own policy arguments and strictly submodular in partner's policy arguments, then linkage provides additional enforcement power.

When domestic policy variables are strategic substitutes, so that the welfare function is submodular in the variables, gains from simultaneous deviation in both 
policies is less than the sum of gains from deviation in each policy independently. Similarly, if the welfare is strictly submodular in the partner's policy choices, then gain from simultaneous cooperation in both policies is greater than the sum of gains from cooperation in each policy independently. Therefore, the single incentive constraint in the linked agreement holds with a slack when defined at the most cooperative levels of nolinkage regime.

\section{Export Biased Technological Spillover}

I now introduce a case where incoming FDI has technological spillovers in the host country's export good. Specifically, the cost of producing good $x(y)$ decreases at a decreasing rate in home (foreign) country as the level of FDI inflow increases. Formally,

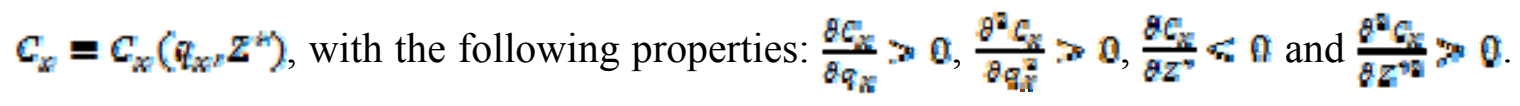

However, this spillover is a pure externality, therefore it does not appear in the investors' maximization problem, $Z^{*}=z^{*}(t)$, where FDI is a decreasing function of the tax rate. I assume that domestic capital stock does not have any effect on cost of production in any country. This structure prevents us from writing welfares with two separate components, i.e., trade and investment related items. However, I can write it as:

$$
W\left(\tau_{r} \tau_{r}^{*} t_{t} t^{n}\right)=V_{x}\left(\tau_{r}^{*} t\right)+V_{y}\left(\tau_{r} t^{n}\right)+Y\left(t_{r} t^{*}\right)
$$

The key to this characterization is that welfare on the home's export (import) sector is a function of home's tax rate (tariff) and foreign's tariff (tax rate). This relation implies that the optimal policy in a certain issue is not a function of the policy variable in other issue. I can show this strategic independence as follows: 


$$
\frac{\partial^{2} W(s)}{\partial t \partial \tau}=\frac{\partial}{\partial t}\left(\frac{\partial V_{y}\left(\tau, t^{n}\right)}{\partial \tau}\right)=0
$$

Intuitively, this independence shows that the marginal change in home's welfare due to a small change in a certain policy variable is independent from of other policy variables. Therefore, simultaneous increases in both policy variables have the same effect on aggregate welfare as the sum of the effects, had the increase in policy variables occur independently. I now provide my main result for export biased technological spillover case.

Proposition 2. Import tariffs and FDI taxes are neither strategic complements nor strategic substitutes in export biased technological spillover case. Therefore, linking the Free Trade Agreement and Tax Treaty does not generate further enforcement power.

Intuitively, technological spillover alters the structure of cooperation in both Free Trade Agreement and Tax Treaty since consequences of actions in a specific policy is no longer contained in the corresponding agreement. A deviation in tax policy changes FDI inflow, reducing the welfare on export good by increasing the cost of production. However, there is no strategic correlation between taxes on FDI and domestic tariffs since the former does not have a spillover effect in import competing sector. Therefore, gain from simultaneous deviations in both arguments is equal to the sum of gains from deviation in each policy independently. The same intuition applies for strategic independence of the partner's policy variables in domestic welfare.

\section{Technological Spillover in Import Competing Sector}

This section introduces a case where foreign direct investment reduces the cost of production at a decreasing rate in the import competing sector of the host country. For the 


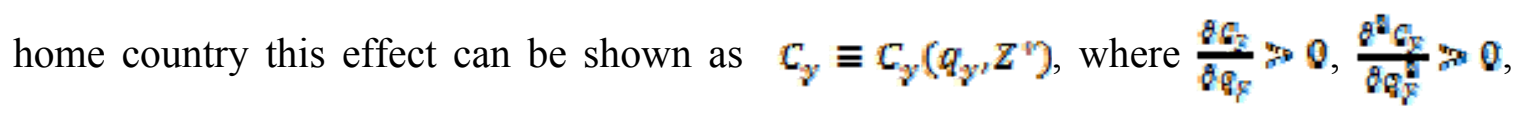

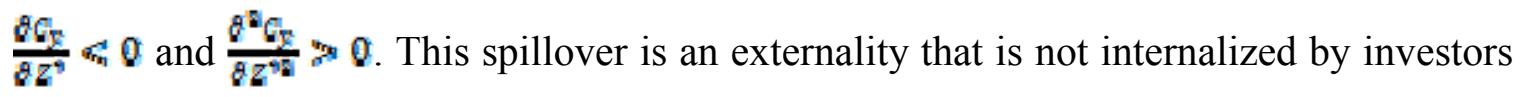
as in the export biased case. Welfare function is not separable in policy arguments, but can be written in trade and investment related components:

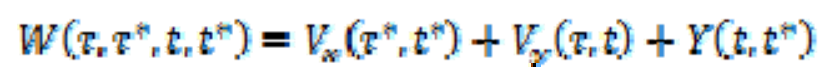

where welfare on the export sector is only a function of the partner's policy variables and welfare on import competing sector is a function of only domestic policy variables, as opposed to the export biased spillover case. I now elaborate the strategic complementarity between tax and tariff rates when there is spillover in import competing sector. Formally,

$$
\frac{\partial^{2} W(\tau)}{\partial t \partial \tau}=\frac{\partial}{\partial t}\left(\frac{\partial v_{y}(\tau, t)}{\partial \tau}\right)=\underbrace{\frac{\partial q_{y}}{\partial t}}_{-} \cdot \underbrace{\left(\frac{\partial \vec{D}_{y}}{\partial \hat{q}_{y}} \cdot \frac{\partial p_{y}}{\partial \varepsilon_{y}}-1\right)} \cdot\left(1-\frac{\partial p_{y}}{\partial \tau}\right)>0
$$

where the first negative sign on the right hand side of the equation shows that domestic producers produce less of the import competing good when the tax rate on FDI is increased. This is because of the fact that foreign investors invest less in the host country as a response to tax hikes, which reduces the amount of cost-reduction in the import competing sector of host country. The second negative sign reflects the fact that the change in demand because of altering equilibrium price is a second order effect, whereas the domestic supply changes as a first order response to altering costs. The first and second arguments together elaborate the change in import demand when the tax rate is increased slightly. The idea here is that as the tax rate on repatriated FDI profits is increased, foreign investors undertake less investment in the host country, which 
increases the cost of production in the import competing sector of the host country. Therefore, the first order effect will be a decrease in domestic production of the import good. This reduction generates secondary effects through an increase in equilibrium market price such as decreasing demand in the domestic economy. Import demand, however, increases since the reduction in domestic production dominates the decrease in domestic demand. The welfare function is also supermodular in the partner's policy variables. The strategic complementarity between foreign tax and tariffs can be expressed as:

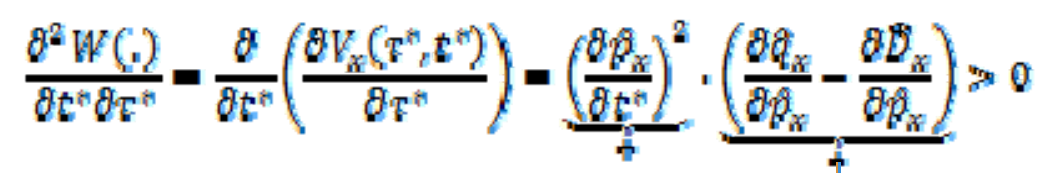

I now introduce my main result for the case with spillover in import competing sector.

Proposition 3. Import tariffs and FDI taxes are strategic complements in a case with FDI-led technological spillovers in import competing sector. Therefore, linking the Free Trade Agreement with the Tax Treaty does not generate further enforcement power.

When tariffs and taxes are strategic complements, so that the welfare function is (strictly) supermodular in own policy variables, gain from deviation in a certain policy increases in the other policy variable. Therefore, a simultaneous deviation in both policies brings a greater welfare gain than sum of the gains from deviation in each argument. Similarly, when the welfare function is (strictly) supermodular in partner's policy variables gain from simultaneous cooperation in both policies is less than the sum of the gains from cooperation in each policy separately. As a result, the single incentive constraint under linkage regime does not generate any slackness when evaluated at the most cooperative values of no-linkage regime. 


\section{II.IV. LINKAGE UNDER LIMITED PUNISHMENTS}

This section drops the Nash reversion structure I used in the previous sections and introduces an analysis of cooperation under limited punishments. Consider a case where trade and investment are not related and countries are symmetric. A stage game has characteristics of a Prisoner's Dilemma in each agreement under no-linkage regime. An important aspect of this type of interaction is the identity of the stage game Nash play and minmax strategies. Therefore, punishment under Grim-Trigger strategies also provides reservation utilities for both players. Linking under the Nash reversion assumption preserves this structure, i.e., any deviation is punished at the greatest scale so that both players get reservation utilities in both issues. However, this is a "compression" that dismisses some interesting cooperative equilibria that arise since linking the issue provides "milder" punishment options. In this section I interpret linkage as allowing cross-retaliation rather than punishing any deviation at greatest scale in both issues. I show that when governments are bounded with Withdrawal of Equivalent Concessions (WEC) rule, they prefer lower deviation values in each policy variable than the Nash reversion case. Moreover, when the two agreements are linked, these optimal deviation values become even smaller if the home and foreign tariffs (taxes) are strategic substitutes. However, I use these results to show that linking the agreements under limited punishment actually reduces the cooperation between governments when: 1 . Home tariffs (taxes) and foreign tariffs (taxes) are strategic substitutes, 2. The WEC rule is applied only when a deviation is non-abusive (deviation in a single policy), whereas an abusive deviation (deviation in both issues) is punished by the Nash Reversion. 
To elaborate my results, I make the following assumptions in regards to welfare functions:

\section{Assumption 1.}

i.) Welfare functions are concave and increasing in own tariffs $V_{1}\left(\tau_{v} \tau^{*}\right) 0$,

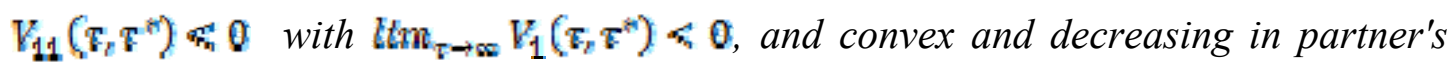

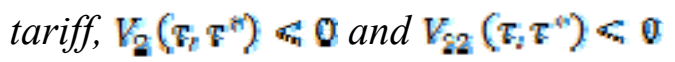

ii.) Domestic tariff and partner's tariff are strategic substitutes, $V_{1 \Omega}\left(\tau, \tau^{n}\right) \aleph_{0}^{\prime \prime} 0$

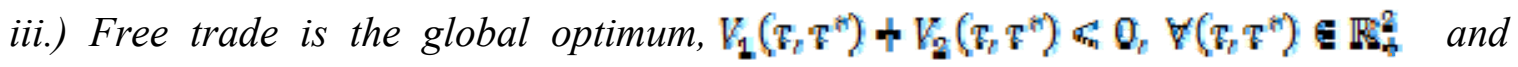
$V_{1}(0,0)+V_{2}(0,0)=0$

Governments face an additional problem, besides the choice of deviation or cooperation, when punishments are limited. A deviating government needs to optimize the level of deviation in order to maximize the sum of one time gain from deviation and infinite stream of punishment payoffs, which is a function of deviation level. I can write this two-step maximization problem as follows:

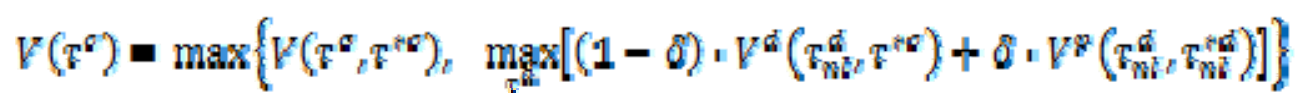

where superscript $p$ and subscript $n$ denote punishment and no-linkage respectively. This formulation tells me that at a given point in time, each government compares the payoff from cooperative action with the maximum payoff that can be generated by adjusting the deviation tariff accordingly. The optimal deviation tariff for a given cooperative tariff $\tau^{\sigma}$ maximizes the sum of one-shot deviation payoff and discounted sum of punishment stage payoffs, formally: 


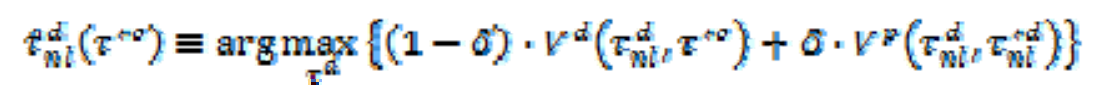

with the following first order condition:

$$
(1-8) \cdot V_{1}^{d}\left(\tau_{m b}^{d} \tau^{n \varepsilon}\right)+8 \cdot\left[V_{1}^{q}\left(\tau_{m b}^{d} \tau_{m b}^{n d}\right)+V_{2}^{v}\left(\tau_{m b}^{d} \tau_{m i}^{n d}\right)\right]=0
$$

The following lemma shows that the deviation tariff that solves this problem is smaller than the one under Nash reversion strategies.

\section{Lemma 2. (Limited deviation under limited punishment)}

i.) Optimal deviation tariff under limited punishments is smaller than the one under the Nash reversion case for every level of cooperative tariff when tariffs are strategic substitutes in deviating country welfare.

ii.) Optimal deviation tariff decreases in the cooperative tariff and discount factor: $\frac{g \tau^{d i}\left(\tau^{2}\right)}{g \tau^{2}}<0, \frac{\theta \theta^{d}\left(\tau^{2}\right)}{g \delta}<0$

First part of this lemma arises from the following observation: when punishments are set at maximum level regardless of the deviation, the best a deviating government can do is to maximize its payoff in the stage game without any consideration of future payoffs. On the other hand, this static solution is no longer optimal when punishments are conditioned on deviation. A dynamic solution trickles the deviation tariff down under limited punishment. The proof of this lemma shows that both tariffs, the ones under limited punishment and Nash reversion strategies, are decreasing in the agreed cooperative tariff $\tau^{*}$ because of strategic substitutability between home and foreign tariffs. However, the deviation tariff under limited punishment is below the other one for every level of $\tau^{\circ}$. The second inequality reflects the fact that as the weight of future flow 
increases in overall payoff, governments prefer a smaller deviation tariff to reduce the future impact of punishment.

Given a discount factor, the most cooperative tariff is defined as the agreed tariff rate that equalizes the maximum payoff under deviation with the payoff under cooperation. Formally,

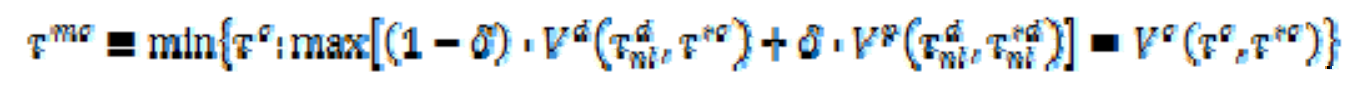

Figure 2 shows the optimal deviation tariffs under Nash Reversion and limited punishment for given levels of cooperative tariffs. The following lemma claims the existence of most cooperative tariff as the lowest tariff that induces no deviation at all.

Lemma 3. There exists a unique most cooperative tariff under limited punishment. Moreover, $f^{\alpha}\left(\tau^{e}\right)-\tau^{e}$ for $\tau^{e} \geq \tau^{m e}$.

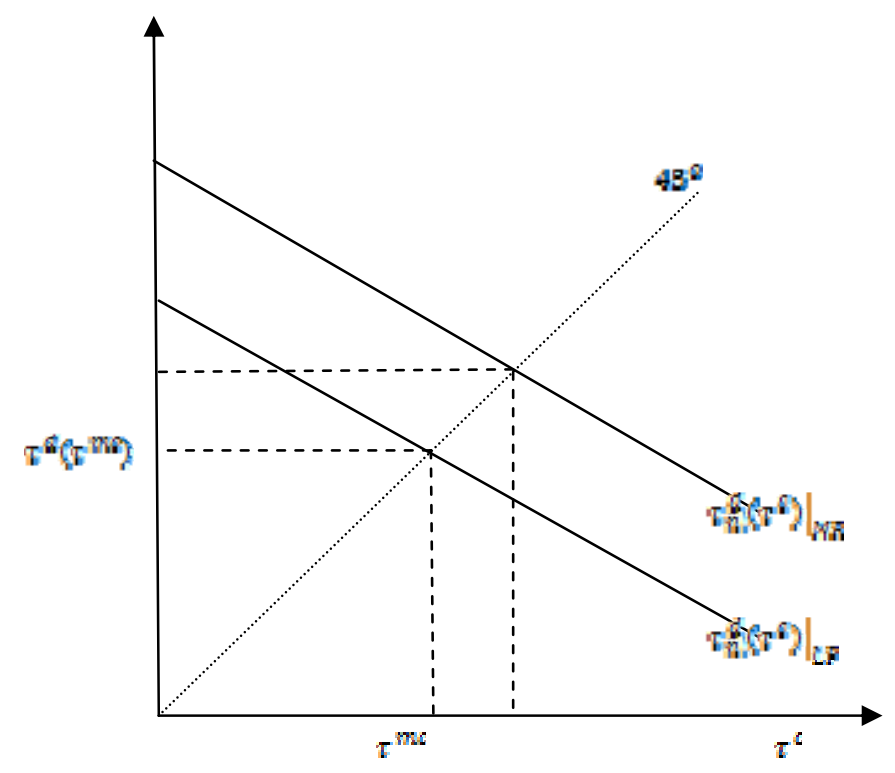

Figure 4. Optimal Deviation Tariff: Nash Reversion and Limited Punishment

I now investigate the change in deviation tariff when cross-retaliation is allowed.

Specifically, each government is allowed to deviate in different agreements by the magnitude of initial deviation after a betrayal is observed, i.e., the deviator (the home 
country in this case) receives a stage game payoff $W^{*}\left(\tau^{e}, \tau^{*}{ }^{*}, t^{c}{ }^{c} t^{* d}\right)$ and the respondent (foreign) receives $W^{n s}\left(\tau^{* \sigma}{ }_{2} \tau^{d}{ }_{2} t^{n d}{ }_{2} t^{c}\right)$ forever. The independence assumption enables me write the overall welfare function in trade and investment components separately. I will assume that the welfares on trade and tax components are generated by identical functions for simplicity, i.e., $\left.V C_{2}\right)=\gamma\left(C_{1}\right)$. Therefore, I can write the two stage decision making problem under linkage as follows,

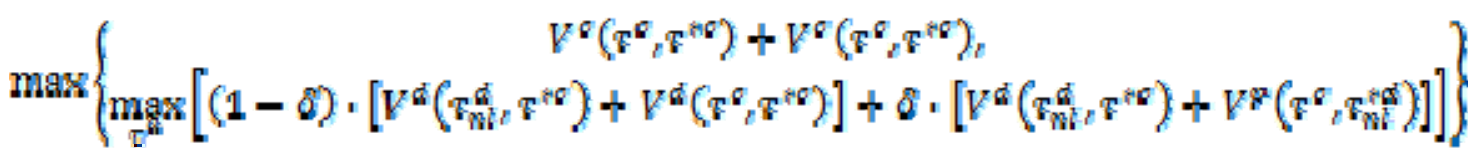

The first order condition for optimization problem in deviation is:

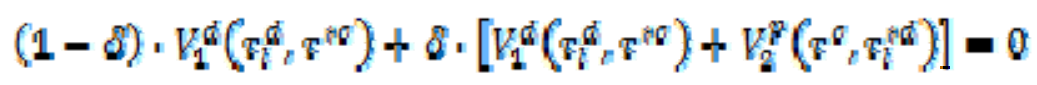

A marginal increase in deviation tariff has three effects in both no-linkage and linkage regimes: First, it increases the payoff in deviation period by assumption $(t)$. Second, it increases the payoff in punishment phase by the same assumption, holding the partner's tariff constant. Third, it decreases the payoff in punishment phase since the partner retaliates by an equal magnitude. The third effect dominates the second effect by assumption $(t t i)$, therefore the overall welfare effect of a marginal increase in deviation tariff is negative in the punishment phase. The major difference in optimal deviation between no-linkage and linkage regimes arises in the second and third effects. Both the second and third affects are greater under linkage than no-linkage. Therefore, the reduction in punishment phase payoff because of a marginal increase in deviation tariff is greater under the no-linkage regime. The following proposition shows that governments 
apply a greater deviation tariff under linkage because of lower marginal impact of deviation on payoffs in the punishment phase.

Proposition 4. (Main Result) Suppose Home and Foreign tariffs (taxes) are strategic substitutes and Withdrawal of Equivalent Concessions rule is applied in disputes, then (a) Optimal deviation tariff under linkage is greater than the one under no linkage for

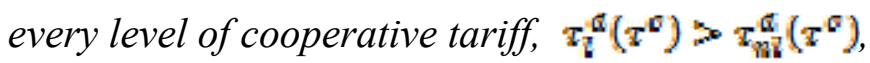

(b) Most cooperative tariff under linkage is greater than the one under no-linkage, $\tau_{i}^{m e} \boldsymbol{T}_{m i}^{m e}$, therefore linkage reduces enforcement under limited punishments.

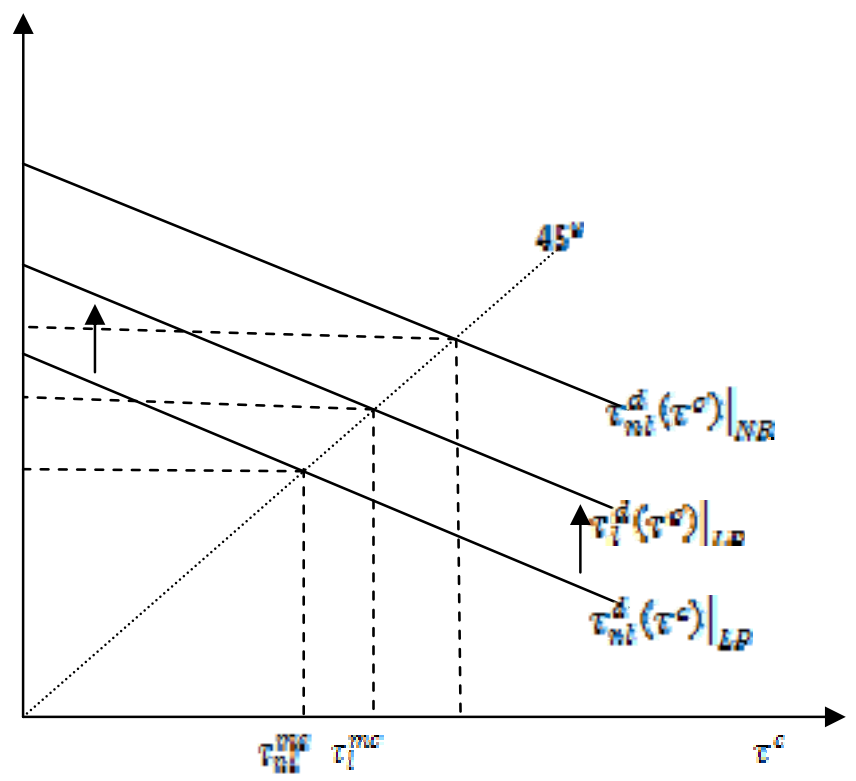

Figure 5. Optimal Deviation under Linkage and Limited Punishment Rule Intuitively, the limited punishment rule tailors the punishment for the "crime." This "mild" punishment option is preferred by both governments since both get higher payoffs than their reservation utilities entailed by the Nash Reversion. However, linkage provides additional reduction in the magnitude of punishment even though it is still determined by initial deviation. This reduction enables governments to increase the deviation tariff under linkage. Therefore, whereas a "milder" punishment phase promotes 
further cooperation between the governments when the transition is from Nash Reversion to Limited Punishment under the no-linkage regime, it reduces the cooperation when the transition is from a no-linkage regime to a linkage regime under the limited punishment rule. Figure 5 illustrates the change in deviation tariff under linkage. Given any cooperative tariff, the linkage deviation tariff is positioned in between the deviation tariffs under the Nash Reversion and no-linkage with limited punishment cases. The following lemma shows that cross-retaliation structure under linkage is incentive compatible for both players.

Lemma 4. Limited punishment path under linkage is subgame perfect.

The proof of this lemma states that once a deviation occurs neither party has an incentive to deviate from the punishment path, i.e., the initial deviator cooperates in its punishment and the punisher does not violate the limited punishment rule. The range of discount rate values that are incentive compatible in cooperative phase also support partial cooperation during the punishment phase.

\section{II.V. CONCLUSIONS}

This paper helps analyze one of the most controversial issues in international cooperation. Increasing level of tension between interconnected economic environment (trade and FDI) and fragmented legal framework (separate trade agreements and tax treaties) boosted the scholars and policy makers seek alternatives to the current system. The WTO, being successful in eliminating barriers against trade, has gained special attention as a possible resort where the fragmented international legal framework could 
be reconciled. I examined the feasibility of linking Free Trade Agreements and Tax Treaties under different economic environments and punishment schemes.

I show that linking the agreements can improve joint welfare by reallocating the scarce enforcement power between the issues, when issues are not related and asymmetric and countries are symmetric. This result is analogous to the one provided by Bernheim \& Whinston (1990) for multimarket interaction between firms. Linkage proves more useful when countries are asymmetric. I analyze a case where a large (developed) country interacts with a small (developing) country. The former has little incentive to reduce tariffs and more incentives to reduce taxes bilaterally, whereas the latter has more incentives to reduce tariffs and little incentives to reduce taxes. Thus, linking the agreements allows a government to undertake favors in one agreement, where it is the "short" side of cooperation, in return for reciprocal favors from the partner in the other agreement. Therefore, linkage improves joint welfare by increasing the level of cooperation in both issues in this case. This result is quite relevant since it shows that linkage might enable a small country get further market access in a large country, and it enables the large country to "secure" its investment in the small one.

I then relaxed my assumption of independent trade and investment by introducing technological spillovers in export sector and import competing sector in the host country. Specifically, I consider cases where FDI inflow has positive efficiency effects in those sectors, i.e., cost of producing domestic goods decreases in investment level. My analysis shows that even though the welfares on trade and investment issues are interconnected in export-biased technological spillover case, the policy variables are not. This independence reflects the fact that investment in the host country does not affect the 
marginal returns on tariffs; in other words they are strategically unrelated. Tariffs and taxes become strategic complements when FDI affects the import competing sector. Obviously, this might imply a case where FDI inflow in a developing country helps domestic producers become more efficient in import goods from a developed country. However, we report that linking the agreements does not help increase the cooperation in this case.

A significant practical concern for reconciliation of trade and investment regimes is the institutional structure of linkage. Other works in the linkage literature use maximum punishment rule to address enforcement issues. However, I emphasize the fact that current international institutions limit the punishments on the basis of continuing legal relationship principle. To analyze the linkage under WTO framework, I impose Withdrawal of Equivalent Concessions rule. I show that, even though limited punishment rule allows further cooperation between governments, linking the agreements under limited punishment rule does not do so when own and partner's policy variables are strategic substitutes. In a partial equilibrium framework, the substitutability condition in trade policy might reflect a case where the imported good is an input for the export good. Therefore, the present paper extends the literature by introducing the consequences of linkage under interaction between own and partner's policy variables, besides applying limited punishments.

An acknowledged shortcoming of this paper is the exclusion of multiple country interactions. I believe that allowing for strategic relationships among FDI host countries, especially competition for FDI, would provide interesting results. An interesting future research project could provide an explanation for bilateral nature of Tax treaties, as 
opposed to multilateral free trade agreements. That would develop a key analytical framework for reconciliation of the two regimes. 


\section{RECONCILIATION OF INTERNATIONAL TRADE AND ENVIRONMENT REGIMES AND GATT ARTICLE XXVIII}

\section{III.I. INTRODUCTION}

Last two decades have witnessed great strides in trade and environmental policy debates. On the one hand, successful trade liberalizations under GATT negotiations have convinced environmental groups to push for a unified international regime in trade and environment. This unification entails a set of minimum environmental standards for GATT signatories and access to dispute resolution mechanisms under the WTO for environmental disputes. On the other hand, the risk of losing hard-earned gains in trade liberalization instigates many trade economists to be suspicious of this idea. A primary concern is that enforcing international cooperation in environmental issues would be undertaken at the expense of liberalized international trading system. I concur with this concern on the basis of an institutional design perspective. This paper shows that the rules designed for implementing further trade liberalization under the GATT system might hinder a beneficial reconciliation of trade and environment regimes under the current institutional structure.

In compliance with the principle of continuing the legal relationships among governments in International Law, GATT Article XXVIII limits the applicable retaliation by a complainant in a trade related dispute. Specifically, under the Withdrawal of Equivalent Concessions (WEC) Rule, retaliation is bounded with the magnitude of initial nullification or impairment. Considered in international trade framework, this rule might enable further cooperation among governments. The idea here is that WEC Rule 
facilitates further cooperation in a trade agreement when tariffs are strategic substitutes, because governments limit initial deviations to avoid provoking aggressive punishments. However, this is not true for linked agreements when evaluated in association with Article 22.3 of Dispute Settlement Understanding (DSU), which determines the conditions where cross-retaliation is allowed. When cross-retaliation is allowed, retaliating governments prefer utilizing it to avoid lower payoffs during the punishment phase. However, this also reduces the magnitude of punishment when policy variables are strategic substitutes, therefore enhancing the incentives to betray the agreement. Hence, this paper raises an objection to incorporation of environmental issues to the existing institutional framework in international trade. I remain silent for other types of reconciliations.

In order to focus on institutional aspects of linking the agreements, I characterize an environment where international trade has negligible environmental effects. This environment is elaborated by a standard two country three good trade model where the non-tradable sector generates all the trans-boundary pollution. In the absence of an environmental agreement, governments apply unilaterally optimal pollution taxes in the non-tradable sector to trickle down the domestic effects of the pollution and compensate for consumer disutility from environmental externalities. However, the non-cooperative equilibrium is characterized by insufficient taxation as compared to the global optimum; therefore there is scope for an international agreement. A self-enforcing environmental agreement specifies a cooperative level of taxation, and cooperation is sustained under the threat of future retaliation in a repeated interaction. Limit to the cooperation is determined by government's discounting for the future stream of payoffs. As opposed to 
the environmental case, a non-cooperative equilibrium in trade is characterized by excessive tariffs on imported goods. Terms of trade externality is the trans-boundary effect that generates the inefficiency of unilateral policies in trade. Governments establish a trade agreement to reduce tariffs on a reciprocal basis. However, I mimic the institutional structure of WTO and assume that a betrayal in the trade agreement is punished according to the WEC rule. To complete the structure of my model, I impose strategic substitutability condition in tariffs by assuming that exported and imported goods are substitute goods in consumption. This assumption is shown to be sufficient to ensure the existence of strategic substitutability in tariffs if the demand functions are separable in prices. I show that limited punishment rule induces a betraying government to apply a limited deviation.

I then analyze the implications of linking the trade and environmental agreements. Specifically, I focus on the alteration in enforcement when WEC rule is applied and cross-retaliation is allowed. Under a linked regime, failure to comply with conditions specified by an agreement can trigger retaliation in the other one. I then show that allowing cross-retaliation increases the deviation tariff and decreases cooperation when tariffs are strategic substitutes under WEC rule. The idea here is that, when a country can retaliate in environmental standards when its partner betrays in import tariffs, then it will prefer to do so. This preference arises because retaliation in the trade agreement, where the betraying government already raised its tariffs, hurts the punisher more than crossretaliation because of the strategic substitutability of tariffs. However, a cross-retaliation also reduces the magnitude of punishment for initial betrayer for the same reason, reducing the set of incentive compatible cooperative tariffs. 
My results and methodology correlate to several areas in the literature. Environmental consequences of trade policy have been investigated thoroughly in trade and environmental policy literature. The main idea here is that once governments sign trade agreements, hence become unable to use tariffs to provide protection for domestic producers, they are prompted to lower environmental standards to gain competitive edge. Copeland (1990), Barrett (1994) and Ederington and Minier (2003) elaborate this "race to the bottom" concern. Ederington (2001) investigates optimal policy making when environmental policy affects welfare only through terms-of-trade externality. His paper shows that governments cooperate in trade policy initially and then relax the cooperation in environmental policy if enforceable. When there is no across-the-border pollution, trade policy has first order effects on terms of trade, whereas the environmental policy has second order effects through cost of production implications. However, these studies do not consider the structure of cooperation in trade and environment issues.

Horn, Maggi and Staiger (2008) investigates optimal cooperation where governments have access to several domestic policy variables besides the trade policy. However, contracting on domestic policy issues is costly because of imperfect observability. Therefore, issues with relatively higher contracting costs and lower manipulation capacity in trading equilibrium will be negotiated at a later stage. However, as in Ederington (2001), Horn, Maggi and Staiger (2008) reduce the trans-boundary effects of domestic policies to the terms of trade effect only. In contrast, Limão (2005) investigates the enforcement implications of linking domestic policy and trade issues by allowing traded goods to generate cross-border production externalities. When tariffs and pollution taxes are strategic complements, a simultaneous deviation in both policies 
grants the deviator less benefit than the sum of individual benefits from deviating in each policy independently. Similarly, gain from cooperation in both policies is greater than the sum of the gain from cooperation in each policy. Therefore, the incentive constraint holds with slackness under linkage, when evaluated at non-linkage levels of policy variables. As opposed to previous work, my paper focuses on the institutional design of linking trade and environmental policies. I allow two channels of cross-boundary externalities, pollution and terms-of-trade effect. However, my result holds when pollution has negligible terms of trade externality implications and when international trade has negligible pollution effects.

I paper also relates to a linkage literature on a game theoretic level. Bernheim and Whinston (1990) show that firms act more cooperatively when they interact in several markets and there is sufficient asymmetry between the markets or firms. The increase in cooperation arises from reallocation of enforcement power through reciprocal exchange of concessions. Spagnolo (1999a) extends the previous work by introducing interaction among the markets via concave firm objective functions. The concavity generates scale economies and provides further collusion by decreasing the incentives to act selfishly in both issues. Chisik (2009) introduces a different environment where correlation of asymmetric information between the issues replaces the structural interaction between them. The paper shows that when the noise is perfectly correlated between different issues, then linkage does not provide any further enforcement benefits. However, linkage will reduce cooperation as degree of correlation decreases by generating more disputes. Ederington (2002) also finds that linking might be detrimental when countries incorrectly detect cheating. A primary methodological difference of my approach is that my results 
do not depend on structural interaction between the issues. I focus on the implications of equilibrium strategies players employ and show that institutional rules, i.e., limited punishment rule, might have an effect on equilibrium outcome in this context.

This paper proceeds as follows. Section two elaborates a trade and environment model and analyzes the behavior of key agents, i.e., consumers, producers and governments, in the equilibrium. The next section investigates the opportunities for cooperation between governments where the international regimes for trade and environment policies are separated. I then establish a unified international regime for trade and environment under GATT Rule XXVIII and elaborate my main result. The last section concludes.

\section{III.II. A TRADE AND ENVIRONMENT MODEL}

I consider a partial equilibrium set up. There are two countries, Home and Foreign, producing and consuming four goods, $\boldsymbol{x}, y, w$ and $\boldsymbol{z}$. The following structure is imposed: $x$ is Home's natural export good, $y$ is Home's natural import good, $w$ is nontradable and $z$ is the numeraire. Preferences of consumers which satisfy this structure are given by the following quasi-linear form of the utility function,

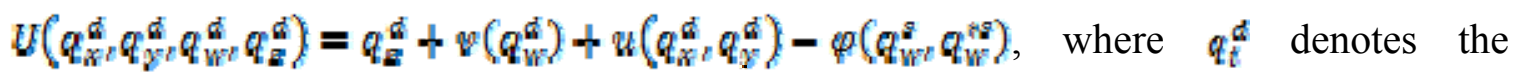
consumption of good $i$. Sub-utility functions $v\left(C_{2}\right)$ and $u($.$) are increasing in their$ arguments and the former one is assumed to be quadratic. The last term in the utility function denotes the disutility to consumers from pollution externalities of production. The last term, $\varphi\left(q_{W}^{q} q_{W}^{*}\right)$, is assumed to be increasing in $q_{w}^{s}$ and $q_{w}^{* s}$, which denotes the 
effect of a weighted sum of production in industries with pollution externalities. Consumers maximize their utilities given equilibrium prices and income,

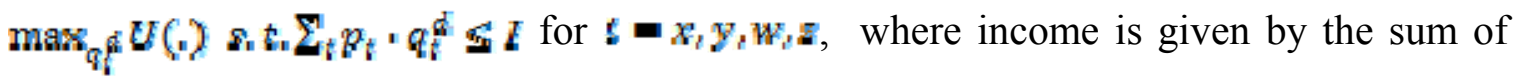
wage earnings, profit share, and redistributed tax and tariff revenues. The first order conditions for the Consumer Maximization problem (CMP) equalize marginal utility of each good with its equilibrium price. Two-stage budgeting provides the following

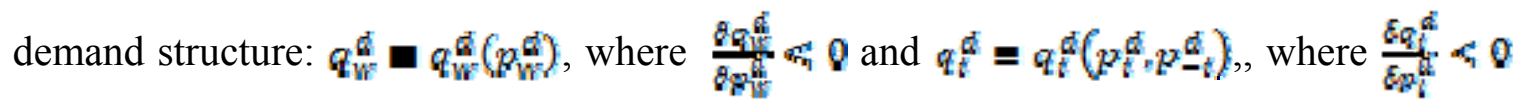
for $t=x y$

The numeraire good is produced under constant returns to scale technology and uses a single unit of labor per output. Given a large enough supply of labor, the numeraire is guaranteed to be produced; therefore, both the numeraire price and wages equal to one in equilibrium. Other goods are produced under increasing marginal costs using labor only. Cost of production is given by $C_{t}\left(q_{t}^{s}\left(w_{t}^{s}\right)\right)$, where superscript $s$ denotes the production of good $i$, for $t=x_{l} y_{l}$ w. Producers maximize corresponding profits given technologies and equilibrium prices, $\pi_{t} \equiv p_{t}^{s} \cdot q_{t}^{s}-\varepsilon_{t}\left(q_{t}^{s}\left(p_{t}^{s}\right)\right)$. The first order conditions for the Producer Maximization Problem (PMP) equalize market price of a good with the marginal cost of producing it at equilibrium level. Within this structure, firms do not bear the environmental cost of producing polluting goods.

Governments maximize domestic welfares by imposing tariffs $\left(\boldsymbol{r}, \boldsymbol{w}^{n}\right)$ on imported goods and production taxes $\left(G_{4} 6^{*}\right)$ on production in polluting sectors. When applicable, tariffs generate a wedge between domestic and international prices, $p_{y}=p_{y}^{*}+\tau$, whereas 
taxes do that for consumer and producer prices, $p_{W}^{\mathbb{W}}=p_{y}^{\mathbb{A}}+t$. Therefore, my model specifies two types of externalities. Terms of trade externality provides the governments with the ability to generate welfare gains by affecting the international prices of their import goods. Trans-boundary pollution, on the other hand, affects welfares because governments do not completely bear the environmental cost of production in polluting industries. The Following section characterizes the behavior of governments in the absence of cooperation.

\section{Unilateral Policy under Unrelated Issues}

I assume that trade and environmental issues are not related in my benchmark case. I represent it by the following structure, $\varphi \mathbf{q} q\left(q_{W}^{q} q_{W}^{*}\right)$. This structure characterizes an environment where pollution externalities are generated only by the nontraded good. Indirect utility of a single consumer society, then, can be written as follows:

$$
\begin{aligned}
& V\left(\tau, \tau^{*}, t_{,} t^{*}\right) \equiv v\left(q_{w}^{d}\left(p_{w}^{d}\right)\right)+v\left[q_{N}^{d}\left(p_{N}, p_{y}\right) q_{y}^{d}\left(p_{y}, p_{N}\right)\right]-\varphi\left[q_{m}^{*}\left(p_{w}^{*}\right), q_{w}^{*}\left(p_{w}^{*}\right)\right]
\end{aligned}
$$

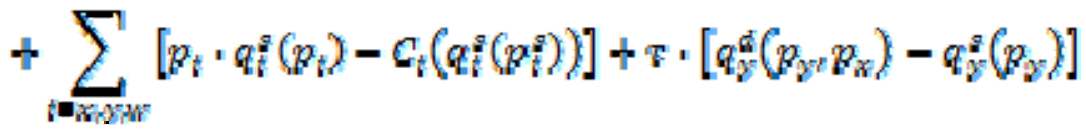

$$
\begin{aligned}
& t \cdot q_{W}^{z}\left(p_{W}^{2}\right)+w^{2} \cdot l-\sum_{t=W W} p_{t} \cdot q_{t} q_{w}\left(p_{t} p_{-t}\right)
\end{aligned}
$$

Note that under the independent issues assumption, this indirect utility function is separable in tariffs and taxes. I show this as $V\left(\tau, \tau^{*}{ }_{t} t_{t} t^{*}\right) \equiv \vartheta\left(\tau_{t} \tau^{*}\right)+\not\left(t, t^{*}\right)$, where the former and latter terms on the right hand side of the equation denote the trade related and environment related indirect utilities, respectively. Unilaterally optimal (Nash) tariff 
is the unique tariff that maximizes the indirect utility of the single consumer society, given other policy variables:

$$
\begin{aligned}
& \frac{\partial V\left(C_{1}\right)}{\partial \tau}=\frac{\partial p_{y}}{\partial \tau} \cdot\left[q_{x 2}^{d} \cdot\left(u_{1}-p_{x}\right)+q_{y 1}^{d} \cdot\left(u_{2}-p_{y}\right)+q_{y 1}^{q} \cdot\left(p_{y}-q_{y}^{b}\right)\right] \\
& +\left(1-\frac{\partial p_{y}}{\partial \tau}\right) \cdot M+\tau \cdot \frac{\partial M}{\partial \tau}=0
\end{aligned}
$$

where $M \equiv q_{y}^{d}\left(p_{y^{\nu}} p_{x}\right)-q_{y}^{z}\left(p_{y}\right)$ is Home's import demand function, and numbers in subscripts denote ordered derivatives. Each term in brackets is equal to zero according to the Envelope Theorem and first order conditions from Consumer Maximization Problem (CMP) and Producer Maximization Problem (PMP). Therefore the optimal tariff is given by:

$$
t\left(\tau^{*}\right)=\frac{M \cdot\left(1-\partial p_{y} / \partial \tau\right)}{\partial M / \partial \tau}
$$

Note that under the related goods assumption, Home's import demand is a function of foreign tariff. Therefore, unilaterally optimal tariff is also a function of the foreign $\operatorname{tariff}^{19}$. The following proposition provides the sufficient conditions under which tariffs are strategic substitutes.

Proposition 1. Home and Foreign tariffs are strategic substitutes in a partial equilibrium environment when:

i.) Export and import goods are substitutes and normal goods

ii.) Demand function for each good is separable in prices

${ }^{19}$ General equilibrium models have this connectivity through income effects of a price chance reflecting applied tariffs. However, partial equilibrium models in the literature generally drop this connection for tractability purposes. Therefore, tariffs are usually designed to be independent in partial equilibrium environment. Our model reintroduces the interconnected optimal tariff structure in a tractable manner. 
Intuitively, when tariffs are strategic substitutes, each government has less incentive to increase its tariff unilaterally when its exports are subject to greater tariffs in the destination country. The idea here is that both foreign and home tariffs reduce the relative price of the export good in the home country. In the absence of significant crosspartial effects, i.e., $x_{y: 1}^{[} \propto 0$, a lower export price diminishes the effect of a tariff hike in the home country when the goods are substitutes in consumption.

Production taxes make firms internalize a portion of pollution externalities. A unilaterally optimal tax maximizes domestic welfare by reducing the production of polluting good and compensating the consumers for the disutility of the pollution by distributing the tax revenue in lump-sum:

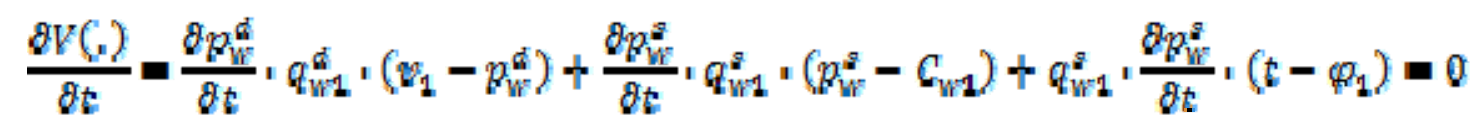

First two terms on the right hand side are equal to zero by the Envelope Theorem, CMP and PMP. Therefore, the optimal tax level is equal to the marginal disutility from environmental distortion:

$$
f=\varphi_{1}\left(q_{W^{r}}^{*} q_{W}^{n}\right)
$$

Unilaterally optimal tax is smaller than globally optimal level since it only compensates for domestic disutility. The following section introduces feasible cooperation schemes between the governments to avoid inefficient unilateral policies.

\section{Separated International Regimes for Trade and Environment}

Suppose that cooperation in trade and environment issues are negotiated separately by governments. Cooperation in both issues are based on reciprocal exchange 
of concessions, i.e., lower tariffs and higher pollution as compared to unilaterally optimal levels. Agreements for both issues are assumed to be self-enforcing; cooperation at a given point in time is sustained by partner's credible threat to withdraw its concessions in the future. Therefore, honoring a credible agreement is incentive compatible for patient governments. This structure constitutes a repeated Prisoner's Dilemma type of interaction.

\section{Trade Agreement}

A trade agreement specifies a cooperative tariff rate $\tau^{2}$ to be applied by both governments. Governments are assumed to be bounded with the Withdrawal of Equivalent Concessions (WEC) rule, in the spirit of GATT Article XXVIII: when a government applies a tariff greater than the cooperative rate, $\tau^{4} \tau^{e}$, the other government is allowed to retaliate only by the same amount, $\tau^{* d}=\tau^{d}$, in the future periods. Therefore, following a trade agreement, incentive compatibility needs to address two issues at a given point in time: First, each government decides the optimal level of deviation given the cooperative tariff rate applied by the partner. Second, they decide whether it is optimal at all to deviate from cooperation using the optimal deviation tariff. Formally, I can write the first stage of this decision making problem as follows:

$$
\tau_{n l}^{d}\left(\tau^{c}\right) \equiv \arg \tau_{\tau^{k}}\left\{(1-\delta) \cdot \vartheta^{d}\left(\tau_{n l}^{d} \tau^{* \sigma}\right)+\delta \cdot \vartheta^{d}\left(\tau_{m l}^{d} \tau_{m l}^{* d}\right)\right\}
$$

where 9() is the trade related component of social welfare and is the discount rate. Superscripts $d_{l} p$ and $c$ denote deviation, punishment and cooperation phases, respectively; whereas the subscript $n i$ shows the variable values in the no-linkage regime. For a given cooperative tariff level, the optimal deviation tariff maximizes the normalized 
sum of present and future payoffs under the specified punishment rule. The first order condition for $(3.5)$ is given by:

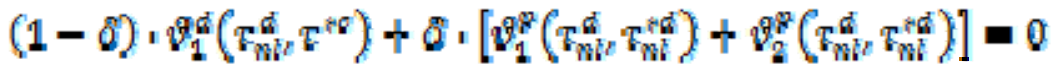

The first order condition states that at the optimal level of deviation tariff, a normalized marginal gain by increasing the deviation tariff is canceled out by a reduction in the normalized payoff during the punishment phase. The following proposition states important comparative statics regarding the optimal deviation tariff.

Proposition 2. Suppose tariffs are strategic substitutes. Then, optimal deviation tariff $\tau_{m l}^{d}\left(\tau^{\circ}\right)$ decreases in cooperative tariff rate $\tau^{\circ}$ and discount factor $\delta$ under limited punishment rule.

The former observation is based on the strategic substitutability of tariffs. The myopically best response tariff that unilaterally maximizes home welfare in the stage game is smaller when the foreign government applies a greater tariff. The latter observation, on the other hand, is simply based on the fact that an increase in the discount factor boosts the weight of punishment phase payoffs within the normalized payoff. Therefore, the magnitude of the punishment is perceived to be greater when governments are more patient.

Once the optimal deviation tariff is determined as a function of the applied cooperative tariff rate, governments compare payoffs under two different scenarios: a "betrayal scenario", which generates a normalized sum of one shot betrayal payoff and infinite stream of punishment phase payoffs, and a "cooperation scenario," which 
generates a normalized sum of cooperative payoffs. Formally, this can be shown as follows:

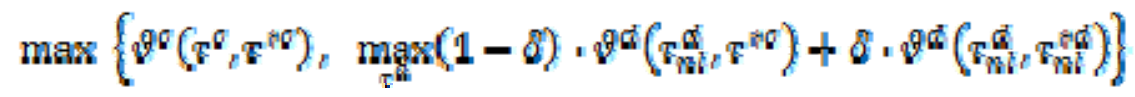

A self enforcing trade agreement defined under these conditions is incentive compatible only when governments choose the cooperation scenario in every period given the cooperative tariff rate. Therefore, the agreement establishes the lowest cooperative tariff rate that will induce cooperation subject to the conditions defined by (3-5) and (3-7). I call this unique level of tariff the most cooperative tariff and formally show it as:

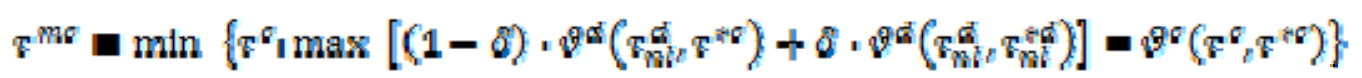

One immediate result from this definition and Lemma 2 is that there exists a selfenforcing level of cooperative tariff where the optimal action is not deviating at all, i.e., $T^{6} \tau^{\sigma}$ as shown in Onder (2009).

\section{Environmental Agreement}

An environmental agreement specifies a cooperative tax rate to be applied by governments, $t^{\sigma}$ is $t^{4}$. In the absence of a limited punishment rule, as opposed to trade agreements, cooperation at a given point in time is sustained by credible threats of applying unilaterally optimal taxes forever upon betrayal. In other words, punishment is at a maximum level regardless of the magnitude of deviation. Therefore, any deviating country applies unilaterally optimal tax in the deviation period when optimal taxes are independent, i.e. $t^{d}=t^{N}$. Incentive compatibility at a given point in time can be written as: 


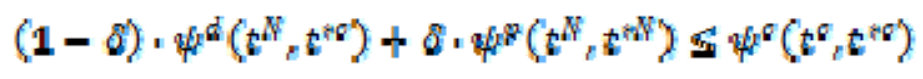

The incentive constraint rules out a profitable one-shot deviation from the cooperatively determined tax rate. The most cooperative tax rate is the maximum possible taxation that does not violate the incentive compatibility condition:

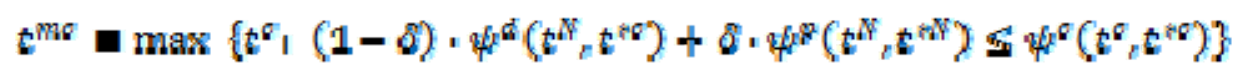

Note that the most cooperative tax rate can be or cannot be equal to globally efficient taxation depending on discount factor. The following section introduces the linkage concept in trade and environment context.

\section{III.III. RECONCILING TRADE AND ENVIRONMENT REGIMES UNDER GATT ARTICLE XXVIII}

In this section I investigate the consequences of linking environmental and trade agreements under the limited punishment rule in terms of its welfare and enforcement implications. Linking the agreements enables the governments to undertake crossretaliation, i.e., betrayal in one agreement can generate a punishment phase in the other one. I will assume that the Withdrawal of Equivalent Concessions rule is applicable only when the initial deviation is not abusive ${ }^{20}$. Decision making in optimal deviation tariff can be expressed as:

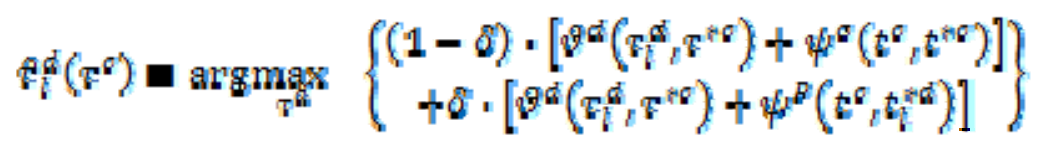

\footnotetext{
${ }^{20}$ This entails Nash reversion in case of betrayal in more than one policy or non-cooperation in punishment phase.
} 
where the subscript "l" denotes the variable values under linkage regime. A deviation in tariff rate generates a stream of gains in trade related component of the welfare; however it also generates a stream of loss in environment related component of welfare as a result of cross retaliation by the partner. The first order condition for this optimization problem is given by:

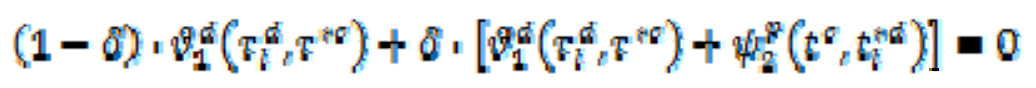

where the last term in brackets shows the change in punishment payoff in environment related issue as a result of a marginal increase in deviation tariff. In this paper, I do not explicitly specify a transition rule which maps deviation tariffs onto allowed magnitudes of punishment in taxes ${ }^{21}$, i.e. $\Gamma: \tau_{l}^{d} \rightarrow t_{l}^{d}$. However, I assume that $t_{l}^{d}$ is decreasing in $\tau_{l}^{d}$. The following proposition elaborates the main result of this paper.

Proposition 3. Suppose trade flows have negligible impact on environment. Linking the agreements under GATT Rule XXVIII will reduce the cooperation in trade policy if the following conditions hold:

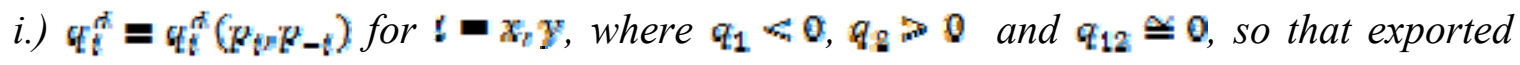
and imported goods are substitutes in consumption with small cross-partials, ii.) $\psi_{2}^{g}\left(t^{\sigma}, t_{l}^{+d}\right) \geqslant \theta_{2}^{q}\left(\tau_{n v}^{d} \tau_{m l}^{+d}\right)$, so that distortion that results from foreign tariff is greater than the one that results from a foreign tax.

Intuitively, this proposition suggests that there might be more incentives to betray in tariffs in a linked agreement. A punishing government retaliates in environmental policy since doing so generates a greater punishment phase payoff for the punisher. However,

\footnotetext{
${ }^{21}$ This remains largely unexplored in the literature. For a brief discussion about magnitude of crossretaliation allowed under WTO rules, see Bown and Ruta (2008).
} 
this also implies that betrayer's punishment is also greater in the same phase due to strategic substitutability of tariffs. Therefore, a milder future punishment generates further incentives to betray at a given point in time.

Structure of cooperation is different in environmental issue. When linked with the trade agreement under the limited punishment rule, there are two opposite effects changing the enforcement of the environmental issue. The first effect is borne by switching from Nash reversion to limited punishment rule, WEC. As opposed to the former one, where the optimal deviation tax is equal to the myopic best response tax rate at any point in time, the optimal deviation tax under the latter rule reflects considerations of future punishments:

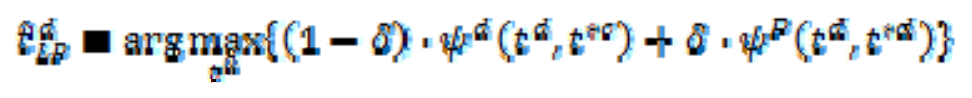

where subscript "LP" denotes the value under limited punishment rule. The first order condition for this problem can be written as follows:

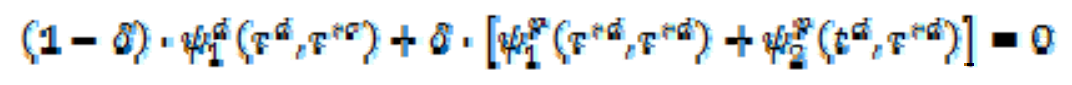

This first order condition implies a limited deviation under limited punishment. Deviation magnitude does not alter the magnitude of punishment under Nash reversion; therefore, governments implement the myopically optimal tax rate in deviation period. However, when the punishment is tailored to the crime, this is no longer optimal. The second effect arises from facilitation of cross-retaliation through linking the agreements. Once the limited punishment rule is effective, cross-retaliation allows governments to retaliate with tariffs by an equal amount when the partner betrays the linked agreement in environmental taxes. Therefore, the incentive constraint becomes: 


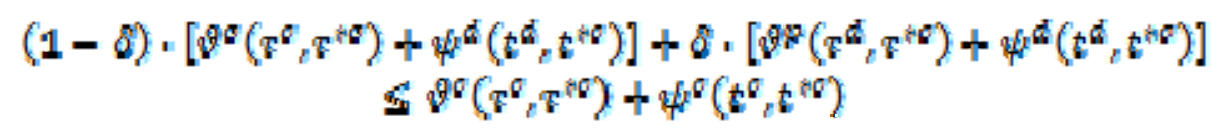

This condition rules out a profitable one shot deviation from the agreed cooperative tax rate when the partner is authorized to retaliate in tariffs. The following proposition reports the results regarding the alteration in environmental cooperation when linked with a trade agreement under Withdrawal of Equivalent Concessions Rule.

Proposition 4. Enforcement in environmental cooperation is shaped by two opposite factors, with ambiguous net effect, when linked with trade agreement under GATT Article XXVIII:

i.) Transition from Nash Reversion to Withdrawal of Equivalent Concession Rule (WEC) increases most cooperative tax rate, the the

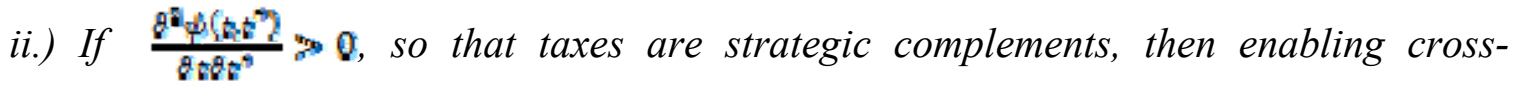
retaliation through linkage reduces most cooperative tax rate

As opposed to the trade policy, a smaller most cooperative tax rate in environmental policy implies a reduction in cooperation since globally efficient tax rates are greater than unilaterally efficient ones. Therefore, the proposition shows that even if overall enforcement of environmental issue increases when it is internalized by international trading regime, this actually is the result of changing punishment strategies based on GATT Article XXVII. Linkage itself reduces the enforcement when compared to the separated regimes where both agreements employ limited punishment rules.

\section{III.IV. CONCLUSIONS}

The question of whether we should have a unified international regime for trade and environment has been an intriguing one for policy makers and researchers. There has 
been significant focus on environmental impacts of international trade, trade implications of environmental regulations and enforcement implications of policy linkages. In this paper, I focus on institutional design of reconciling trade and environmental policies under existing legal body. I show that even under circumstances where other research find no harm of linking these two issues, i.e., no significant relation between trade and environmental issues, a closer look on current rules that were tailored to promote further trade liberalization will emphasize the importance of institutional design in linking these issues. My results encourage implementation of a limited punishment rule in environmental agreements a la Withdrawal of Equivalent Concessions rule of GATT (Article XXVIII); on the other hand, I also provide an argument supporting the suspicion of linking the environmental issue with trade.

An interesting question that would provide an appealing extension to my work would be about the sequence of agreement formation. Allowing some interaction between trade and environmental issues, one can expect dynamic non-stationarities in enforcement. Is signing a trade agreement first a stepping stone to a more comprehensive collaboration in a unified international regime, or is it actually a stumbling block where further cooperation in domestic issues is prevented since governments have already depleted the enforcement power in trade agreement? Answers for this question would improve our understanding of the structure of international cooperation in trade and environment policies. 


\section{LIST OF REFERENCES}

Abrego, L.E., Perroni, C., Whalley, J., Wigle, R.M., 2001. Trade and environment: bargaining outcomes from linked negotiations. Review of International Economics 9 (3), 414-428.

Bagwell, K., Staiger, R., 1999. An Economic Theory of GATT. American Economic Review 89(1), 215-248.

Baldwin, R. 2006. Multilateralising Regionalism: Spaghetti Bowls as Building Blocs on the Path to Global Free Trade. The World Economy 29(11), 1451-1518.

Barret, S., 1994. Strategic Environmental Policy and International Trade. Journal of Public Economics 54, 325-38.

Bernheim, D., and Whinston, M., 1990. Multimarket Contact and Collusive Behavior. RAND Journal of Economics 21, 1-26.

Bhagwati, J. 1988. Protectionism. MIT Press., Cambridge, MA.

Blanchard, E.J., 2007. Foreign Direct Investment, Endogenous Tariffs, and Preferential Trade Agreements. Advances in The B.E. Journal of Economic Analysis\&Policy 7(1), Article 54.

Bond, E.B., Park,J.H., 2002. Gradualism in trade agreements with asymmetric countries, Review of Economic Studies 69, 379-406.

Bown, C.P., Ruta, M., 2008. The Economics of Permissible WTO Retaliation. WTO Staff Working Paper ERSD-2008-04.

Brauner, Y., 2005. International Trade and Tax Agreements May be Coordinated, but not Reconciled. Virginia Tax Review 251

Cesar, H., de Zewe, A., 1996. Issue Linkage in Global Environmental Problems. Economic Policy for the Environment and Natural Resources: Techniques for the Management and Control of Pollution. Elgar, Cheltenham, UK, pp. 158-173

Chisik, R., 2003. Gradualism in free trade agreements: A theoretical justification. Journal of International Economics 59, 367-397.

Chisik, R., 2009. Limited Incremental Linkage and Unlinked Trade Agreements. FIU Working Paper.

Chisik, R., Davies, R.B., 2004. Gradualism in Tax Treaties with Irreversible Foreign Direct Investment. International Economic Review 45(1), 113-139 
Conconi, P., Perroni, C. 2004. The Economics of Special and Differential Trade Regimes. CEPR Discussion Paper. 4508

Copeland, B., 1990. A Strategic Interaction Among Nations: Negotiable and NonNegotiable Trade Barriers. Canadian Journal of Economics 23, 64-108.

Ederington, J., 2001. International Coordination of Trade and Domestic Policies. American Economic Review 91, 1580-93.

Ederington, J., 2002. Trade and Domestic Policy Linkage in International Agreements. International Economic Review 43(4), 1347-1367.

Ederington, J., and Minier, J., 2003. Is Environmental Policy a Secondary Trade Barrier? An Empirical Analysis. Canadian Journal of Economics 36, 137-54.

Ethier, W.J., 1998. Regionalism in a multilateral world. Journal of Political Economy $106,1214-1245$

Furusawa, T., Lai, E.L.-C., 1999. Adjustment costs and gradual trade liberalization. Journal of International Economics 49, 333-361.

Furusawa, T. (forthcoming). Gradualism in the existence of outside options. Journal of Economic Behavior \&Organization.

Graetz, J.G., Warren, A.C., 2006. Income Tax Discrimination and the Political and Economic Integration of Europe. The Yale Law Journal 115, 1186-1255.

Horn, H., Maggi, G., and Staiger, R., 2008. Trade Agreements as Endogenously Incomplete Contracts. Working Paper.

Laffont, J-J., Tirole, J. 1990. Adverse Selection and Renegotiation in Procurement. Review of Economic Studies 57, 597-625

Limão, N., 2005. Trade Policy, Cross-border Externalities and Lobbies: Do Linked Agreements Enforce More Cooperative Outcomes? Journal of International Economics, 67, 175-199.

Maggi, G., Rodriguez-Clare, A. 2005. A Political-economy Theory of Trade Agreements. NBER Working Paper. 11716.

Matsushima, H., 2001. Multimarket Contact, Imperfect Monitoring, and Implicit Collusion. Journal of Economic Theory 98, 158-178.

McDaniel, P.R., 2004. The David R. Tillinghast Lecture: Trade Agreements and Income Taxation: Interactions, Conflicts and Resolutions. Tax Law Review 275. 
Onder, H., 2009. International Cooperation in Trade and Environment: (When) Does Linking the Agreements Help?. Florida International University, manuscript.

Rixen, T., 2008. The Institutional Design of International Double Tax Avoidance. MPRA Paper \# 8322.

Sadiqhodjaev, S., 2009. Retaliation in the WTO Dispute Settlement System. Kluwer Law International, The Netherlands.

Slemrod, J., Avi-Yonah, R., 2002. (How) Should Trade Agreements Deal With Income Tax Issues?. Tax Law Review 533.

Spagnolo, G., 1999a. On Interdependent Supergames: Multimarket Contact, Concavity, and Collusion. Journal of Economic Theory, 89, 127-139

Spagnolo, G., 1999b. Issue Linkage, Delegation and International Policy Cooperation. University of Cambridge, DAE Working Paper \#9913.

Staiger, R., 1995. A theory of gradual trade liberalization. In: J. Levinsohn, A.V. Deardorff and R.M. Stern (Eds), New Directions in Trade Theory, University of Michigan Press, Ann Arbor, MI.

Watson, J. 1999. Starting small and renegotiation. Journal of economic Theory 85, 52-90.

Watson, J. 2002. Starting small and commitment. Games and Economic Behavior 38, $176-199$.

Zissimos, B., 2007. The GATT and gradualism, Journal of International Economics 71, 410-433. 


\section{APPENDICES}

\section{APPENDIX A: PROOFS FOR CHAPTER I}

\section{A.1. Proof of Lemma 1}

Substituting the market clearing prices in $(2.8)$ and differentiating it with respect to $\tau^{*}$ I obtain the Nash tariff of foreign country as a function of political economy parameter $\tau *(\gamma)$. Using this Nash tariff and market clearing price, the Nash welfare on an import good becomes:

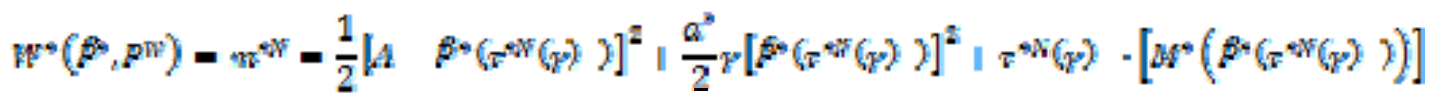

Whereas the cooperative welfare on an import good is defined as:

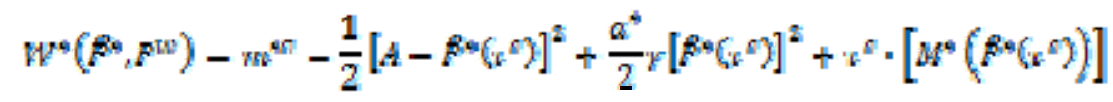

Welfares of foreign country on export goods with Nash tariff and cooperative tariff are:

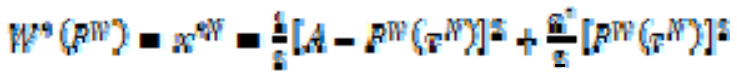

$$
\begin{aligned}
& W^{*}\left(y^{n}\right)=x^{4}=\frac{1}{2}\left[A-F^{m}\left(\tau^{c}\right)\right]^{2}+\frac{Q^{2}}{q}\left[F^{n}\left(\tau^{c}\right)\right]^{2}
\end{aligned}
$$

The results from Lemma 1 follow immediately from differentiating $\Omega^{S}=m^{9 \varepsilon}+x^{9 S}=m^{9 V}=x^{\text {SVF }}$ and

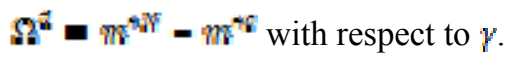

\section{A.2. Proof of Lemma 2}

I prove this by showing that the paths that make type- 1 and type- 2 indifferent between cooperating and betraying in consecutive periods is necessarily downward sloping in a pooling equilibrium case. Suppose

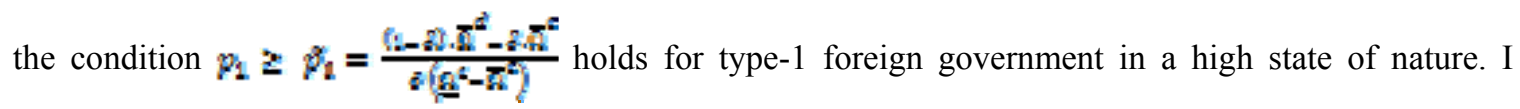
assume $\varepsilon_{i+1} \geq \alpha_{l} \forall i \in[0, z-1]$, to show this cannot be correct. I solve the cooperation level values that satisfy $\left(\mathbb{U C}-1{ }^{*}\right\rangle$ with equality backward from period $\hat{t}$ :

$$
\alpha_{r-1}=\bar{\alpha}\left(\frac{E\left(\Omega^{2} \mid \eta_{1}\right)}{\Omega^{2}} \delta\right) \cdot\left(\frac{1}{1-\alpha^{2}}\right) \cdot\left[\delta\left(\frac{E\left(\Omega^{2} \mid \eta_{1}\right)}{\Omega^{2}}+1\right)\right]^{\sigma}
$$




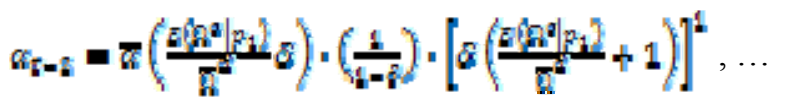

This pattern gives us the borderline path of incentive compatibility for cooperation level:

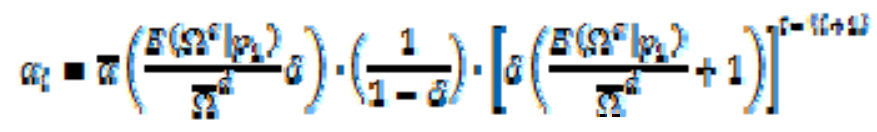

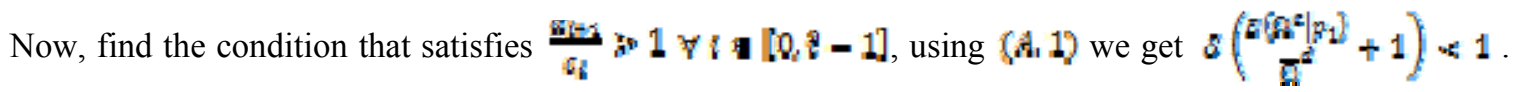

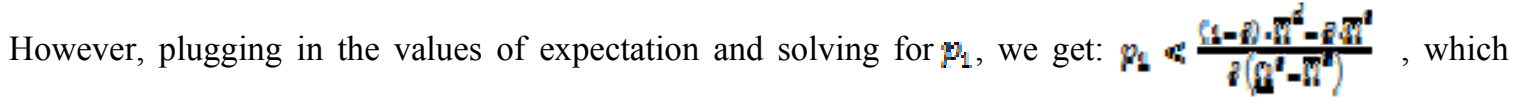
contradicts with my initial assumption.

The part for type- 2 foreign government is identical with the type-1 case. However, the expected future gain from betraying is included in the analysis. The path defines the sequence of cooperation levels that satisfy $(E E-2 E)$ is:

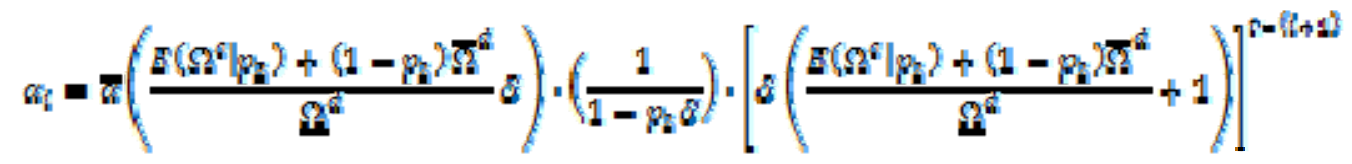

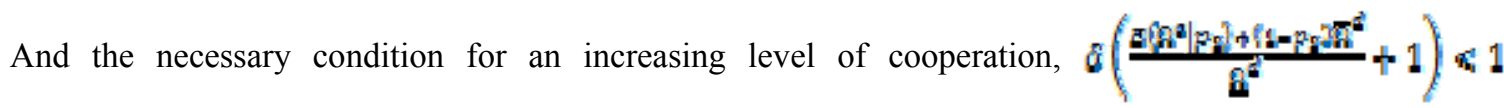
contradicts with my initial assumption $\eta_{2} \geq \gamma_{2}=\frac{a^{2}-6\left(\pi^{2}+\pi^{2}\right)}{a^{2}+\underline{n}^{2}-\left(\pi^{2}+\pi^{2}\right)}$.

\section{A.3. Proof of Lemma 3}

Suppose $\alpha_{l}=\bar{a} \forall \varepsilon z \bar{z}$ and $\alpha_{L} \propto \bar{c} \forall \varepsilon<\bar{z}$. Let the periods $\bar{t} \geq \bar{t}$ be maximum cooperation phase. The only non-stationary variable in this phase is the belief of the home government about the foreign governments' cooperation. Therefore, I can easily write a general rule for continuation values in this phase:

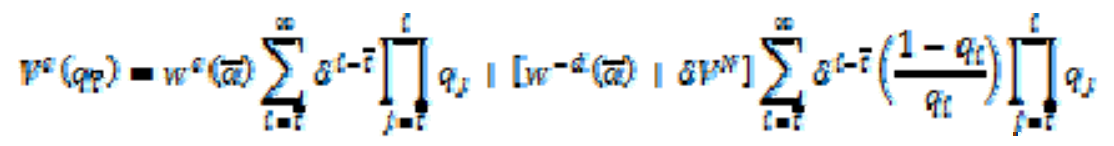

Note that this continuation value increases in $q$. Remembering $q_{t+1}>\alpha_{t}$ as long as the foreign government does not betray, I can show this as follows: For an arbitrary $t \geq \bar{\varepsilon}$, the first term on the right hand side of 
(8.8) increases in $q_{t}$ obviously. In order to see that the second term also increases, I write down the explicit form of it:

$$
\left.\left(1-q_{i}\right)+\delta q_{i}\left[\left(1-q_{i+1}\right)+\delta q_{i+1}\left(1-q_{i+2}\right)_{1}\right]\right]
$$

But, the recursive term in the brackets is the second component of $\mathrm{F}^{e}\left(q_{q_{5+2}}\right)$. Let ,

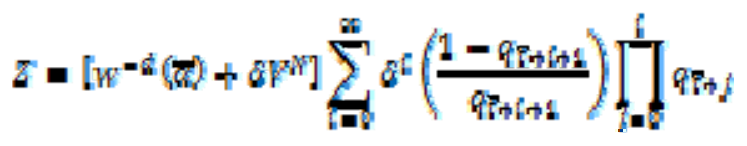

Then the second component of $F^{s}\left(q_{t}\right)$ becomes $\left(1-q_{n}\right)+\theta q_{t} Z$, which is smaller than $Z$. To see this I

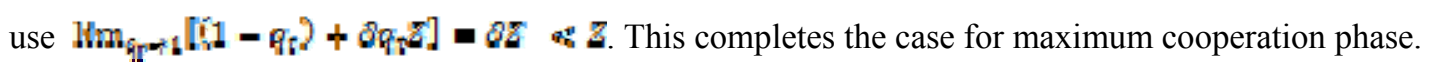

Let periods $t<\bar{t}$ be gradual cooperation phase. I define the continuation values in this phase with reference to the first continuation value of the maximum cooperation phase, $\mathbb{F}^{*}\left(q^{2}\right)$. Solving for continuation values backwards starting from period $\bar{f}$, we get a general rule for continuation values in gradual cooperation phase with reference to $\left.F^{2}(q)^{2}\right)_{:}$

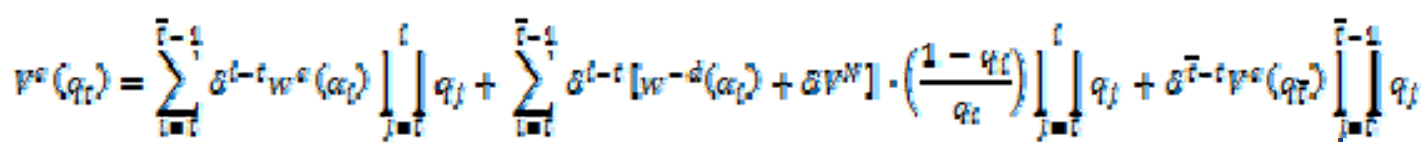

Comparing the explicit forms, one can easily show that $\mathbb{F}^{2}\left(q_{\mathrm{n}+\mathrm{k}}\right)$ and $\mathbb{F}^{0}\left(\mathrm{P}_{\mathrm{N}}\right)$ are infinite sequences with the former having greater value in each period due to higher beliefs and cooperation levels. Therefore, discounted sum of a sequence of values that is greater in each period compared to another sequence is also greater than the discounted some of the latter.

\section{APPENDIX B: PROOFS FOR CHAPTER II}

\section{B.1. Proof of Lemma 2}

The first order condition for optimal deviation tariff under no-linkage regime is given by:

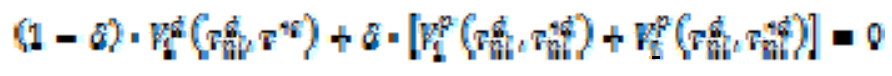




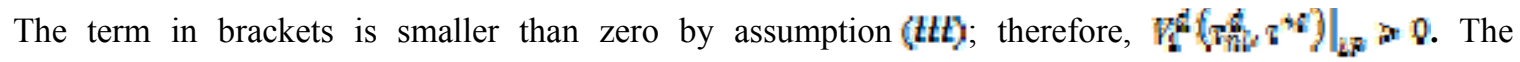
deviation tariff under the Nash reversion, however, maximizes stage game payoff since the punishment is not related with magnitude of the deviation. Then, $\left.v_{1}^{d}(\tau, n)\right|_{W R}=0$, by definition. Therefore,

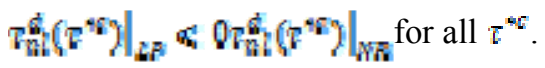

To see that optimal deviation tariff is decreasing in cooperative tariff, differentiate the f.o.c. with respect to cooperative tariff to get:

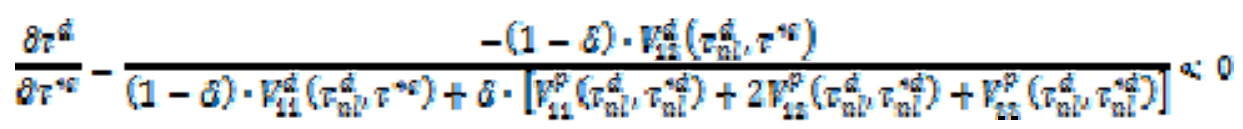

where the denominator is the second order condition and is negative. The effect of discount factor on deviation tariff can be shown in the same way.

\section{B.2. Proof of Proposition 4}

I solve optimal deviation tariffs for identical cooperative tariff rates under no-linkage and linkage regimes. The former one has the following first order condition:

$$
\left(1-\sigma^{2}\right) \cdot p_{2}^{d}\left(\tau_{m}^{t}, \tau^{4}\right)+\sigma \cdot\left[F_{1}^{p}\left(\tau_{m}^{d}, \tau_{n}^{d}\right)+p_{2}^{p}\left(\tau_{3 L}^{d}, \tau_{m}^{d}\right)\right]=0
$$

whereas the first order condition under linkage is the following:

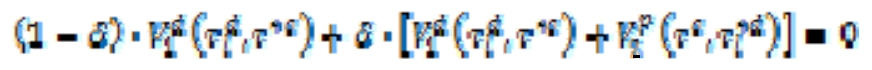

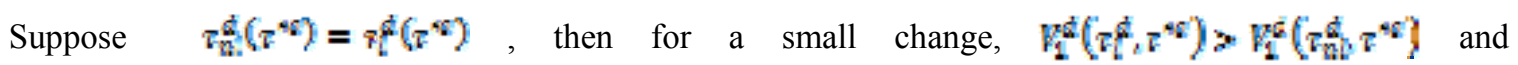

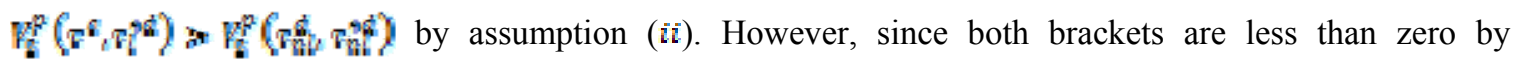

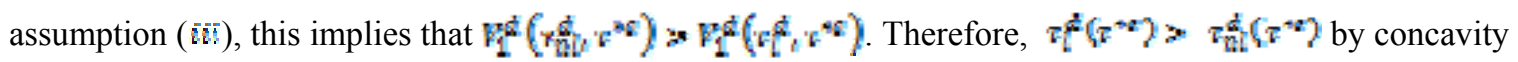
assumption (i).

Part (b) follows from the fact that deviation tariffs are decreasing in the cooperative tariff, and the deviation tariff under linkage regime is always greater than the deviation tariff under no-linkage regime.

\section{B.2. Proof of Lemma 4}

For each player there are two ways to deviate from the punishment path. The initial deviator might deviate again in the same issue, or might not participate in its punishment by deviating in the other issue. Similarly 
the punisher might apply greater punishment in cross-retaliation, or might not cooperate in the original deviation issue. Proofs are similar; therefore we will provide the proof only for the former one.

Claim 1: The initial deviator does not deviate again in the same issue.

Proof: Consider the initial optimal deviation tariff under linkage regime:

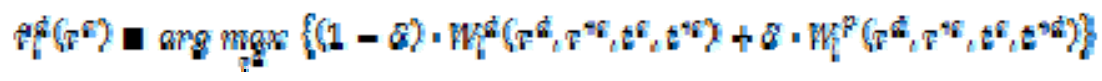

Now, suppose there exists a $\tau^{r}(\tau) \geqslant \tau(\tau)$ where,

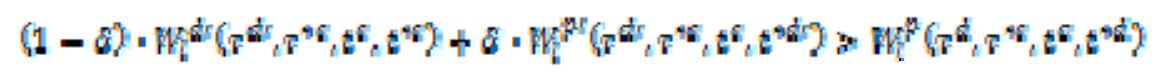

But this contradicts with the definition of $4 \tau \%$, since then it is not maximizing the initial stream of payoffs. Therefore, there is no profitable deviation within the same policy after the initial deviation.

Claim 2: The deviator does not deviate from its punishment.

Suppose there exists a $t^{5}$ where the following inequality holds:

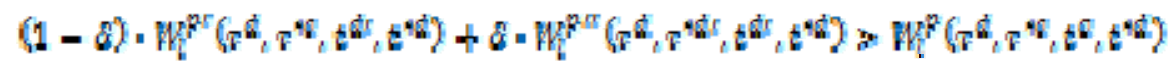

Now, I show that the discount rates that support cooperation in the beginning (before the initial deviation) also support cooperation in punishment. Let $W$ additional gain from deviation in the other issue during the punishment phase and

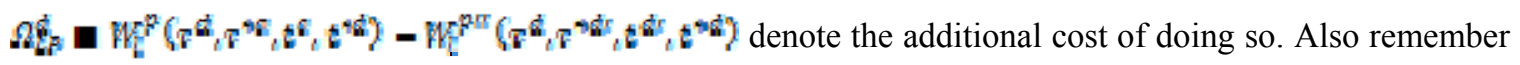

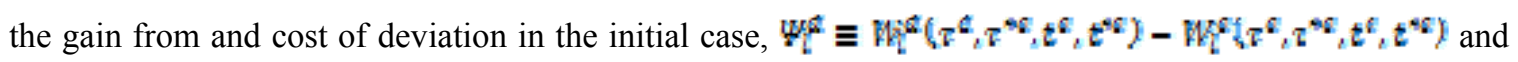

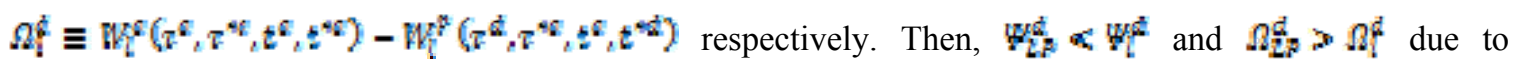
strategic substitutability. To see this, write down the second condition as:

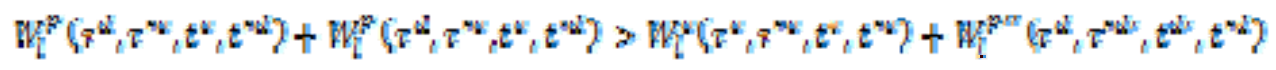

Issues are not inter-related; therefore we can write this condition in two parts:

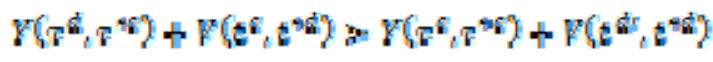

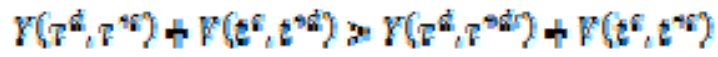

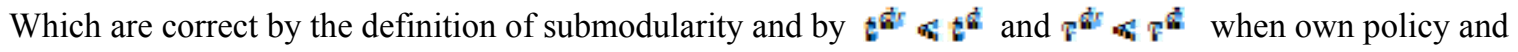
foreign policy arguments are strategic substitutes. 


\section{APPENDIX C: PROOFS FOR CHAPTER III}

\section{C.1. Proof of Proposition 1}

Differentiating the first order condition for government's problem with respect to foreign tariff and simplifying provides us the following condition:

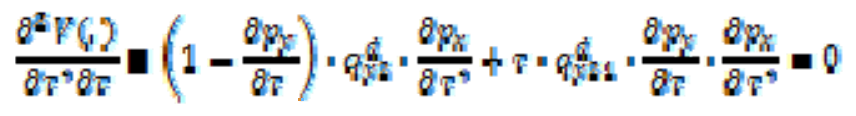

Suppose the demand function for good $y$ is given in the following form, $q_{y}^{\frac{d}{d}}\left(p_{x}, p_{x}\right) \equiv \xi_{x}\left(p_{x}\right)+\xi_{x}\left(p_{\gamma}\right)$,

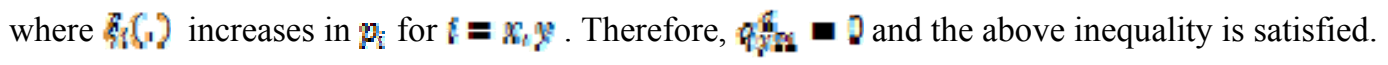

\section{C.2. Proof of Proposition 3}

Suppose deviation tariffs are identical in separated and unified regimes, i.e. components on the left hand side of the first order conditions are identical. Now, I check the brackets. For a

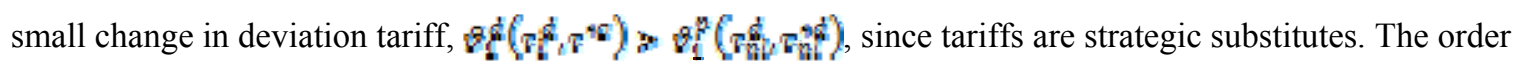
of the second components inside the brackets is ambiguous since they are generated by different functions. Nevertheless, when Home's welfare is relatively insensitive to a hike in foreign tax compared to a hike in

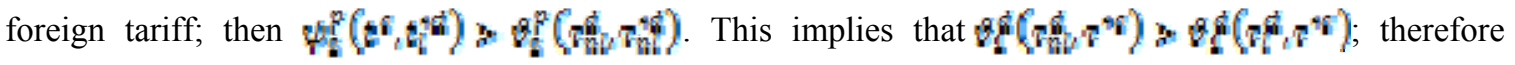
$\tau_{f}>\tau_{\mathrm{m}}^{\mathrm{d}}$ by concavity of welfare in tariffs. By Proposition 2 and Onder (2009), this shows that the self enforcing tariff level is greater under linkage.

\section{C.3. Proof of Proposition 4}

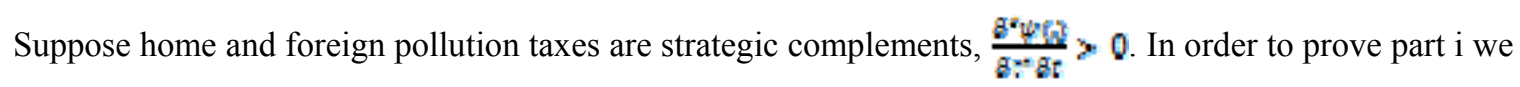
compare first order conditions under Nash reversion and limited punishment rules. The former one implies that the optimal deviation tax is equal to the myopic best response tax:

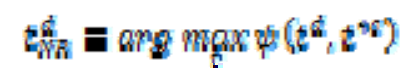

whereas the optimal deviation tax under limited punishment reflect the considerations for future punishment:

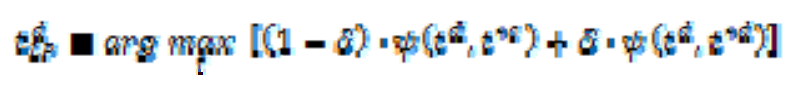

I find that deviation tax is greater under limited punishment as compared to the Nash reversion case for a

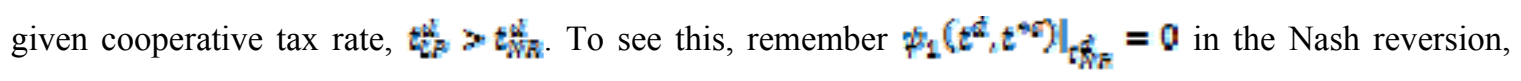




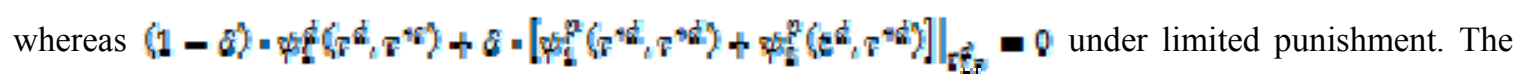

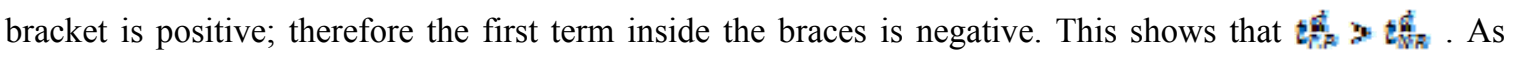
elaborated in Onder (2009), a higher deviation tax for a given cooperative tax rate implies a greater most cooperative tax rate. The second part of the proof follows from comparison of unlinked and linked first order conditions under limited punishment rule a la Proposition 3. 
VITA

\section{HARUN ONDER}

B.A. in Economics

Middle East Technical University

Ankara, Turkey

2008

M.A. in Economics

Florida International University

Miami, Florida, USA

2009-2010

Dissertation Year Fellowship

Florida International University

Miami, Florida, USA

\section{PRESENTATIONS}

Onder, Harun (April, 2009). Starting Small in Free Trade Agreements. Paper presented at Florida Atlantic University in Boca Raton, Florida, USA.

Onder, Harun (May, 2009). Starting Small in Free Trade Agreements. Paper presented at Midwest International Economics Summer 2009 Meetings at University of Iowa in Iowa City, Iowa, USA.

Onder, Harun (September, 2009). International Cooperation in Trade and Investment: (When) Does Linking the Agreements Help?. Paper presented at Midwest International Economics Fall 2009 Meetings at Penn State University in State College, Pennsylvania, USA.

Onder, Harun (February, 2010). International Cooperation in Trade and Investment: (When) Does Linking the Agreements Help?. Paper presented at Bogazici University in Istanbul, Turkey

Onder, Harun (February, 2010). International Cooperation in Trade and Investment: (When) Does Linking the Agreements Help?. Paper presented at Middle East Technical University in Ankara, Turkey. 